\title{
Innovation Practice Transfer and Capability Development within the Multinational Enterprise
}

Nathaniel C. Lupton, University of Western Ontario

Supervisor: Paul W. Beamish, The University of Western Ontario

A thesis submitted in partial fulfillment of the requirements for the Doctor of Philosophy degree in Business

(C) Nathaniel C. Lupton 2011

Follow this and additional works at: https://ir.lib.uwo.ca/etd

Part of the Business Administration, Management, and Operations Commons

\section{Recommended Citation}

Lupton, Nathaniel C., "Innovation Practice Transfer and Capability Development within the Multinational Enterprise" (2011). Electronic Thesis and Dissertation Repository. 223.

https://ir.lib.uwo.ca/etd/223

This Dissertation/Thesis is brought to you for free and open access by Scholarship@Western. It has been accepted for inclusion in Electronic Thesis and Dissertation Repository by an authorized administrator of Scholarship@Western. For more information, please contact wlswadmin@uwo.ca. 


\section{INNOVATION PRACTICE TRANSFER AND CAPABILITY DEVELOPMENT WITHIN THE MULTINATIONAL ENTERPRISE}

(Spine Title: Innovation Practice Transfer in Multinational Enterprises)

(Thesis Format: Monograph)

by

Nathaniel C. Lupton

Graduate Program in Business Administration

A thesis submitted in partial fulfillment of the requirements for the degree of

Doctor of Philosophy

School of Graduate and Postdoctoral Studies

The University of Western Ontario

London, Ontario, Canada

(C) Nathaniel C. Lupton 2011 


\section{CERTIFICATE OF EXAMINATION}

Supervisor
Dr. Paul W. Beamish
$\underline{\text { Supervisory Committee }}$
Dr. Christopher Williams

$\underline{\text { Examiners }}$

Dr. Jean-Louis Schaan

Dr. Christopher Williams

Dr. Trevor Hunter

Dr. Torben Pedersen

The thesis by

\section{Nathaniel C. Lupton}

entitled:

Innovation Practice Transfer and Capability Development within the Multinational Enterprise

is accepted in partial fulfillment of the requirements for the degree of

Doctor of Philosophy 


\section{Abstract}

For many firms, there is no long term effective strategy except to continue to grow and evolve through innovation. Hence, investment in developing these capabilities is a significant managerial priority. The original view within international business research holds that these capabilities are developed in the headquarters of the multinational enterprise (MNE) and are subsequently exploited globally through foreign affiliates. However, as MNEs become established in a multitude of foreign markets, affiliates are now often involved in innovation activities themselves.

Establishing innovation mandates within foreign affiliates often requires the transfer of practices from elsewhere within the MNE network. If, in accordance with the knowledge based theory of the firm, the MNE is superior to markets in the exploitation and diffusion of knowledge and capabilities, it must identify and diffuse superior practices throughout the innovation network.

Case study methodology is used to examine the transfer, adaptation and diffusion of innovation practices and the resulting development and enhancement of associated capabilities within four MNEs. Contributions from this study include a) the role of headquarters in creating mutual interdependencies amongst subsidiaries in order to hasten innovation capability development and enhance knowledge flow, b) an identification of different modes of innovation practice transfer consisting of central administration, brokering, and organic diffusion, the structural configurations which favour them, and the role of headquarters in creating signals to indirectly control the flow of practices. 
Furthermore, the relative influences on innovation practice adoption and adaptation at the national, organizational, subsidiary and practice levels of analysis were identified.

\section{Key Words}

Content: International business, multinational enterprises, knowledge based theory of the firm, institutional theory, internationalization of innovation, subsidiary capability development, practice transfer.

Methodology: Case studies, qualitative, theory building. 


\section{Personal Statement}

It is generally accepted that measurement instruments affect that which they are trying to measure, thus biasing the value of the measurement from the 'true' value. This phenomenon is referred to as measurement error and there are often statistical and mechanical ways to 'correct' for it. In qualitative, interpretive research such as this, the measurement device is the researcher, in this case me. Therefore, I provide this brief introduction to give the reader some assistance as they interpret the contents of this thesis.

Prior to pursuing an academic career, I worked for several large and small multinational enterprises in the telecommunications industry, and also a small family run business as a systems analyst. The industries represented in this research are aerospace, in particular the design of both electronic and mechanical components for commercial and defence aircraft, software, and telecommunications. I know very little about aerospace, but much more about how electronics, software and telecommunications work. In general, I did not find the technical jargon or frequent use of acronyms in the interviews much of a challenge.

My interest in the topic of innovation within multinationals is naturally linked to my professional history. My view of innovation has changed substantially over time, as a result of my exposure to the term in scholarly research, interaction with managers in present day innovative organizations, whose work is carried out much more globally than it was during my tenure in industry, and of course the evolution of my own thinking on the subject. 
To me, real innovation has always been about much more than repackaging existing technologies into a new form. However, since I left industry, this is increasingly how it seems innovation is viewed within industry and society. Indeed, this view is likely based on good reason, given the immense value generated according to this more 'incremental' form of innovation. This was reflected in my research as it seemed that the organizations who participated were far more invested in quickly adapting technologies for new and existing markets than in developing wholly new technologies. Hence, I am inclined to view innovation as a rather broad term which brings in all the research and development activities, whether related to products and services, processes, markets, or management itself. It seems this broad approach captures the reality of what has been published by academic scholars over the many decades of research in innovation as well.

This thesis is also about knowledge sharing, although the actual words used are 'practice transfer'. In general, I think knowledge transfer makes something very complex and difficult sound easy. For many of the respondents in my thesis research, knowledge transfer was greatly facilitated by the fact that different members of the organization were all trained in the language and methods of engineering and project management. Without that common framework, I suspect that knowledge transfer would have been nearly impossible. Furthermore, I have encountered substantial resistance to knowledge sharing both in my personal and professional life. The attribution I am most inclined to make for this resistance is that people have a natural tendency to want to hold on to what they know, thereby protecting its value for their own personal use. Hence, even within organizations, there may be reasons that know-how does not flow readily, beyond its tacit nature, the ability of knowledge providers to disseminate knowledge, and the ability of 
recipients to absorb and retain it. While my analysis of the data for this thinking was done with that in mind, I hope that any potential bias arising from this experience has been mitigated through reflexive thought, and honest introspection.

I employed a qualitative methodology in formulating and conducting the research which eventually lead to this thesis. Qualitative methodology is often described as 'iterative', which can mean a number of different things. To me, iterative means that, while there are a vast array of good techniques one may, and generally will, use in the analysis of qualitative data, the exact order is not clearly specified. As Richards (2005) suggests, where one begins is not very critical, so long as they are faithful and trustworthy in their efforts. 


\section{Dedication}

This thesis is dedicated to the memory of my father. He was my first and most influential mentor in all aspects of life and more universal matters. Without his mentorship, I would not have had the will to finish what was started five years ago, nor recognize it as one small step in a bigger, more complex, and more important journey. 


\section{Acknowledgements}

A number of people have been highly influential on my development as a scholar and individual over the course of my doctoral studies. First is my advisor Dr. Paul Beamish who worked most closely with me and never turned me away when I showed up unexpectedly at his office door. Dr. Christopher Williams also provided many hours of his time to discuss both the theory and practice of the academic world, and to provide feedback on my work during all phases. I also sincerely thank the other members of my thesis examination committee, Dr. Torben Pedersen, Dr. Jean-Louis Schaan, and Dr. Trevor Hunter, who devoted substantial portions of their time to aid in my development.

I am very grateful to Dr. Mary Teagarden and Dr. Andreas Schotter who provided valuable assistance to me in completing this thesis. I of course could not have completed this research without the participation of the many managers, who shall remain anonymous by necessity, who shared their valuable time in providing me with their personal insights and experience. I thank Dr. Rishikesha Krishnan at the Indian Institute of Management, Bangalore, and Dr. Charles Dhanaraj of Indiana University, both of whom helped me immensely during my time in India. Likewise, I would like to express my appreciation to Dr. Zhou Changhui at the Guanghua School of Management, Peking University, who accommodated me in Beijing.

The support of family and friends was paramount during my doctoral studies. I sincerely thank my immediate and extended family for providing me with emotional support and necessary occasional distractions. I hope I can repay their kindness and dedication in the future. Likewise, I express my appreciation to Fr. Murray Sample, Fr. 
John Sharp, and all at St. Michael's Parish, Diocese of London, for their tremendous support and friendship.

Finally, I thank Dr. Deborah Compeau and Linda Dittmer-Pino from the PhD Program Office and all the staff at the Richard Ivey School of Business, including the Engaging Emerging Markets Centre, for their support throughout my studies. 


\section{Table of Contents}

CERTIFICATE OF EXAMINATION ..................................................................... ii

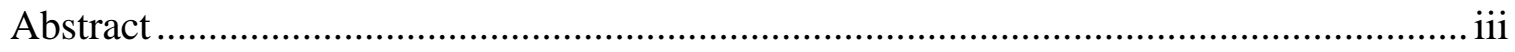

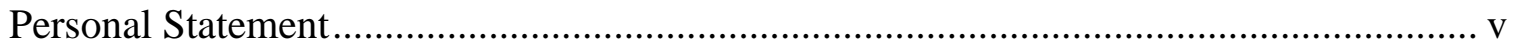

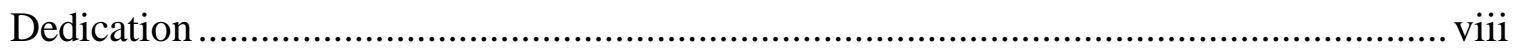

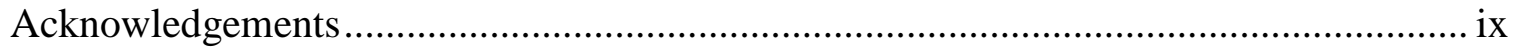

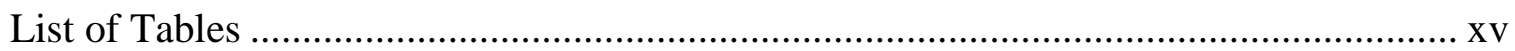

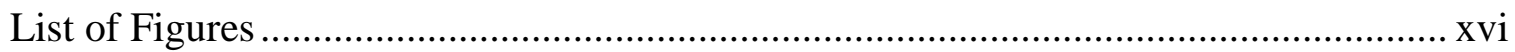

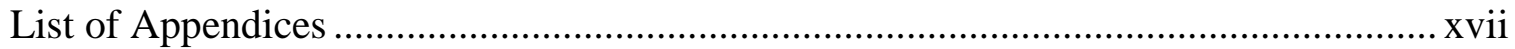

List of Abbreviations .................................................................................... Xviii

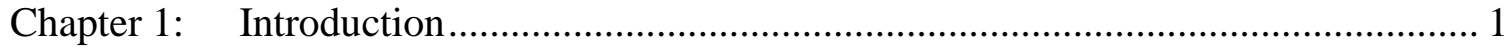

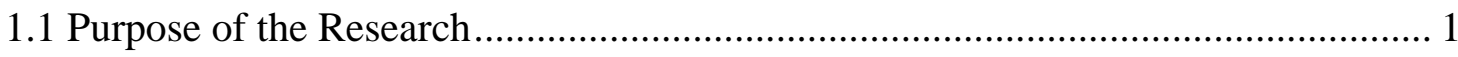

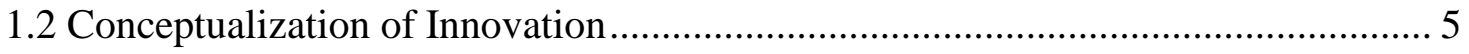

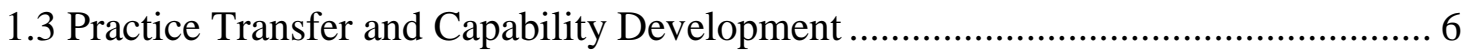

1.4 Introduction to the Theoretical Background .................................................. 8

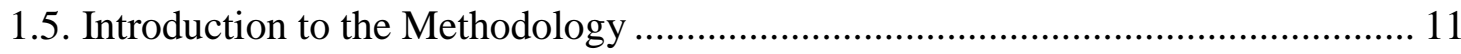

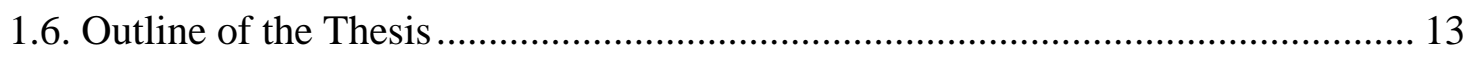

Chapter 2: $\quad$ MNE Innovation and Subsidiary Mandates ............................................ 16

2.1 Motives for Foreign Direct Investment................................................... 18

2.2 Subsidiary Mandate Characteristics and Evolution ......................................... 22

2.2.1 Defining and Characterizing Subsidiary Innovation Mandates ..................... 22

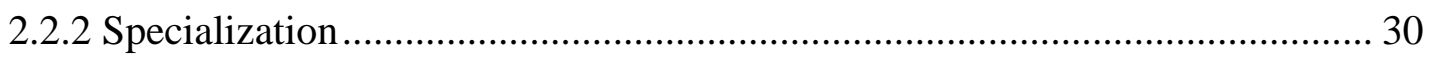

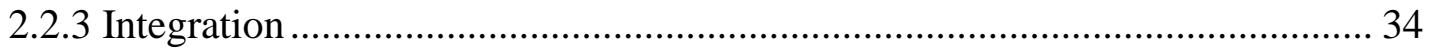


2.2.4 Innovation Mandate Characteristics and Practice Transfer

Chapter 3: The Organizational Context of Knowledge ........................................... 42

3.1 Organizational Knowledge, Capabilities and Practices .................................... 43

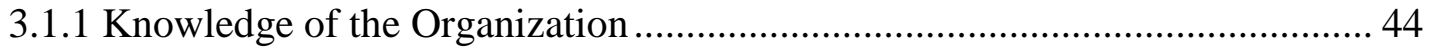

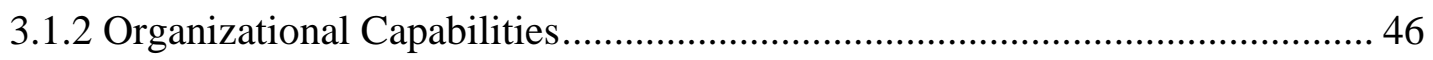

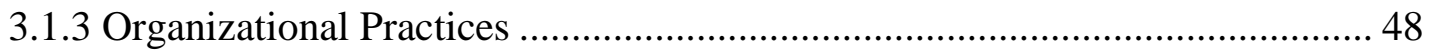

3.1.4 Organizational Roadmap from Routines to Value Creation .......................... 52

3.1.5 Innovation in Communities of Practice .................................................... 54

3.2 The Origin and Constitution of Innovation Practices ...................................... 55

3.3 Innovation as Legitimate Peripheral Participation............................................ 62

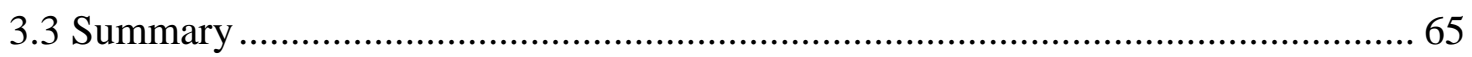

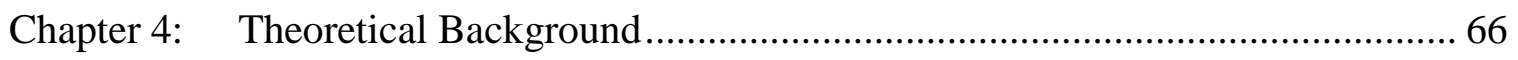

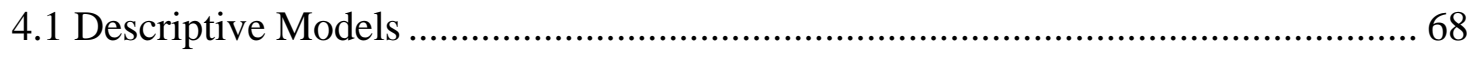

4.2 National Level Influences on Practice Transfer............................................. 72

4.3 Organizational Level Influences on Practice Transfer....................................... 78

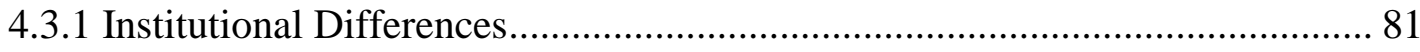

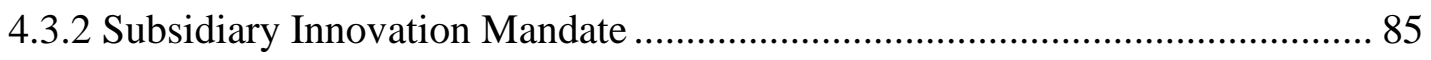

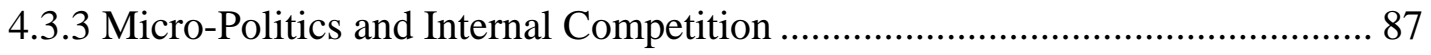

4.3.4 Organizational Requirements for Innovation........................................ 89

4.4 Innovation Practice Characteristics and Transfer ........................................... 90

4.5 Practice Adaptation and Capability Development ........................................... 93

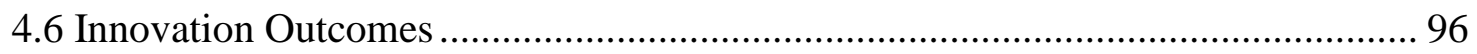

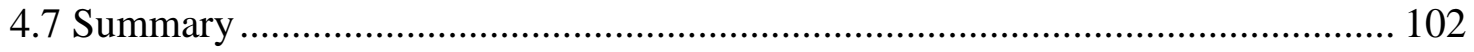

xii 


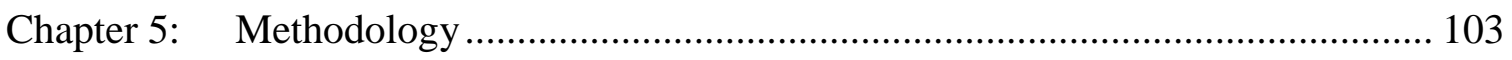

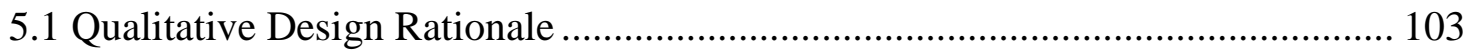

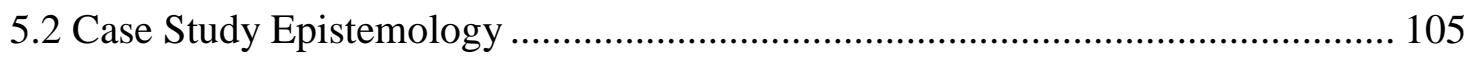

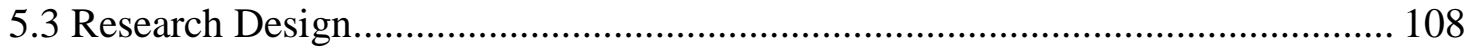

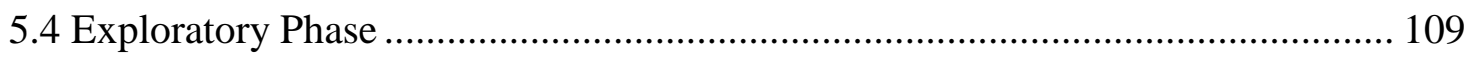

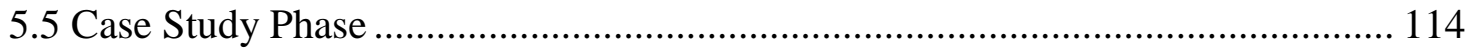

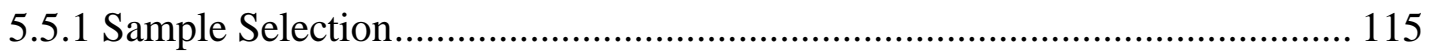

5.5.2 Data Collection and Analysis.................................................................... 118

Chapter 6: Subsidiary Capability Development ……………………..................... 124

6.1 Overview of the MNEs Included in this Research.............................................. 124

6.2 Innovation Practice Transfer and Capability Development .................................. 129

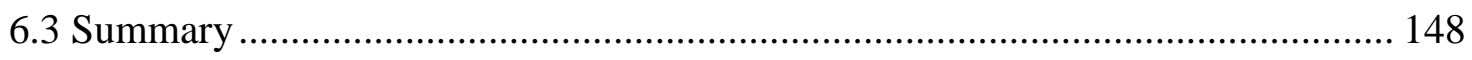

Chapter 7: Diffusion and Adaptation of Innovation Practices.................................... 150

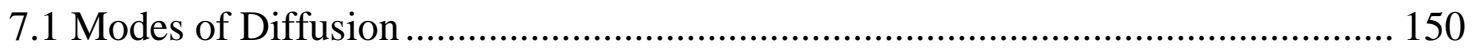

7.2 Innovation Practice Adoption and Adaptation.................................................... 155

7.2.1 Regulatory Pressures................................................................................. 158

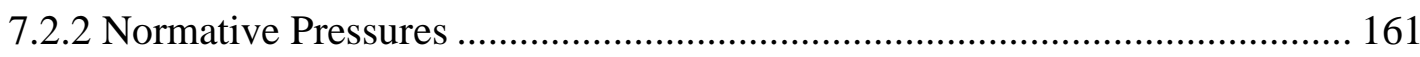

7.2.3 Organizational Pressures............................................................................ 164

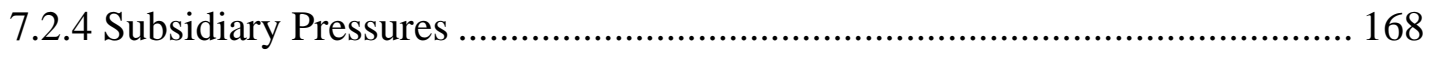

7.2.5 Practice Characteristics and Innovation Practice Adaptation ......................... 178

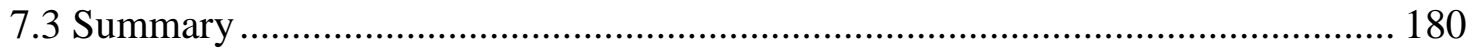

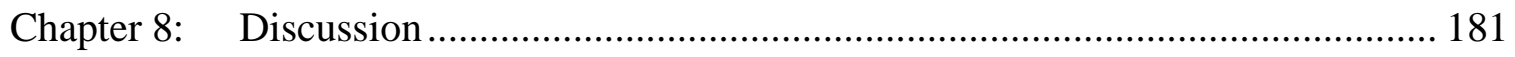

8.1 The Shared Context of the MNE and Knowledge Integration.............................. 182 xiii 
8.2 Modes of Diffusion and Innovation Network Characteristics ........................... 188

8.3 Adaptation and the Evolution of Innovation Practices ..................................... 193

8.4 Subsidiary Impatience and Institutional Duality........................................ 200

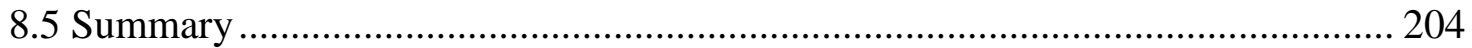

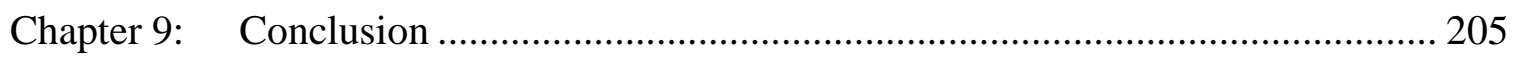

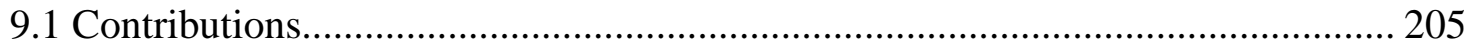

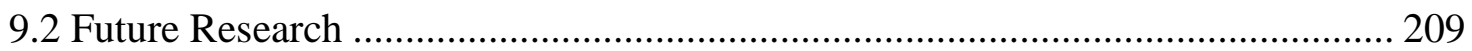

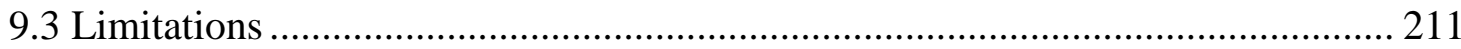

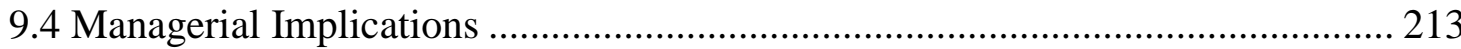

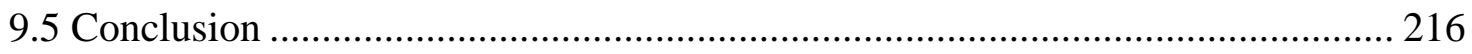

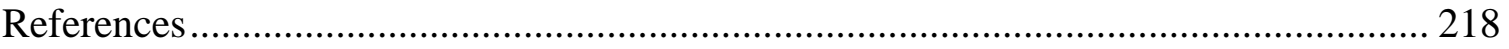

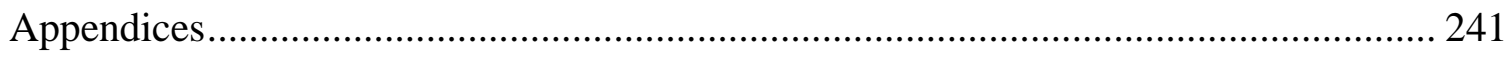

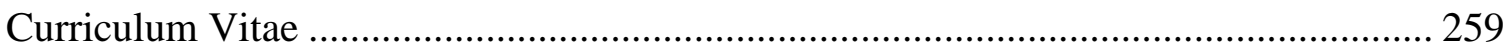




\section{List of Tables}

Table 1: Internationalization motives, rent seeking logic, and subsidiary innovation

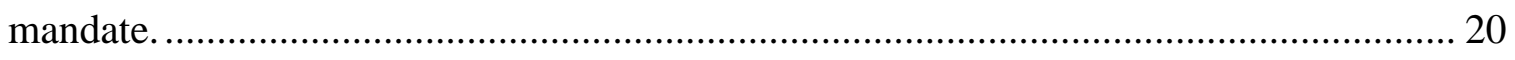

Table 2: Characteristics and examples of existing subsidiary mandate typologies......... 24

Table 3: Interviews conducted during the exploratory phase of the research................ 110

Table 4: Characteristics of MNEs in the sample. .................................................. 116

Table 5: Interviews conducted in the course of the research.................................... 117

Table 6: Innovation practice transfer discussed across four MNE cases...................... 120

Table 7: MNE Innovation, control, subsidiary mandate, industry innovation cycle and innovation practice diffusion characteristics. ..................................................... 126

Table 8: Attributions of innovation practice adaptation indicated at each MNE. ......... 158 


\section{List of Figures}

Figure 1: Position of innovation mandates with respect to competency creation and

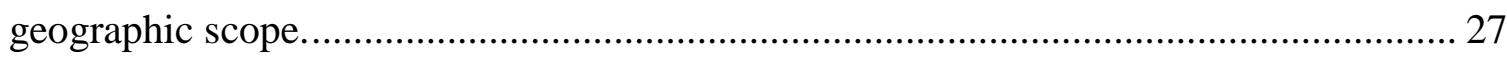

Figure 2: Subsidiary innovation mandate characteristics and implications for innovation

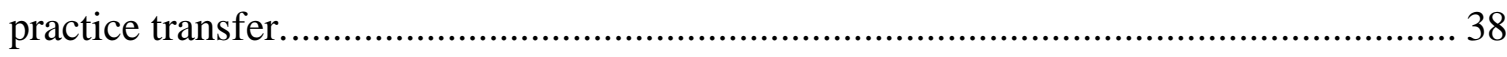

Figure 3: Model of the knowledge composition of the MNE and value creation............. 53

Figure 4: Innovation practice lifecycle model........................................................70

Figure 5: Multilevel descriptive model of influences on innovation practice transfer......71

Figure 6: Multilevel descriptive model of influences on innovation practice transfer

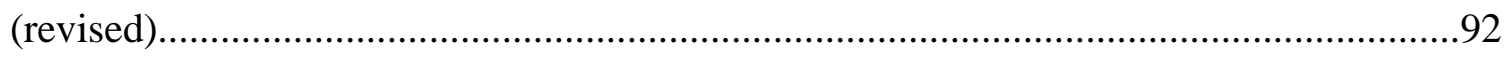

Figure 7: Progression of research phases............................................................ 109

Figure 8: The role of practice transfer in subsidiary capability development. .............. 183

Figure 9: Processes of diffusion of innovation practices amongst subsidiaries............. 189

Figure 10: Adaptation pressures on innovation practices........................................ 194 


\section{List of Appendices}

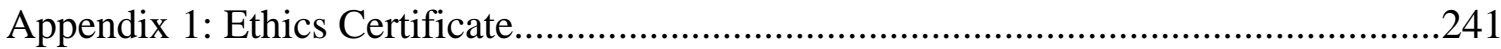

Appendix 2: Letter of Information and Consent..............................................................243

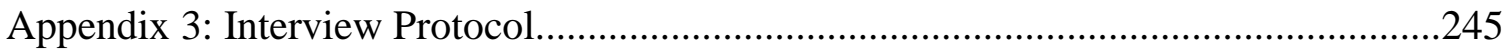

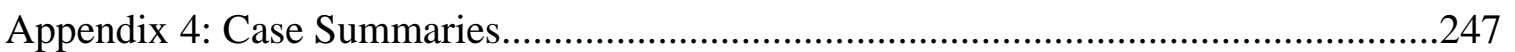




\section{List of Abbreviations}

B - Billion

$\mathrm{CC}$ - Competency Creating

$\mathrm{CE}$ - Competency Exploiting

CME - Coordinated Market Economy

FAA - Federal Aviation Administration

FDI - Foreign Direct Investment

HQ - Headquarters

HRM - Human Resource Management

IS - Information Systems

IT - Information Technology

$\mathrm{K}$ - Thousand

KBT - Knowledge Based Theory (of the firm)

$\mathrm{KM}$ - Knowledge Management

LME - Liberal Market Economy

LPP - Legitimate Peripheral Participation

MNE - Multinational Enterprise

NSI - National System of Innovation

PMI - Project Management Institute

R\&D - Research and Development

UK - United Kingdom

US - United States

USD - United States Dollars 


\section{Chapter 1: Introduction}

\subsection{Purpose of the Research}

The purpose of this thesis is to contribute to a growing body of research which recognizes the increasing contribution of foreign subsidiaries to the competitiveness of

the MNE. In particular, I investigate and build theory to explain the phenomenon of practice transfer and adaptation within the network of MNE subsidiaries and headquarters, and how these activities contribute to the development of new capabilities which allow MNE affiliates to create new value through innovation.

Innovation is widely considered a key value adding activity of the firm, the principal basis of a competitive economy and crucial in addressing social issues (Brown and Eisenhardt, 1995; Dosi, Gaffard and Nesta, 2008; Hamel, 2006; Jaffe and Lerner, 2004; Schumpeter, 1942; Tellis, Prabhu and Chandy, 2009; Zander, 1999). The Schumpeterian view of competition, holding that there is no long term effective strategy except to continue to grow and evolve through innovation has long been a central feature of fast growing, short product lifecycle industries such as electronics, telecommunications, pharmaceuticals and a host of others.

While innovation is a function of the MNE which is shaped by its overall strategy and structure, it is a particularly influential component as the primary evolutionary engine driving the development of capabilities, strategic competencies, and ultimately the growth of the firm (Zanfei, 2000). Hence, investment in innovation and the development 
of associated requisite capabilities represents an important decision area for managers (Cohen and Levinthal, 1990; Ethiraj, Kale, Krishnan and Singh; 2005).

Historically, innovation activity, and hence research, was rooted in the context of industrialized societies during periods of higher economic growth, leading to a pathdependent view of technological capability development in which a few nations became technological centers by virtue of initial investments and the efforts of firms operating inside their borders (Dosi, 1982; 1988; Jaffe and Lerner, 2004; Nelson and Winter, 1977; 1982; 2002). According to this view, multinational enterprises (MNEs) develop capabilities close to home, almost exclusively countries of the western world, and exploit these capabilities abroad in foreign subsidiaries in order to benefit from the advantages afforded by scale and scope economies. The underlying assumption of this focus is the traditional efficiency view that the role of foreign subsidiaries is the replication and exploitation of technology developed in the MNE home country (Kindleberger, 1969; Stopford and Wells, 1972; Vernon, 1966). This view has now evolved to acknowledge the role that foreign subsidiaries play in enhancing existing capabilities in the MNE and creating new ones (e.g. Cantwell and Mudambi, 2005; Kuemmerle 1999b).

Of the many forces shaping globalization including politics, culture, and social institutions, technology diffuses the most readily and rapidly throughout the world (Archibugi and Iammarino, 2002). As a result, scholars and practitioners alike largely focused on the exploitation of MNE capabilities abroad. However, the forces associated with global economic integration, including competition for new and emerging markets 
and knowledge workers, have now turned the attention of managers and researchers to the creation of new capabilities via knowledge integration and coordination amongst foreign affiliates.

Increasingly, subsidiaries are becoming contributing participants in innovation activities including the production of new technologies, broadly construed as products, processes, and administrative practices (Cantwell, 1995; Dunning, 1994; Florida, 1997). This in part reflects a shift in the logic of technological competition from scale economies to innovation (Cantwell and Fai, 1999). Hence, the mirror side of the efficiency ratio, represented by value generation through coordination and exploitation of globally dispersed assets, is presently deserving of more scholarly attention (Dunning, 1993; 1996; Zander, 1997). As MNEs continue to deploy their innovation activity internationally, partially shifting the logic of geographic expansion in order to take advantage of comparative country advantages, managers must deal with increasingly complex integration and coordination amongst geographically diverse affiliates (Cantwell and Janne, 1999; Papanastassiou and Pearce, 1997; Pearce, 1999; Zander 1999). Hence, contemporary innovation research now needs to focus on the challenges inherent in developing capabilities in the context of geographically dispersed innovation occurring in global networks. This thesis focuses on the value generation side of the efficiency equation through an examination of innovation capability development in foreign subsidiaries with a mandate to produce new value through innovation, and further how MNE innovation practices evolve in the process of international dispersion. The term 
'innovation practice' used in this thesis refers to the variegated, institutionalized processes involved with innovation. Examples include agile development, user-led design, and stage gate process. Within any given MNE, there will also be many more practices which have emerged and become institutionalized, and hence are idiosyncratic to the organization.

In addition to coordination issues, and somewhat paradoxically, successful innovation requires the production of something new, which in turn implies the use of novel means. Under these conditions, the probability that subsidiaries will modify, augment, and/or replace organizational practices of the MNE increases. Hence, internationalization of innovation within the MNE creates a new challenge for managers in identifying and diffusing valuable practices developed in a geographically dispersed network of subsidiaries. This research examines the phenomenon of innovation practice transfer, adaptation and evolution motivated by the following questions:

RQ1) What is the role of organizational practices transfer in the development of innovation capabilities in foreign subsidiaries?

\author{
RQ2) What influences lead to subsidiaries' adaptation of innovation \\ practices?
}

RQ3) How are innovation practices diffused within the MNE? 


\subsection{Conceptualization of Innovation}

There is neither a consistent definition, nor operationalization of innovation in existing literature (Adams, Bessant and Phelps, 2006). Innovation may be better described as a body of literature, delineated into diffusion of innovation, organizational innovativeness, and innovation processes (Wolfe, 1994), or perhaps as an 'umbrella' construct (Suddaby, 2010) that encapsulates a variety of loosely related dimensions. Innovation is multidimensional in nature, consisting of innovation process stages, levels of analysis, types, and scope (Camisón-Zornoza et al, 2004). The term innovation therefore refers to both an outcome and the inputs and processes which produced it. The main reason for this is that innovation captures the inseparable coproduction of processes and outcomes; inseparable because creating something entirely novel typically requires novel means.

Consistent with the characterization of innovation as both process and outcome in the literature, the following definition is employed for the purpose of this research: innovation is the intentional production of novelty to fulfill a practical goal in order to create new value for the MNE. In essence, innovation is characterized by the calling into being of that which did not exist prior. As with the existing body of literature, this definition refers both to the processes of innovation as well as the tangible or intangible outcomes of those processes. This definition also indicates that in order for an outcome from processes of innovation to be considered an innovation, it must satisfy some practical purpose and create a source of value for the MNE. This requirement 
differentiates innovation from invention which may result in something tangible, but which does not necessarily involve implementation or add value (Garcia and Calantone, 2002).

\subsection{Practice Transfer and Capability Development}

In order to build capabilities within foreign subsidiaries, MNEs typically transfer those practices identified with its core competencies, and which are often a source of competitive advantage (Kostova, 1999). These practices embody organizational knowledge and the value adding capability of the firm, as these provide a source of competitiveness which must be exploited to realize a competitive advantage (Bartlett and Ghoshal, 1997; Eisenhardt and Martin, 2000; Ghoshal and Bartlett, 1988; Grant, 1996; Kogut, 1991; Nohria and Ghoshal, 1997; Zander and Kogut 1995). Organizational practices refer to the routinized manner in which the members of a firm work collectively to complete various activities (Kostova, 1999). Similar to organizational routines (Dosi, Nelson and Winter, 2000; Nelson and Winter, 1982; Szulanski, 1996), practices represent repeated patterns of regularity in the collective behaviour of organizations which evolve in accordance with the interaction of environmental stimuli and individual agency (Becker, 2004). Examples of organizational practices include recognized industry standards and managerial 'fads' (Abrahamson, 1991; Birkinshaw, Hamel and Mol, 2008), such as total quality management and continuous improvement, but most are the product of path dependencies emergent from the socio-structural processes of the organization (Brown and Duguid, 1991; Lave and Wenger, 1991). 
The most recognized practices, from the perspective of individual firm managers, are those related to the particular strategic competencies of the firm. In this thesis, the focus is on practices of the firm related to innovation. Even this class of practices can be quite broadly construed as consisting of particular ways of developing new products and services (e.g. technology development practices: Ethiraj et al 2005), encouraging employee innovativeness (e.g. human resource practices: Chen and Huang, 2009; Laursen and Foss, 2003; Starbuck, 1992), stimulating project development (e.g. finance practices: McGrath and Nerkar, 2004), and sharing knowledge across organizational units (e.g. knowledge management practices: Miller, Fern and Cardinal, 2007; Tsai, 2001). A more parsimonious and generalized categorization is used in this research, consisting of the level of tacit knowledge required to understand and internalize an innovation practice, and the extent to which the practice is institutionalized.

Transferring practices is often deceptively challenging (Gupta and Govindarajan, 1991) because, in addition to the expected challenges inherent in learning something new, transfer is often impeded by aspects of the practice, such as its tacit quality, as well as aspects of the organization itself including structure and modes of coordination (Ghoshal and Bartlett, 1988; Kedia and Bhagat, 1988; Kostova, 1999; Szulanski, 1996; Zander and Kogut, 1995). In the international environment, additional challenges arise from the plurality in cultures (Lemak and Arunthanes, 1997), government policies (Kostova and Roth, 2002) and consumer preferences (Bartlett and Ghoshal, 1989; Cui and Liu, 2001; Prahalad and Doz, 1987) faced by the MNE (Jensen and Szulanski, 2004). The transfer of 
innovation practices to a foreign subsidiary is especially challenging given the complexity and interrelatedness of the variegated processes and sources of knowledge involved, and heightened causal ambiguity in new value creation.

In many cases, isolated foreign subsidiaries engaged in similar but uncoordinated functions develop different practices according to their own histories, experiences, and the preferences and agency of the members of communities of practice from which practices arise (Roberts, 2006; Wenger, McDermott and Snyder, 2002). Efforts by the parent firm to integrate and coordinate the work of foreign affiliates with heterogeneous practices can prove challenging, as was found by the German multinational Siemens, for example. Employees of subsidiaries in Munich, Germany and Boca Raton, Florida reported that working together was complicated by substantial differences in software development practices which both sides refused to agree upon. Furthermore, problems encountered when troubleshooting newly implemented systems at customer sites could be traced back to the practice of software developers in an Indian affiliate who would immediately focus on fixing, rather than documenting software faults in great detail, as per their German counterparts (Thomke and Nimgade, 2001).

\subsection{Introduction to the Theoretical Background}

Practice generation, evolution and diffusion within the MNE are phenomena influenced by factors at various levels of analysis including national, organizational and the characteristics of the practice itself. In constructing the initial descriptive framework, conceptual challenges inherent in studying multilevel phenomena were dealt with by 
applying a complementary set of theoretical lenses operating at these different levels of analysis (Hitt, Beamish, Jackson and Mathieu, 2007; Kozlowski and Klein, 2000). First and central to this research is the knowledge based theory $(\mathrm{KBT})$ of the firm which posits that firms are superior to markets in the dissemination and exploitation of knowledge due to the facilitating presence of social ties amongst organizational members (Grant 1996; Hedlund, 1994; Kogut and Zander, 1992; Nonaka, 1994). Hence, the capabilities involved in transferring, diffusing and adapting practices provide a potential source of competitive advantage for the MNE, similar to the notion of second order, or dynamic capabilities (Teece, 2007; Zahra, Sapienza and Davidsson, 2006; Zollo and Winter, 2002).

Institutional theory (DiMaggio and Powell, 1983; Meyer and Rowan, 1977; Scott, 1995) provides a lens on factors influencing the adoption and diffusion of organizational practices, with a particular focus on factors influencing the legitimacy of the adopting unit. As posited by institutional theorists, organizations face normative, regulative and cognitive pressures to adopt organizational practices in order to achieve legitimacy, which result in some degree of practice consistency within identifiable groups such as industries. At the country level of analysis, distinctive national cultural and legal systems are sources of pressures which shape management practice, resulting in variance across borders (Gooderham, Nordhaug and Ringdal, 1999; Rosenzweig and Singh, 1991). As MNEs by definition must coordinate assets located in multiple nations, subsidiaries often face situations of 'institutional duality' in which potentially conflicting pressures from 
the host country and MNE environment impede the diffusion of practices throughout the MNE, and provide impetus for adaptation (Kostova, 1999; Kostova and Roth, 2002; Kostova and Zaheer, 1999; Morgan and Kristensen, 2006). Practice adaptation provides one avenue for alleviating legitimacy threats arising from institutional duality (Jensen and Szulanski, 2004).

Finally, the practice itself is the product of an emergent effort of a collective group of individuals with various expertise, commitment to the practice, distributed agency, and access to organizational support (Anand, Gardner and Morris, 2007). Hence, while adaptation of practices may be shaped by institutional pressures in the focal subsidiary, selection and diffusion of adapted practices may be impeded by micropolitical pressures operating within loosely coordinated affiliates (Morgan and Kristensen, 2006).

Together, KBT, institutional theory, and micro-political view within communities of practice helped to provide a comprehensive view of the various factors constraining and enabling practice transfer and adaptation, and the resulting development of innovation capabilities. The primary contribution of this thesis is in linking KBT to the communities of practice perspective on innovation, with emphasis on examining how innovation practices within the MNE, incorporating tacit knowledge and the skills of communities of practice as crucial inputs, are developed. Hence, this research contributes to an emerging area of research which examines how organizational 
knowledge is created, transferred, adapted, and contributes to MNE capability development (Adams, Bessant and Phelps, 2006; Anand et al, 2007).

The innovative value emanating from communities of practice is sufficient reason for organizations to guide and potentially even nurture their development (Brown and Duguid, 2001). Understanding how their emergence and usefulness are variably influenced by their organizational, institutional and cultural environments (Roberts, 2006) and how innovation practices evolve within them is a crucial initial step in formulating guidance for management practitioners. Likewise, understanding the evolution of innovation practices provides momentum for the development of a contemporary theory of innovation from the perspective of the organizations which contribute substantially to that effort.

\subsection{Introduction to the Methodology}

In pursuing this research agenda, the processes of practice transfer, adaptation, and capability development were investigated in the context of the MNE, from the perspective of both subsidiaries and headquarters, where foreign subsidiaries are given a mandate to produce new value through innovation. The empirical research was conducted according to the replication logic of multiple case studies in which the primary units of analyses are practices transferred between affiliates of an MNE. Case study research is particularly useful in building theory on processes (Langley, 1999; Pettigrew, Woodman and Cameron, 2001), when the researcher has little or no control over subject behaviour, which is very nearly always the situation in organizational research, and 
where it is very difficult to discern the phenomenon of interest from the context in which it occurs (Eisenhardt and Graebner, 2007; Yin, 2009).

Multiple case studies have proven especially valuable in studying group processes including the building of communities of practice (e.g. Anand et al, 2007; Edmondson, Bohmer, and Pisano, 2001). Each of the four cases in this study is a MNE which is, or is attempting, to produce and capture new value through innovation in multiple geographic locations. Replicating this research across the four MNEs, in accordance with the logic of literal replication, improves the generalizability of the theory generated (Yin, 2009). By examining multiple accounts of practice transfer in the words of those involved within each MNE, new theory on international innovation practice transfer is built which contributes to a growing body of research on how subsidiaries contribute enhanced and even new capabilities to the MNE. Each case is akin to an experiment in that it is approached with a set of intermediate questions and propositions to be tested. As the data for each case was collected and analyzed, these initial questions lead to new questions and new propositions to be tested.

Although qualitative research, especially that employing a hermeneutic approach, is typically more inductive and interpretive than deductive and positivist (Miles and Huberman, 1994), relevant literature was reviewed in order to guide the study as well as interpret the data collected. In the initial phases, which included the construction of a research proposal, existing theory, combined with preliminary fieldwork, was used to create a descriptive framework and set of initial propositions to guide data collection and 
analysis. During data collection and analysis, the descriptive framework provided some initial conceptual 'bins' to place observations in. As new insights were constructed from analyses of the data, the descriptive framework was gradually revised into an explanatory framework (Miles and Huberman, 1994; Richards, 2005).

\subsection{Outline of the Thesis}

The remainder of this thesis is structured as follows. Chapter 2 provides a brief, high level overview of firm internationalization, which covers the motive and pattern of firm internationalization before transitioning into a discussion on the motives for the internationalization of innovation and as a consequence, capability development. This chapter serves to position the study within the relevant literature on firm internationalization and capability exploitation as well as explicating some of the relationships between internationalization motivation, subsidiary mandate, and innovation practice transfer.

Chapter 3 reviews literature pertaining to organizational knowledge, capabilities and practices and their position in organizational value creation. It also provides the communities of practice perspective on innovation, taking into consideration the impediments to community emergence and gaining new membership, in the global setting. While researchers of communities of practice suggest that knowledge sharing and innovation is enhanced within these social structures, geographic dispersion of MNE innovation networks creates impediments to their functioning, and hence issues of managerial importance. 
Chapter 4 develops the theoretical baseline and multilevel descriptive framework which guided the empirical research. Institutional theory and KBT are reviewed, as relevant to practice transfer, in order to develop an initial set of factors which may influence the transfer, adaptation and diffusion of innovation practices. This section also contains a review of literature on practice transfer and evolution, innovation, KBT and institutional theory in order to develop a holistic process model of the 'innovation practice lifecycle'.

In Chapter 5, the case based methodology used in the design and data collection for this research, and qualitative analytical approach used to analyze the data in order to derive new theory are presented. This chapter provides details on the exploratory phase of the research which motivated the research questions and design of the final phase. This exploratory phase consisted of interviews with MNE managers located in Canada, China and India. This chapter also provides an overview of the four MNEs which comprised the case studies conducted.

In Chapters 6 and 7, the theory developed during the study is presented. Chapter 6 builds theory on the role of innovation practice transfer in developing subsidiary capabilities. Within this chapter propositions are developed relating to the role of innovation practice transfer in promoting the use of organizational knowledge to be applied in the context of problem solving by MNEs. Through this process, the tacit components of innovation practices, and hence associated capabilities, are developed by the subsidiary. The role of innovation practices in contributing to a shared environment 
is also presented. Chapter 7 develops propositions related to the diffusion of innovation practices within the MNE innovation network and factors which create pressures for practice adaptation at the national, organizational, subsidiary, and practice levels of analysis.

Chapter 8 provides a discussion of the theoretical and practical implications of the propositions developed. Theoretical models of the role of innovation practice transfer in subsidiary capability development, the diffusion of innovation practices, and forces for adaptation are provided. Finally, Chapter 9 summarizes the contributions, future research avenues suggested, limitations, and managerial implications of this research. Following this, a conclusion to the thesis is provided. 


\section{Chapter 2: MNE Innovation and Subsidiary Mandates}

Context matters in innovation practice transfer and capability development. Practices are not transferred, nor are capabilities developed, in the absence of existing practices and capabilities. Innovation in the MNE is highly tacit, unstructured and difficult to control across borders. It is also more likely to lead to adaptation of practices as transfer occurs in subsidiaries which face competing and sometimes conflicting pressures originating from the MNE and host country environments. In this thesis, factors influencing the transfer process and subsequent capability development of subsidiaries are considered at the national and organizational levels of analysis, as well as their potential interactions with the characteristics of the practices itself. Hence, multiple levels of analysis are considered, but it is the transfer process which is of primary interest.

In order to gain an appreciation for how innovation practices are transferred and evolve, it is important to appreciate the various motives for, and subsequent patterns of, the geographic dispersion of innovation activities by the MNE. The extent and pattern of innovation internationalization undertaken by any particular firm is, for example, explained in part by the technological capabilities required to compete within the relevant industry, and the congruent national competencies of its home country and nations in which it invests (Cantwell and Janne, 1999). 
Most relevant to this research, capability development is a continual learning process of which practice transfer is an integral component. An empirical examination of the process of practice transfer and capability building can take place at any moment in the history of the subsidiary, and so an appreciation of the stage of development of the subsidiary's mandate (e.g. Delany, 2000), and its evolutionary path (Birkinshaw and Hood, 1998) is needed in order to understand the forces acting upon subsequent practice transfer and capability development.

Where an innovation mandate has already been established for some time in a subsidiary, for example, transferring practices is potentially done in the context of more evolved communities of practice from which similar, complementary and/or conflicting practices may have already emerged. Understanding the impact of history and other major influences on the motives of a firm to transfer innovation practices to foreign affiliates provides important contextual information useful in developing the initial theoretical baseline in the following chapter.

The first section in this chapter is a review of research concerning the internationalization of innovation activities by the MNE in order to provide context for the current study. This first section includes and examination of the motives for foreign direct investment (FDI), which result in the internationalization of MNE activities. From this, the motives for internationalizing innovation activities are derived, which in turn establishes the general conditions under which the subsidiary is or is not granted an innovation mandate at inception. 
The next section provides an examination of the evolution of the MNE innovation network which results in varying levels of specialization and integration of its constituent affiliates with respect to their innovation mandate. Within this section, literature is also reviewed pertaining to subsidiary mandate typologies in order to define innovation mandates, and to provide a positioning for the current research, which examines subsidiaries with a globally scoped, competency creation role within the MNE innovation network. Next, the key dimensions of the subsidiary mandate, consisting of the level of specialization and integration of a subsidiary's mandate as well as factors which may potentially lead to changes to subsidiary mandates are discussed. Implications for practice transfer according to the type of mandate received by the subsidiary, and when it was received in relation to its initial establishment are provided. Subsidiaries which do not participate in the MNE innovation network are not within the scope of this research, and hence are not discussed.

\subsection{Motives for Foreign Direct Investment}

The purpose of this section is to relate the initial motives for establishing a new subsidiary to whether or not it will possess, as part of its overall mandate, responsibility for carrying out innovation activities which add new or enhanced capabilities and hence value to the MNE. Modern MNEs have been characterized as geographically dispersed innovation networks which create and integrate new knowledge in order to generate new value (Almeida, 1996; Bartlett and Ghoshal, 1989; Birkinshaw, 1997; Cantwell, 1989; Feinburg and Gupta, 2004; Hedlund, 1986; Zander, 1999). Each subsidiary within the 
network is initially established for one or more reasons including market, resource, efficiency and strategic asset seeking (Dunning, 2000). A particular subsidiary may not initially be part of the MNE innovation network, but its mandate can evolve over time as it develops capabilities and takes on new roles (Birkinshaw and Hood, 1998; Frost, Birkinshaw and Ensign, 2002; Garcia-Pont et al, 2009). This section provides an examination of which initial motives for establishing a subsidiary are more likely to result in an innovation component as part of the overall subsidiary mandate.

Market seeking involves setting up foreign sales and service affiliates to tap new markets with existing products and services, but can also include varying levels of R\&D to adapt or develop new products and services for local sale (Cantwell and Mudambi, 2005; Kuemmerle, 1999b). Firms following a resource seeking motive for FDI are interested in accessing the natural resources and labour forces of the host nation while the efficiency seeking motive entails geographical diversification amongst functional areas of the MNE in order to achieve division of labour and its associated specialization advantages. Finally, MNE FDI is sometimes motivated to improve its competitive positioning viz. its competitors by accessing complementary strategic assets through FDI which augment existing competencies. The rent seeking logic and potential innovation mandates of newly established foreign subsidiaries are summarized in Table 1.

Market seeking is associated primarily with demand-pull oriented innovation in that local adaptation is often necessary to effectively serve markets. Resource seeking motives are not associated with an innovation mandate as the logic is primarily associated 
with sourcing material inputs to production more efficiently. Efficiency seeking motives primarily entail foreign investments made to benefit from labour cost differences between the home and host country. Subsidiaries set up according to an efficiency seeking motive may provide the MNE efficiency gains in supporting the R\&D function, but do not, at least initially, actively contribute to competency creation. Strategic asset seeking, conversely, is associated with supply-push innovation, in that knowledge assets acquired through FDI give the MNE opportunities to integrate and coordinate internationally dispersed strategic assets for the purpose of globally focused innovation.

Table 1: Internationalization motives, rent seeking logic, and subsidiary innovation mandate.

\begin{tabular}{|c|c|c|c|}
\hline & & $\begin{array}{l}\text { Rent Seeking Logic } \\
\text { (Dunning, 2000) }\end{array}$ & Innovation Mandate \\
\hline \multirow{4}{*}{ 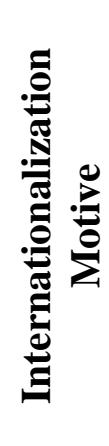 } & \begin{tabular}{|l} 
Markets \\
Seeking
\end{tabular} & $\begin{array}{l}\text { Economies of } \\
\text { scale/scope }\end{array}$ & $\begin{array}{l}\text { Adaptation of MNE } \\
\text { capabilities to local context. }\end{array}$ \\
\hline & $\begin{array}{l}\text { Resource } \\
\text { Seeking }\end{array}$ & Input cost reduction & No initial innovation mandate. \\
\hline & $\begin{array}{l}\text { Efficiency } \\
\text { Seeking }\end{array}$ & $\begin{array}{l}\text { Production cost } \\
\text { reduction }\end{array}$ & No initial innovation mandate. \\
\hline & $\begin{array}{l}\text { Strategic } \\
\text { Asset } \\
\text { Seeking }\end{array}$ & $\begin{array}{l}\text { Enhanced } \\
\text { competencies or } \\
\text { competitive positioning }\end{array}$ & $\begin{array}{l}\text { Augmentation of MNE } \\
\text { capabilities. }\end{array}$ \\
\hline
\end{tabular}

In Dunning's original formulation of the eclectic paradigm (1977; 1988; 1993; 1998), the MNE primarily internationalized to exploit assets developed at home, and hence strategic motives for internationalization were mainly considered in the context of 
industry positioning. Later, researchers recognized that internationalization was also undertaken to secure increasingly strategic knowledge assets (Almeida, 1996; Cantwell, 1995; Dunning and Narula, 1995; Kogut and Chang, 1991). Hence, strategic asset seeking is now more often associated with the motivation to acquire geographically dispersed strategic assets, most often in the form of knowledge workers.

This preceding review establishes a general linkage between the initial motives of the MNE for establishing a particular subsidiary and the type of innovation mandate, if extant, that the subsidiary receives. There are three caveats to address before proceeding to the discussion on subsidiary mandate characteristics and evolution. First is that in the presence of any of the four motives it is not absolutely certain that an innovation mandate will be established. MNEs can access markets without making any adaptations by setting up marketing and/or production satellites (White and Poynter, 1984), or by making any necessary adaptations from a subsidiary located elsewhere. As well, although less often the case, firms may access pools of knowledge workers through FDI without granting an innovation mandate. Such would be the case, for example, in a pharmaceutical company managing clinical trials through a foreign subsidiary while handling drug discovery elsewhere. Second, it is important to note that the innovation mandates proposed in Table 1 refer only to the initial purposes for which the subsidiary was established. Although head office assignment of mandates is perhaps the most common mode of establishment, it is not the only one (Birkinshaw and Hood, 1998). As the MNE evolves, mandates can change with subsidiaries taking on new or enhanced responsibilities for 
value creation (Delany, 2000). Hence, innovation internationalization and associated capability development pathways evolve contemporaneously with subsidiary mandates (Cantwell and Piscitello, 2000). The evolution of subsidiary mandates, and their relation to established taxonomies are presented in the next section. Finally, although the four categories presented here are conceptually distinct from one another, MNEs may be pursuing multiple objectives when establishing foreign subsidiaries. In any case, the presence of a market or strategic asset seeking motive greatly increases the likelihood that a subsidiary will receive an innovation mandate at inception, hastening the transfer of innovation practices from the MNE.

\subsection{Subsidiary Mandate Characteristics and Evolution}

This section begins by defining an innovation mandate and positioning it within existing taxonomies. Next, the integration and specialization dimensions of a subsidiary innovation mandate are identified, and their implications for innovation practice adoption and adaptation are proposed. Within this section, the stage of subsidiary development is presented as an important contextual consideration which influences innovation practice transfer.

\subsubsection{Defining and Characterizing Subsidiary Innovation Mandates}

A subsidiary's mandate is the role which is granted to it by regional or corporate headquarters, but which can subsequently evolve as a result of either headquarters or subsidiary initiatives (Birkinshaw, 1996; Birkinshaw and Hood, 1998; Delany, 2000). 
Over the past three decades, several typologies of subsidiary mandates have been presented in the literature including those related to the scope of the subsidiaries responsibilities, its role in exploiting and contributing knowledge, its integration within the MNE vs. its host country environment, and its role in decision making within the MNE (Manolopoulos, 2008). Table 2 lists these existing typologies, outlines the key dimensions of the mandate used in categorizing subsidiaries, identifies the general focus of the research employing these typologies and provides some examples of each. This table is not exhaustive in its identification of the research employing subsidiary mandate typologies, nor the mandate types recorded in the literature. Manolopoulos (2008) provides a more detailed and integrated typology review for the interested reader.

Early research classified subsidiary mandates according to the extent of responsibility and control over markets, products and the value-chain (White and Poynter, 1984). World product mandates grant the subsidiary full control over the complete range of value-adding activities for a particular product line (Rugman and Douglas, 1986). Roth and Morrison (1992) extended the world product mandate type by differentiating between subsidiaries which were part of, and hence dependent upon, the overall MNE value chain, and those which have complete control over the entire value chain for a particular product or product line. World product mandates are of interest to researchers in evaluating the effect that the strategic importance of a subsidiary has on its development and survival (e.g. Feinberg, 2000). 
Knowledge-related typologies (e.g. Bartlett and Ghoshal, 1989; Jarillo and Martinez, 1990; Papanastassiou and Pearce, 1999) focus on the extent to which knowledge and competencies are utilized the subsidiary. Prior research has found that the range of knowledge sources available to a subsidiary from within the MNE and its host environment, as well as its ability to utilize them, has a positive impact on subsidiary innovation (Almeida and Phene, 2004; Phene and Almeida, 2008).

Table 2: Characteristics and examples of existing subsidiary mandate typologies.

\begin{tabular}{|c|c|c|c|}
\hline Typology & Dimensions & $\begin{array}{c}\text { Focus on } \\
\text { Subsidiary Role }\end{array}$ & Examples \\
\hline Scope & $\begin{array}{l}\text { Scope of Activities } \\
\text { (product, marketing) } \\
\text { Subsidiary competency }\end{array}$ & $\begin{array}{l}\text { Strategic } \\
\text { importance } \\
\text { Development }\end{array}$ & $\begin{array}{l}\text { Product specialist } \\
\text { Strategic independent } \\
\text { Rationalized manufacturer } \\
\text { Marketing satellite } \\
\text { Miniature replica } \\
\text { (White and Poynter, 1984) }\end{array}$ \\
\hline Knowledge & $\begin{array}{l}\text { Degree of integration } \\
\text { Adaptation to host } \\
\text { country }\end{array}$ & $\begin{array}{l}\text { Strategic } \\
\text { importance }\end{array}$ & $\begin{array}{l}\text { Global innovator } \\
\text { Integrated player } \\
\text { Implementer } \\
\text { Black hole } \\
\text { (Bartlett and Ghoshal, } \\
\text { 1989; Gupta and } \\
\text { Govindarajan, 1991) }\end{array}$ \\
\hline $\begin{array}{l}\text { Integration - } \\
\text { Responsiveness }\end{array}$ & $\begin{array}{l}\text { Degree of local } \\
\text { responsiveness } \\
\text { Degree of integration }\end{array}$ & $\begin{array}{l}\text { Integration within } \\
\text { MNE } \\
\text { Responsiveness to } \\
\text { host country }\end{array}$ & $\begin{array}{l}\text { Active } \\
\text { Receptive } \\
\text { Autonomous } \\
\text { Quiescent } \\
\text { (Jarillo and Martinez, 1990; } \\
\text { Taggart, 1998) }\end{array}$ \\
\hline $\begin{array}{l}\text { Autonomy - } \\
\text { Procedural } \\
\text { Justice }\end{array}$ & $\begin{array}{l}\text { Degree of autonomy } \\
\text { Degree of influence in } \\
\text { MNE decision making }\end{array}$ & $\begin{array}{l}\text { Autonomy and } \\
\text { participation in } \\
\text { decision making } \\
\text { Strategic } \\
\text { importance }\end{array}$ & $\begin{array}{l}\text { Partner } \\
\text { Militant } \\
\text { Collaborator } \\
\text { Vassal } \\
\text { (Taggart, 1997) }\end{array}$ \\
\hline
\end{tabular}


A third typology, extensively employed in research, considers the extent of subsidiary integration within the global MNE network, and its capacity to respond to local market needs (Bartlett and Ghoshal, 1989; Doz, Bartlett and Prahalad, 1981; Prahalad and Doz, 1987). Whereas these authors initially characterized integration and responsiveness as involving a trade off, Jarillo and Martinez (1990) treated these dimensions as independent. Other researchers found that subsidiaries with high levels of embedment within the local environment also have higher strategic importance to the MNE (e.g. Cantwell, 1995; Kuemmerle, 1999b).

The final typology of subsidiary mandates considers procedural justice, the extent to which the process of allocating decision making rights is deemed fair by the subsidiary (Kim and Mauborgne, 1991; 1993), and the level of subsidiary autonomy (Taggart, 1997). Subsidiaries with higher degrees of autonomy are greater contributors to the MNE, and hence of more strategic importance, and those which have access to greater procedural justice work in a more integrated and collaborative fashion with MNE headquarters and other subsidiaries (Taggart, 1997).

Mandate typologies provide mutually exclusive categorizations of each subsidiary to which they are applied. Innovation mandates do not fall within a particular typology, but each typology provides implications according to their dimensions. Delany (2000) divides subsidiaries according to a linear development model in which they obtain progressively larger scope, from basic, to enhanced, and finally to advanced. However, the innovation activities of the MNE, especially in knowledge intensive industries, are 
located furthest upstream in terms of contribution to MNE capability development. Hence, these mandates are advanced regardless of the scope of the mandate. With respect to geographic scope, the subsidiary may innovate for the local, regional or global market. However, this research employs the transnational view of the MNE (Bartlett and Ghoshal, 1989) and focuses on subsidiaries with global innovation mandates. These mandates involve greater complexity, uncertainty, risk and learning, and hence they present an especially important management challenge.

In general, subsidiaries are mandated to either exploit existing MNE capabilities or to participate in the creation of new capabilities (Cantwell and Janne, 1999; Kuemmerle, 1999b). These are not mutually exclusive categories, as subsidiaries can engage in both capability exploitation (CE) and capability creation (CC) to varying extents, which is sometimes a result of competing pressures for efficiency and local adaptation (Rosenzweig and Singh, 1991; Westney, 1993). However, consistent with other current research (e.g. Cantwell and Mudambi, 2005) the focus here is on subsidiaries which play a significant role in MNE innovation and hence capability creation. Where a subsidiary possesses an innovation mandate, it is expected to contribute to MNE capability creation thus creating a source of new value. A subsidiary can have many mandates, including manufacturing, marketing, sales and distribution, but the focus of this research is on subsidiaries with innovation mandates. Figure 1 depicts the classification of innovation mandates considered in this research according to their global scope and role in contributing to MNE capability creation. 
Figure 1: Position of innovation mandates with respect to competency creation and geographic scope.

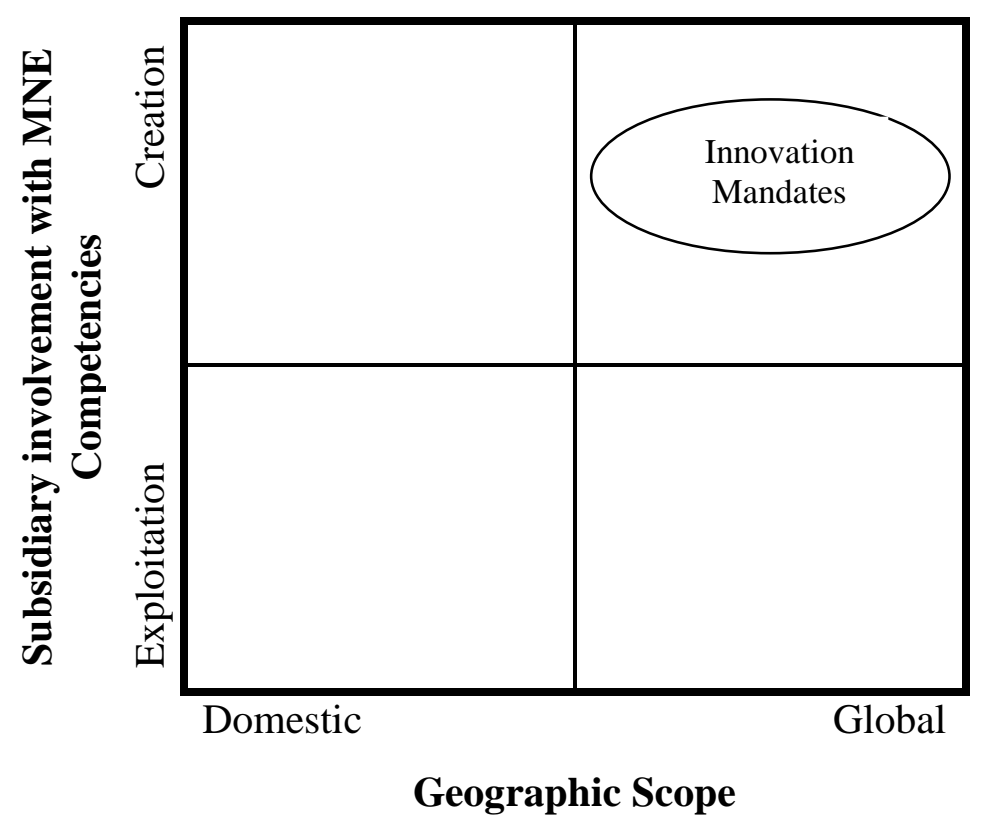

While transferring practices from the MNE to the subsidiary represents capability exploitation, a subsidiary that is given an innovation mandate needs to build upon those competences in order to add new value. The outcomes of innovation are always highly uncertain and cannot be achieved solely through the application of a set of practices. Generally speaking, innovation is highly resistant to systematization (Frenkel, Maital and Grupp, 2000), a feature which makes highly innovative organizations stronger competitors. It is not possible to fully codify the capability required to innovate, nor can 
innovation be entirely routinized, which creates an impediment to efficiently transferring the capability throughout the MNE network.

Mandated subsidiaries develop new capabilities over time, with resources sourced from within the MNE, in order to innovate. The adoption of practices from the MNE headquarters is therefore a necessary but not sufficient condition for developing innovation capabilities. Furthermore, in the process of innovation practice diffusion, it is quite possible, even likely, that some practices will be adapted or discarded, and new practices created. New and adapted practices might be of value to the MNE, but only if it is able to recognize that value and diffuse the practice.

The research comprising this thesis focuses specifically on the internationalization of competency creation (CC), a phenomenon which has interested scholars for some time, although empirical accounts have largely focused on the determinants of international R\&D investment (inter alia Cantwell, 1995; Cantwell and Mudambi, 2005; Kuemmerle, 1999a; 1999b; Pavitt, 2001; 2002) and patent citation patterns (e.g. Frost and Zhou, 2005; Phene and Almeida, 2008). This focus is novel because the process of CC through innovation practice transfer is examined, as opposed to practice transfer in general, and furthermore attempts are made to take into account the role of the subsidiary within the overall network according to a more comprehensive set of parameters than prior empirical examinations.

The mandate dimensions listed in Table 2, as applicable to subsidiary innovation mandates, can be summarized as scope of the mandate or degree of specialization, 
subsidiary competency, extent of integration within the MNE innovation network, responsiveness to the local country, and decision making autonomy and participation. Scope of mandate often refers to the range of value chain segments over which a subsidiary has control (White and Poynter, 1984). As this research pertains to the role of innovation practice transfer in the development of subsidiary capabilities, competency is considered a dependent variable as opposed to a mandate dimension. While competency and mandate are mutually reinforcing (Birkinshaw and Hood, 1998), it is the role that transferring innovation practices plays in building capabilities which is the focus of this research. Responsiveness to the host country environment can impede practice transfer, as the subsidiary faces greater pressures to adapt to the local environment, thus increasing the likelihood and extent to which innovation practices will be adapted. However, only those subsidiaries with global innovation mandates are considered here and hence the focus is on global integration. The role of subsidiary autonomy and influence over MNE strategic decision making partially overlaps with the pressures for local adaptation. The micro-political dynamics of headquarter and subsidiary interaction are considered in the next chapter, in the context of organizational influences on innovation practice transfer.

In this research, scope is not considered from a value chain perspective, as innovation can apply to any segment, but instead is considered the scope of functional expertise to which a transferred innovation practice applies. Degree of integration within the MNE innovation network influences the emergence of communities of practice, which in turn influence practice transfer. Hence the specialization and integration 
dimensions of a subsidiary's innovation mandate are both likely to influence the ease of transfer, and degree of adaptation of innovation practices.

The next sections examine the influence of subsidiary innovation mandate integration and specialization on innovation practice transfer in more depth. First, the degree of specialization according to functional expertise is considered. Following this, the level of integration of a focal subsidiary, which is defined as the extent to which it interacts with the overall MNE innovation network, is discussed. Following this the specialization and integration components of subsidiary mandate are related to potential implications for innovation practice transfer.

\subsubsection{Specialization}

The relationship between MNE internationalization and innovation capability development has evolved from a state in which the two processes were relatively disconnected to a state in which they are mutually reinforcing, as MNEs increasingly access local innovation expertise where they reside (Cantwell and Piscitello, 2000). The product cycle model (Vernon, 1966) provided some of the earliest thinking on patterns of internationalizing innovation activities. This model assumes that demand conditions are the primary drivers of innovation, that home markets are both the primary source of this demand, and the preferred location for developing new technologies due to the availability of the required resources, most notably a skilled workforce (Vernon, 1979). Following this logic, MNEs innovate close to home and then exploit the resulting technology globally through international expansion in order to achieve efficiencies of 
scale and scope. This in turn produces path dependencies in both technological development and national comparative advantages in innovation. Furthermore, it implies that practices flow in one direction, from the MNE home location, to the foreign subsidiary, and that no capability enhancement would be obtained.

Under the assumptions that innovation is resource intensive and path dependent (Dosi, 1982; 1988; Jaffe and Lerner, 2004; Nelson and Winter, 1977; 1982; Porter, 1980), and that knowledge spillovers play an important role in technological path development, geographically bounded agglomeration is the expected result (Almeida and Kogut, 1997; Cantwell, 1991; Feldman, 1993; Jaffe, Trajtenberg and Henderson, 1993). As a result of this agglomeration, nations experience the 'Matthew effect', that is, those rich in resources and capabilities as a result of initial technology development will accrue more, while those which lack adequate resources will have their stock reduced (Merton, 1968; 1988). Hence, only successful innovators in the present would be able to innovate in the future.

A counterpoint to the product lifecycle logic, is the emergence of location-bound expertise either due to the development of a comparative national advantage in specific industries or functions related to innovation (e.g. Cantwell and Janne, 1999; Cantwell and Mudambi, 2005; Cantwell and Piscitello, 2000) or the evolution of subsidiary capabilities which enables downstream movement along the value chain (Birkinshaw and Hood, 1998; Zander 1997). Under these conditions, regional and subsidiary specific centers of 
excellence may develop and the role of the MNE in innovation becomes the coordinator and integrator of the various centers (Cantwell and Piscitello, 2000; Frost et al, 2002).

Centers of excellence can refer either to subsidiaries with advanced, high valueadded mandates (Fratochii and Holm, 1998; Holm and Pedersen, 2000) or a source of best practices to be exploited abroad (Lyle and Zawacki, 1997; Moore and Birkinshaw, 1998). According to the latter view, a subsidiary may contain several centers of excellence. Frost et al (2000) found that Canadian subsidiaries of MNEs were more likely to develop into centers of excellence when they had access to internal and external sources of competencies, and the MNE has substantially invested in them. To the extent that subsidiaries house centers of excellence, the more unique their competencies, and hence the more specialized their mandate, as compared with other subsidiaries in the MNE innovation network. Such subsidiaries may be sources of competency creating innovation practices, either to be exploited or diffused.

As the type of innovation activity carried out abroad varies in accordance to firm strategy, and the industry-specific advantages of home and host nations (Cantwell and Janne, 1999; Cantwell and Mudambi, 2005), the type and direction of practice flow will also vary. When MNEs follow a strategy of diversifying innovation activities amongst their foreign affiliates in order to enhance existing capabilities (Kuemmerle, 1999b), for example, not all practices of the firm are likely to be transferred, and furthermore, there is greater likelihood that foreign affiliates will adapt and develop their own practices based on host country advantages and traditions, according to their area of expertise. 
Conversely, when a MNE replicates its innovation activity to exploit its existing capabilities in foreign nations (Kuemmerle, 1999b) there is greater incentive to transfer a full complement of practices. In this situation, adaptation of existing practices, and adoption of new practices may be detrimental, unless headquarters coordinates and diffuses best practices throughout the firm regardless of their origin. Therefore, for reasons which can mainly be attributed to the evolution of location and subsidiary bound expertise, specialization of the innovation mandate of a foreign affiliate can be categorized according to the extent of its expertise.

If a focal subsidiary has gained its innovation mandate as a result of the local national competitive advantage, then its innovation practices will more closely resemble those prevalent in the host country industry. These practices may be utilized by the MNE either by leveraging their value through integration within the MNE network, or by initiating and encouraging diffusion to other subsidiaries. In contrast, if the subsidiary gained its mandate as a natural evolution of its role within the innovation network, it is more likely that practices will have transferred from within the MNE. As the host country context provides the subsidiary with its source of uniqueness, expertise and strategic importance (Frost et al, 2002), pressures for adaptation of innovation practices will be high. Conversely, subsidiaries which provide less unique capabilities within the MNE innovation network are likely to be recipients of innovation practices, and forces for adaptation will be lower. The integration component of a subsidiary's mandate is 
examined next, followed by a discussion concerning how these characteristics may influence innovation practice transfer.

\subsubsection{Integration}

The internationalization of innovation has proceeded in parallel with the increasing integration of national economies (i.e. globalization) with the two reinforcing each other with increasing interdependence (Archibugi and Iammarino, 2002). The partially overlapping facets of innovation globalization which have emerged sequentially are the global exploitation of innovations developed nationally, the international generation of innovation, and international collaboration for innovation (Archibugi and Michie, 1995). Each of these facets, inter alia, set the stage for the next in sequence. As firms exploited their technology and capabilities in increasingly larger markets, their international presence provided both the necessity and opportunity to involve foreign affiliates in producing new value through innovation.

Likewise, international collaborations amongst MNEs and institutions such as foreign governments, public research institutes, consortia, and universities are all part of a natural and most likely inevitable progression from national to international innovation systems (Carlsson, 2006; Lundvall, Johnson, Anderson and Dalum 2002). Hence, the internationalization of innovation, and to some extent national innovation systems (NSI), has resulted in heterogeneous MNE innovation networks, constituted by the unique competencies of subsidiaries. To the extent that MNE competencies are geographically distributed, coordination and integration is complicated. Transfer of innovation practices 
should improve communication and coordination amongst subsidiaries, hence providing a source of integration.

The necessity for innovation may be driven by a need for local market adaptation of MNE capabilities or through accessing nationally bound comparative advantages in competencies, which the MNE can exploit globally over time. Once subsidiaries are established in foreign markets to tap local knowledge and competencies, MNEs have the opportunity to provide global innovation mandates to local affiliates in order to benefit by recombining globally dispersed capabilities (Bartlett and Ghoshal, 1989; Hedlund, 1994; Perlmutter, 1969; Prahalad and Doz, 1987). Doing so requires the MNE to establish mechanisms of coordination such as the alignment of human resource practices with organizational goals (Zander, 1997).

The extent to which firms internationalize their innovation activities depends in part on the nationality of the firm in question. Japanese MNEs have tended to be fairly conservative with the internationalization of innovation, while European MNEs tended towards more internationalization and American MNEs conduct the most innovation abroad (Pauly and Reich, 1997; Von Zedtwitz and Gassman, 2002). Different levels of firm internationalization result from the interaction of history, local market conditions, and availability of resources in the local country. Firms located in larger markets, for example, previously faced fewer pressures to internationalize, while those in smaller markets needed access to foreign markets to achieve sufficient economies of scale. Counterbalancing this demand-pull argument for innovation internationalization is the 
supply-side argument that innovation within smaller nations is limited by resource constraints (Cantwell and Janne, 1999). These constraints encourage firms from these countries to operate in a more narrowly defined technological domain, and replicate these efforts abroad rather than integrate new capabilities.

While resource availability, especially for knowledge intensive competencies, is a particularly salient motive for the internationalization of innovation, it does not fully account for international patterns of innovation investment. U.S. MNEs internationalize innovation to a greater extent than those of other nationalities such as Japan and German, in part due to the different ideologies, corporate governance structures, and corporate finance (Pauly and Reich, 1997). These differences seem to be durable, despite the integrating forces of globalization.

The combined influences of home country characteristics and advantages, as well as the evolutionary forces of globalization have reshaped MNE networks and consequently subsidiary mandates. Inevitably, MNE innovation networks will evolve to contain a heterogeneous group of subsidiary mandates. The level of integration is added, in addition to specialization, as a further influential characteristic of subsidiary mandates. A highly integrated mandate means that a focal subsidiary's activities must be substantially coordinated with other network constituents in order to achieve innovation outcomes. Hence, the extent to which a subsidiary is integrated within the overall MNE network influences the amount of coordination required to achieve innovation outcomes. Factors positively affecting subsidiary integration within the MNE network include level 
of experience of the MNE and subsidiary, the extent of basic research undertaken by the subsidiary, and interaction through training and site visits (Williams and Nones, 2009). This effect is similar to how internal embeddedness, which is the number and quality of social ties within the MNE network (Birkinshaw and Sölvell, 2000; Garcia-Pont et al., 2009), enhances knowledge flows to a focal subsidiary, thus enabling its capability development (Grant, 1996; Kogut, 2000; Kogut and Zander, 1993).

As transferring knowledge is a critical component of transferring practices, greater integration within the MNE network should reduce impediments caused by home and host country differences (e.g. Kostova and Roth, 2002; Szulanski and Jensen, 2006). Hence, innovation practices should diffuse more readily to and from subsidiaries with highly integrated innovation mandates. Subsidiaries which are more integrated within the MNE innovation network are also more influenced by internal socialization forces (Kostova and Roth, 2002). Hence, adaptation of innovation practices by the subsidiary will be impeded. However, if the subsidiary is a source of unique capabilities, via its specialization, it will be less impacted by the internal socialization forces, and thus able to create desired adaptations more readily. Hence, innovation practice adaptation is more likely to be a function of a subsidiary's degree of specialization than its integration.

\subsubsection{Innovation Mandate Characteristics and Practice Transfer}

Figure 2 summarizes subsidiary innovation mandate characteristics and the associated implications for the transfer, adaptation and diffusion of practices. The implications disclosed are not meant to be exhaustive, but to provide some general 
guidance for the research. While not formalized, the implications presented were considered in the data collection and analysis performed for this research.

Figure 2: Subsidiary innovation mandate characteristics and implications for innovation practice transfer.

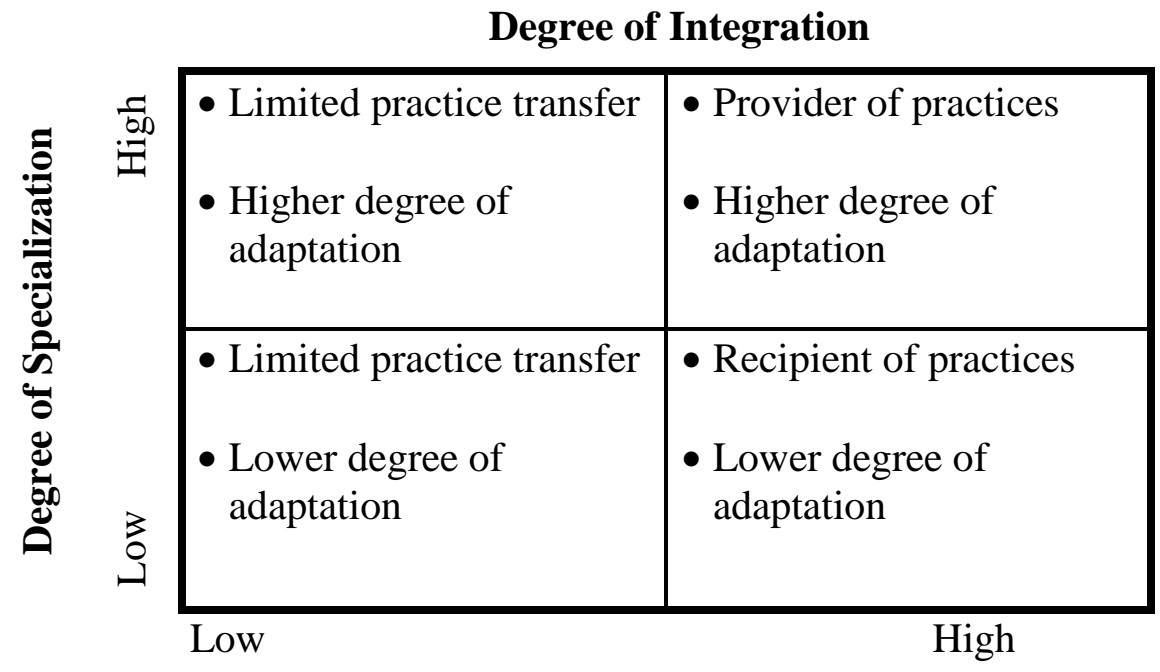

Transferring practices to highly integrated subsidiaries is likely to be easier and lead to lower levels of adaptation as integration leads to greater socialization, thus reinforcing the institutionalized practices of the MNE. These transfers can occur within the context of either horizontally integrated subsidiaries or vertically integrated subsidiaries and headquarters (Gupta \& Govindarajan, 2000; Kurokawa Iwata and Roberts, 2007). When subsidiaries are horizontally integrated within the MNE network, innovation practice adaptations may diffuse through an organic process of variation, 
selection and retention. Conversely, vertically integrated subsidiaries are encouraged to adopt common practices by headquarters, thus implying greater pressures against adaptation.

Being integrated within the overall MNE innovation network enables any adaptations that do occur to more readily diffuse amongst affiliates as there is increased interaction, subsidiaries have greater influence (Mudambi and Navarra, 2004), and requirements for coordination (Garcia-Pont et al, 2009). In fact, this higher diffusion rate is enabled and enhanced by the lower absolute number and degree of adaptations occurring in integrated subsidiaries. A high degree of practice variability would, conversely, limit the institutionalization of any particular practice (Cohen and Levinthal, 1990).

Conversely, subsidiaries with mandates characterized by less integration within the MNE network have less motivation, and face fewer pressures to accept practices, and are more likely to adapt them extensively. This is especially applicable to more specialized subsidiaries which, in general, are more likely to adapt practices than more generalized subsidiaries, as expertise increases as a function of specialization. This represents a potential loss of opportunity for the MNE in that subsidiaries become islands of expertise which are inaccessible to the overall network (Williams and Nones, 2009; Zanfei, 2000).

In addition to the implications mentioned above, transferring practices at a point in a subsidiary's evolution substantially later than inception will more likely be done in 
the presence of established practices which may impede the transfer process and increase the likelihood of adaptation. The sources of these impediments range from the necessity of the subsidiary to 'unlearn' old innovation practices (Bettis and Prahalad, 1995), the political power afforded it by its strategic importance to the MNE (Andersson, Forsgren and Pedersen, 2001), the legitimacy afforded it by its embedment in the local environment (Chan and Makino, 2007), or because the innovation practice to be transferred is incongruent with existing practices. Hence, the stage of a subsidiary's development matters.

It is necessary also to consider influences arising from the subsidiary's internal and external environment on the innovation practice adoption, adaptation and diffusion. While subsidiary development is expected to evolve over time, this evolution can also include a reduced mandate as a result of failure to develop required capabilities (Birkinshaw and Hood, 1998), strategic initiatives of the headquarters, or through acquisition, which can either reduce or increase the subsidiary's strategic importance to the MNE (Delany, 2000). Hence, the tenure of the subsidiary, the evolution of its role, and mode of establishment are all potential influences on the adoption and adaptation of innovation practices, in addition to the subsidiary's innovation mandate. Contextual factors at the national and organizational levels of analysis therefore need to be considered, as their relative influence and potential interactions have not been substantially investigated in prior research on practice transfer. 
Finally, it must be acknowledged that the characteristics of subsidiary mandates can change as capabilities are developed, and its specific role and function evolve. Factors which influence changes to a subsidiary's mandate can be divided into decisions made by headquarters, by the subsidiary, and environmental characteristics (Asmussan, Pedersen and Dhanaraj, 2009; Birkinshaw and Hood, 1998). Through these decisions, and the influence of factors in the local environment, a change in a subsidiary's charter may induce, or be the result, of enhanced or new capabilities. While the goal of this research was not to specifically investigate factors affecting subsidiary mandate evolution, it is nonetheless important to appreciate that the types of practices transferred to and from a subsidiary are, in part, a function of headquarters' intentions for the subsidiary, as well as the motivation and ability of the subsidiary to draw resources from the MNE network and from external sources (Andersson, Björkman and Forsgren, 2005; Kurokawa et al 2007; Phene and Almeida, 2008). Furthermore, subsidiary mandate evolution and capability development are mutually influential (Birkinshaw and Hood, 1998). 


\section{Chapter 3: The Organizational Context of Knowledge}

This chapter examines the many forms and roles of knowledge in the MNE. First, definitions and relationships between the highly related but not identical constructs of organizational knowledge, capabilities and practices are drawn. These three constructs provide the building blocks for competitiveness and value creation of the MNE, according to KBT. Practice diffusion is an important mode of transferring organizational knowledge and building capabilities in foreign subsidiaries. In accordance with KBT, building capabilities is central to the creation of new value and competitiveness (Grant, 1996; Kogut and Zander, 1993).

The next section contains a review of constructivist organizational learning in innovation communities and how practices emerge within and between organizations. Mapping these processes is essential to understanding how practices are transferred as, to varying extents, transfer involves relearning the tacit knowledge partially embodied in the practices. The processes involved in organizational relearning provide fertile ground for making adaptations to existing practices, by both the practice provider and recipient. Just as subsidiaries can receive an initial innovation mandate at any point in their existence starting from inception, practice transfer can occur at any point during the execution of a mandate. It is important to appreciate the extent of capability development a subsidiary has achieved when a particular practice transfer event occurs, as history and the quality of 
the relationships between headquarters and subsidiaries, as well as between subsidiaries, play an important role in the transfer process, and influences adaptation.

\subsection{Organizational Knowledge, Capabilities and Practices}

The concepts knowledge, capability, and practice are highly interrelated and thus easily confused. In this chapter some clarity is brought to these terms by delineating their specific meanings, and identifying how they critically interrelate to serve the efficient and effective functioning of an organization. However, it must be stressed and maintained throughout that considering each of these related constructs in isolation from one another can provide a false sense of how they shape behaviour, broadly construed, in organizations. Knowledge, capabilities and practice are mutually influential, and all are influenced by the social milieu in which they are created, used and evolve. Furthermore, and as is detailed later in this discussion, knowledge is a necessary, although not sufficient, resource for the creation of practices, and the existence of capabilities in the MNE.

In each instance, although the terms knowledge, capability and practice are meaningful when applied to individuals, this discussion is focused on the organizational level, as this better suits the purposes of this research. Hence, although the term 'organizational' is omitted, it can be assumed to proceed each of the defined terms in the discussion. Learning is a process which occurs throughout the creation, diffusion and augmentation of knowledge, capabilities and practices. It will be dealt with in a later section as it applies specifically to innovation in communities of practice. Likewise, the 
discussion proceeds from a general discussion on practices and their relationship to knowledge and capabilities in this section, to a specific discussion of the relationship of practices to innovation in a subsequent section.

\subsubsection{Knowledge of the Organization}

The precise nature and definition of knowledge, personal or organizational, has thus far escaped consensus building amongst organizational researchers. While many have identified characteristics (e.g. subjectivity, values and assumptions: Nonaka and Takeuchi, 1995; codifiability and complexity: Rogers 1983), developed taxonomies (e.g. tacit vs. explicit: Polanyi, 1975; know-what vs. know-how: Kogut and Zander, 1992), and delineated it from related concepts such as data and information (e.g. Davenport and Prusak, 1998; Nonaka and Takeuchi, 1995) the exact link between knowledge and action remains unknown, despite positive claims to the existence of such a link (Tsoukas and Vladimirou, 2001).

Building from the personal characterization of knowledge (Polanyi, 1975) and the collective characterization (Wittgenstein, 1958), Tsoukas and Vladimirou (2001, p. 983) define knowledge as "the individual capability to draw distinctions, within a domain of action, based on an appreciation of context or theory, or both", and organizational knowledge as "the capability members of an organization have developed to draw distinctions in the process of carrying out their work, in particular concrete contexts, by enacting a set of generalizations...whose application depends on historically evolved collective understanding and experiences." Knowledge differs from data and information 
in that it incorporates the role of values and beliefs, and directs action (Davenport and Prusak, 1998; Nonaka and Takeuchi, 1995). Hence, knowledge does not exist in the absence of the experience of individuals who possess it. In this sense, knowledge is personal in that it is a capability which guides actions performed by individuals. Furthermore, and especially relevant in the organizational sense, individual experience is not entirely personal but shapes the interaction amongst organizational members. Hence, knowledge is collective in that the shared experience of individuals shapes it and forms its boundaries.

Knowledge is particularly important for the present discussion in that it precedes action. Under the assumption that organizations engage in activities with a view to what are perceived to be desirable outcomes, knowledge guides individual action, and to the extent that it is shared, organizational action. The two important aspects of this guidance are that 1) knowledge embodies means-ends relationships in that it specifies the link between action and outcome, and 2) the extent to which outcomes can be classified as desirable or undesirable depends upon the values and norms of individuals which are largely shaped through interaction with the relevant social context in which actions are engaged in. In the most simple and abstract sense, knowledge can be expressed as a proposition: if A then B where A is an action, and B is the associated outcome. However, no such relationship can be observed in the absence of historical, experiential and social influences which suggest what the outcome should be, and which action will achieve it. 
Furthermore, there are varying degrees of uncertainty and ambiguity in every situation in which knowledge is applied.

\subsubsection{Organizational Capabilities}

Organizational capabilities are "a firm's capacity to deploy resources, usually in combination, using organizational processes, to effect a desired end" (Amit and Schoemaker, 1993: 35). Although the definition of knowledge given in the previous subsection suggests that it is in itself a capability, organizational capabilities differ in the sense that they guide collective action towards the pursuit of an outcome. Each organizational member's capability, conversely, is towards an end which contributes to, but is not the organizational end in itself. Furthermore, organizational capabilities involve the deployment of resources, which implies the possession or access to these resources, of which knowledge forms a subset. In essence, capabilities are what a firm can demonstrably do, and hence the production of observable outcomes is a critical component of this definition. Where a firm has never produced a particular outcome, it has no claim to the associated capability, and even if said outcomes have occurred in the past but are no longer pursued, the claim may be called into question. Capabilities are, therefore, a critical predecessor of a firm's claims to value creation, its survival, and its growth. Capabilities are not easily developed, do not transfer readily in markets, are not easily observed, are ambiguously associated with observable outcomes, and evolve in a somewhat path-dependent manner. Thus they can be a substantial source of performance 
variation amongst firms (Barney, 1991; Ethiraj et al, 2005; Nelson, 1991; Nelson and Winter; 1982; Peteraf; 1993; Wernerfelt, 1984).

Organizational capabilities can be delineated into operating and dynamic capabilities. Operating capabilities consist of what a firm does to fulfill its basic mission of creating products or services (Newey and Zahra, 2009; Winter, 2003; Zahra, Sapienza and Davidson, 2006) while dynamic capabilities allow a firm to adapt and evolve, especially in the face of exogenous changes which significantly alter supply and/or demand conditions (Teece, 2007; Zollo and Winter, 2002). Operating capabilities allow the firm to survive in the short term while dynamic capabilities are required in the long term, assuming that environmental conditions also change.

Since innovation entails creating something new, thereby potentially changing the environment by enhancing products sold, services delivered, organizational processes, or even the manner in which business is conducted, it essentially represents a dynamic capability. However, innovation is most commonly engaged in as an internal, endogenous, and/or entrepreneurial effort of a firm, as opposed to a response to external shock (Helfat et al, 2007). Therefore, innovation involves the use of both (A) operating capabilities which are built from organizational practices, as will be explained in a subsequent section, and (B) dynamic capabilities to continually evolve those operating capabilities. Therefore, innovation is achieved through an interaction of operating and dynamic capabilities (Newey and Zahra, 2009). 


\subsubsection{Organizational Practices}

The concept of practices overlaps substantially within the literature with the concept of routines ${ }^{1}$. While the former has been derived from institutional theory (DiMaggio and Powell, 1983; Meyer and Rowan, 1977; Zucker, 1991), hence emphasizing the influential role of social forces in creating homogeneity and stability, the latter is rooted in the evolutionary theory of the firm (Nelson and Winter, 1982), thereby emphasizing change. While there is not complete agreement upon the definition of routines in existing literature, there is some consistency with respect to their characteristics, namely that they consist of patterns of organizational behaviour which are repeated, involve collective action, are process-oriented in nature, and are developed through path dependent, context specific learning processes (c.f. Becker, 2004).

Following institutional theorists (Meyer \& Rowan, 1977; Selznick, 1957; Zucker, 1991), Kostova and Roth (2002, p.216) define organizational practices as: "an organization's routine use of knowledge for conducting a particular function that has evolved over time under the influence of the organization's history, people, interests, and actions" (see also Kogut and Zander, 1992; Kostova, 1999; Szulanski, 1996). Practices, therefore, embody organizational knowledge regarding the way things are done within a particular organization, and the actions required for performing them. Consistent with the objectives of this research, innovation practices are considered a subset of organizational

\footnotetext{
${ }^{1}$ According to the Concise Oxford English Dictionary (2006), 'routine' is defined as "a sequence of actions regularly followed; a fixed unvarying programme" and 'practice' is defined as "the customary or expected procedure or way of doing something". The latter definition is consistent with the importance of the formal and normative nature of practices, and the social influences on them, as discussed in this thesis.
} 
practices which focus on novelty generation. While not necessarily using the term practice explicitly, there are precursors in the literature which appear to refer to the same general concept. In a discussion on the components of technology transfer, for example, Zander and Kogut (1995, p. 77) highlight the prerequisite of "organizational principles by which individual skill and competence are gained and used, and by which work among people is organized and coordinated." This characterization of organizational principles is highly consistent with the definition of practices used here, and highlights the need for the pre-existence of something identifiable in order to transfer new knowledge and capabilities.

Despite these different points of emphasis, the literature on both routines and practices does not, in sum, deny the existence of both change and stability in either. Both are processes, embody a set of guidelines or rules for how specific activities are conducted (i.e. organizational knowledge), and are open to adaptation based on feedback provided from use (Becker, 2004; Kostova, 1999; Kostova and Roth, 2002; Nelson and Winter, 1982; Teece and Pisano, 1994). In essence, the terms are nearly identical in ontological content but arrived at through different epistemological vantages. Thus, in order to facilitate a discussion on practice transfer, adaptation and evolution, it is assumed that both routines and practices are subject to the same influences with largely the same effect, albeit with slight differences in extent. As detailed in the next subsection, practices are less specific than routines with regard to functions, are more frequently repeated in the organization, and are more resistant to change. 
Practices are institutionalized and thus relatively homogenous within a particular grouping (e.g. an organizational subunit) while routines are emergent from groups, and can potentially be heterogeneous across the organization. While Kostova (1999) does not specifically include any discussion on the extent of diffusion, her focus on 'strategic' practices implies that it is limited to the organization. Her later work with Roth focuses exclusively on the transfer of quality management practices of a single organization to subsidiaries in ten countries. These researchers suggested that the regulatory, cognitive, and normative institutional environments (Scott, 1995) of different subsidiary locales would impact the adoption and internalization of quality management practices.

This manner of observing practice transfer creates some ambiguity as to the exact nature of practices. That is, if a practice is specific to an organization, or in this case segment of an organization, some aspects of the external institutional environment of the subsidiary should not be applicable. Rather than subsidiary employees being intimately familiar with the practices to be transferred, as represented by the cognitive pillar of institutional theory, they would at best be familiar with the practice in name only, suggesting that to be recognizable, a practice must be of the 'management fashion' persuasion (Abrahamson, 1991). Since this does not fit the espoused definition of practice, it is important to keep in mind that deep familiarity with practices is achieved through interaction with them only, a perspective which is presented in more detail in a subsequent discussion on communities of practice. Practices can also diffuse beyond the boundaries of a single organizational unit, such as when geographically dispersed 
individuals within a MNE pursue new opportunities together (Lee and Williams; 2007). However, their exact form will depend upon implementation, which is influenced by history, location and relational context (Barney 1991; Simon, 1991; Dyer and Singh, 1998).

In summary, routines emerge from communities, and may become institutionalized at the organizational level, at which point they are referred to as practices. For example, a community of software developers may devise routines to hasten the completion of their work by dividing it amongst themselves and engaging customers more frequently. These routines can become further integrated with a firm's overall capabilities and established at the organizational level, perhaps through managerial intervention, and thus come to represent a common practice used throughout the MNE. This is not to say that everyone in the organization is a participant in a certain practice. Instead, the practice is engaged in by everyone attempting to accomplish similar functions.

A practice becomes more identifiable, but less consistent, when it is institutionalized beyond the context of a single organization, to whole industries. Hence, routines form the building blocks for practices under institutionalization pressures, while practices are the building blocks of capabilities, which in turn directly address the value creation proposition of the firm. As routines represent more generalized functions within the organization, it is their combinations which form the unique practices and capabilities 
of the firm. In the final subsection, routines, practices, capabilities and knowledge are related in order to construct a view of the firm consistent with KBT.

\subsubsection{Organizational Roadmap from Routines to Value Creation}

A descriptive model of the linkages amongst routines, practices, and capabilities, their relationship to the firm's realization of value is depicted in Figure 3. Also depicted are two entry points for the influence of organizational knowledge. The arrows between routines and practices, and practices and capabilities, depict compositional linkages. Routines are involved in achieving more generalized functions while practices, which are typically characterized as embodiments of a firm's superior or strategic knowledge (Kostova, 1999), tend to fulfill functions much closer to overall organizational goals, and thus are more specific. Conversely, routines more frequently recur within organization, as compared to practices.

Organizational knowledge enters the model in two places, although in reality it is diffused throughout all organizational processes. Routines and practices embody procedural knowledge which includes both cognitive and behavioural aspects (Becker, 2004; Cohen and Bacaydan, 1994). Hence, routines represent organizational memory regarding the operations of the firm, solutions to previously encountered problems and, unlike other repositories, are able to capture tacit knowledge (Becker, 2004; Grant, 1996; Nelson and Winter, 1982; Teece and Pisano, 1994; Winter 1995; Zollo and Winter 2002). Knowledge therefore has the 'bottom up' effect of building some routinization into the value proposition of the organization, which is necessary for its immediate existence. 
Figure 3: Model of the knowledge composition of the MNE and value creation.

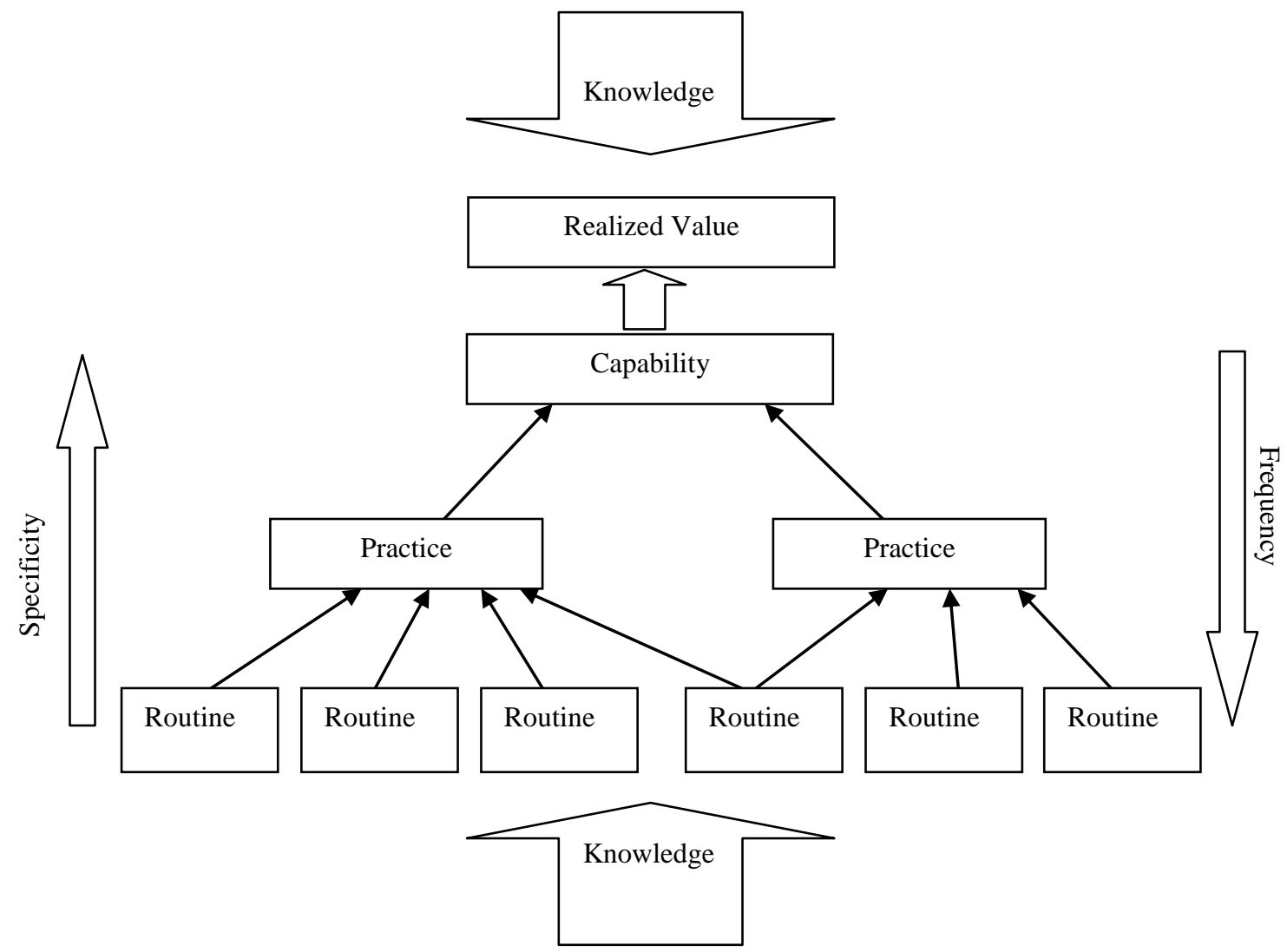

Inevitably, trends and discontinuities in the internal and external environment of the firm call for either or both a change in the value proposition of the firm and its capability to accomplish it. Whether this change is exogenous or endogenous, knowledge of the firm, its capabilities, and trends in external environments are all vital inputs when reshaping organizational objectives and capabilities through reconfiguration and adaptation of existing practices, or development of new ones. Given that routines provide more generalized functions than practices and can be used to create more than one practice, they are more resistant to change. However, sets of routines are readily 
reconfigurable to be used in new practices. In the language of Penrose (1959), routines represent resources which can be recombined to provide new services.

This descriptive model of capability composition, development and value creation is a somewhat novel view of the organization although it heavily borrows from, and is consistent with KBT. In addition, it preserves the notion that routines make up the 'genetic material' and hence basic building blocks of organization which are subject to evolutionary forces through selection, retention and adaptation (Nelson and Winter, 1982; 2002; Winter and Szulanksi, 2001). The model presents, in abstract fashion, the basic processes which store and transform knowledge in the form of routines and capabilities, respectively. The processes involved in storing organizational knowledge (i.e. institutionalization) and capability development is learning. This discussion is specifically focused on constructivist learning within communities of practice which provides a useful lens on innovation (Brown and Duguid, 1991; Lave and Wenger, 1991).

\subsubsection{Innovation in Communities of Practice}

The purpose of this section is to review literature on the origin and characteristics of practices, and discuss the processes involved in 'doing the work' of innovation in organizations. The discussion here has its origins in Tönnies' work on 'gemeinschaft und gesselschaft', or 'community and society' (Tönnies, 1887), which represent opposite ends of a continuum of social organization. Community, according to this view is an end in itself, rather than purely a means to an end as in society. Individuals interact within a 
community because, in a sense, it is only through their interaction with other members that they can be considered to belong.

This conceptualization parallels the notion of membership within a profession such as engineering or medicine. Communities provide members with a shared identity which fosters the development of trust, which in turn facilitates the transfer and integration of tacit knowledge in order to enhance or build new competencies (Kogut and Zander, 1995; Nonaka, 1994). This interaction and coordination amongst community members, with a shared identity and thus common objectives, has been termed a 'focal point' (Schelling, 1960). Brown and Duguid (1991) argue that communities of practice tend to emerge in organizations, especially when working practices are absent or inadequately specified.

In the following section, the processes through which innovation practices are generated in organizations are examined. Next, a typology of innovation practices is developed according to the aspect of innovation which they address and whether they involve interaction within or external to the MNE. Following this, the process of innovation is examined, both in terms of practice and in terms of capability development, according to the constructive learning paradigm termed 'legitimate peripheral practice' (LPP: Lave and Wenger, 1991).

\subsection{The Origin and Constitution of Innovation Practices}

Thus far, a general model has been outlined for the position of practices within an organization, and their relationship amongst knowledge, capabilities, and organizational 
routines. It is important to also establish the composition and genesis of practices in order to build an overall theory of innovation practice transfer. This is the case as practices contain substantial tacit knowledge embedded in routines, and thus transfer always requires learning (Anand et al, 2007; Wenger, 1998). Here, a delineation of innovation practice types is provided, and the limited evidence on their production explicated. All management practices can be considered innovations in their own right (Birkinshaw et al 2008). Innovation practices, however, specifically refer to the variegated, institutionalized processes involved with innovation, which are the subject of this research.

The term 'innovation practice' is somewhat of an oxymoron in that the calling into being of that which did not exist prior tends to resist systematization (Frenkel et al, 2000). Nonetheless, in managers' desire to enhance the innovativeness of their organization, a variety of techniques have been implemented including knowledge management, learning systems, project and portfolio management, leadership, building a 'culture' of innovation, and so forth (Adams et al, 2006; Mahnke, Pedersen and Venzin, 2005). Project management practices, for example, are one category of practices often related to innovation, especially in the area of new product development (Adams et al, 2006). Recognizable examples include the stage gate process, total design, phased development, agile development, user led development, open source and crowd sourcing. Innovation is not equivalent to research and development (R\&D). While the latter focuses primarily on the generation and exploitation of new knowledge, innovation 
involves the generation of new value throughout the organization, in any function and at any level. Hence, innovation is embodied in a host of organizational practices including $R \& D$, human resource management (HRM), knowledge management (KM), and so forth. What is unique about innovation practices, as opposed to organizational practices in general is that the intended outcomes involve the creation of something new and thus are somewhat difficult to specify beforehand. However, innovation practices of separate firms, even if called by the same name, are organization-specific and should therefore be considered heterogeneous. The conceptualization of innovation used here, and that of most other authors, is broader than this. A more generalized, parsimonious and conceptually distinct set of practice categories can be developed by linking them with the organizational requirements for innovation. These consist of the requirement for financial commitment to innovation, learning, and the integration of human and physical assets (O’Sullivan, 2000).

The following is an example of an innovation practice. In the exploratory phases of this research, the Head of Engineering for a large Indian software company described how new knowledge was developed and integrated in the company to enable innovation. This manager is describing the practice of using what may be referred to as "subject matter experts" as a mode of creating, sharing, and integrating new knowledge. The references to 'environment' also tend to characterize the community of innovation to some extent. These individuals were given an opportunity to become experts in a chosen area of research deemed pertinent to the organization. It was expected that the 
knowledge developed by these subject matter experts would be used by other software developers within the organization. Hence, this practice can be classified as a learning practice, in that individual subject matter experts were expected to remain very current, or even surpass existing knowledge in their chosen area of expertise.

This is a very different working environment [compared to other parts of the firm], employees associate themselves with a different class of people saying they have specialized skills and they have specialized treatment... as opposed to just being in the crowd and being one of the many thousands [of software developers]. Many of these employees have aspirations, they have aspirations to grow in a specialized field and when you look at regular [software] delivery, regular [software] delivery is more like a cookie cutter standard solutioning type of thing. (Head of Engineering, Indian Software MNE)

The manner in which these individuals interact with software developers to solve customer problems and offer new products and services could be classified as integration. This example also illustrates the characteristics of a practice, namely that it is distributed, has evolved over time, and is institutionalized within the organization (Kostova, 1999). It is distributed, in that there are many subject matter experts and their knowledge may be drawn upon by a host of developers as necessary. Presumably this practice has evolved over time, given that this firm had no innovation mandate initially, 
and it is certainly institutionalized as these subject matter experts hold legitimate positions within the firm.

Practices can involve the inclusion of resources outside the firm in the overall process of innovation, or resources internal to the firm. This distinction is made to acknowledge the important influence of the external environment on the type of mandate a subsidiary possesses, and how it might evolve. Interaction with the external environment can contribute to the subsidiary's overall level of 'distinctiveness' (Andersson et al, 2001; Garcia-Pont et al, 2009; Kurokawa et al, 2007), that is its overall unique contribution to the MNE innovation network. Meanwhile, resources drawn from within the MNE network can contribute to the efficient development of capabilities (Phene and Almeida, 2008).

It is assumed for the purposes of this research that MNE managers engage in the transfer of innovation practices with a view to new value creation. The outcomes from the transfer process are examined both in terms of the potential evolution of the practice, and the innovation yield which results, although the goal is not to assess the effectiveness of the practice itself. However, the use of the term 'transfer' is somewhat misleading, although convenient when used in the context of this research. As detailed in the following discussion, practices emerge from communities engaged in a continuous process of learning.

When a foreign subsidiary gains an innovation mandate, it typically must develop the capabilities required to fulfill it. Transferring innovation practices from other units 
within the MNE can aid in developing those capabilities via innovation practices. However the process is much more complex, ambiguous and uncertain, given the higher tacit knowledge requirements as compared to transferring manufacturing practices which are more codified. Just as capabilities are gained through learning processes engaged in by others in the organization, so too must subsidiary employees learn the tacit components of practices transferred from another MNE affiliate. Obviously, these learning processes will differ when the goal is to replicate something which emerged within a different area of the firm. In this section, the processes of practice emergence and replication are examined.

The origin of practices can involve emergence and embedment in knowledgeintensive organizations such as consulting firms (Anand et al, 2007), or through practice sharing as new communities form to pursue new opportunities (Lee and Williams, 2007). The process from inception through to institutionalization can take multiple routes, but always begins with individual agency and involves organizational support, the development of new expertise, and must gain some initial support from powerful stakeholders (Anand et al, 2007). Hence, practices are not spontaneously created, but rather are 'championed' by an individual and group. The remainder of the process is largely a matter of legitimizing the practice, as the manner in which functions are accomplished must be institutionalized, implying widespread acceptance and adherence throughout the organization, in order to be considered practices (Kostova 1999). 
However, given that this research is concerned with practice transfer, and that transfer entails learning, replication is also considered a point of origin.

Replication involves the transfer of the entire business model including all organizational processes and is typically reserved for those firms in which such detailed codification is possible (Winter and Szulanski, 2001). However, practice transfer of any scope and function is largely an attempt at replication which is intended to recreate valueadding mechanisms, increasing the scope and scale of the overall enterprise. Most practices are the product of more than what is readily codified, given that institutional pressures shape them during their emergence. The institutional pressures which shape practices also infuse them with meaning shared most readily amongst immediate members of the community from which the practices emerged (Kostova and Roth, 2002; Meyer and Rowan, 1977). Hence, transferring innovation practices has strategic implications in that the institutionalization processes that give a firm's practices value are not easily visible to other firms, thus increasing causal ambiguity.

However, diffusing practices from one organizational unit to another is also complicated by a lack of shared meaning, understanding, and history, as well as pluralistic institutional backgrounds such as culture and legal systems (Kostova and Roth, 2002), which often result in attempts to adapt practices to the local environment. Jensen and Szulanski (2004) found that this sort of adaptation further impedes the cross border transfer of practices within the MNE. The study of practice transfer within the MNE therefore contributes to the development of institutional theory by accounting for the 
influence of national institutional plurality (Kostova and Roth, 2002). The current study of innovation practice transfer furthers this endeavour because the nature of the innovation function of the MNE is more likely to lead to adaptation of practices transferred within an institutionally pluralistic environment, creating greater uncertainty and ambiguity in the institutionalization processes.

\subsection{Innovation as Legitimate Peripheral Participation}

The full cycle of innovation, from conception to implementation, is not achievable by isolated individuals. Hence, innovation is a collective effort (e.g. Burgelman, 1983; Carpenter, Lazonick and O'Sullivan, 2003). Following the constructivist learning paradigm which provides a useful lens on innovation, these collectives are referred to as communities of practice, the members of which are engaged in the process of 'legitimate peripheral participation' (LPP: Brown and Duguid, 1991; Lave and Wenger, 1991). The communities of practice lens on innovation is not intended to answer questions about how innovation is encouraged or what its value is, but rather to describe the manner in which the work of innovation is accomplished.

The communities of practice view is an appropriate lens on innovation because, as important as it may be to an organization, it is not a 'function' in the canonical sense of the word, as is finance or even new product development. Instead, innovation involves both practice as well as learning, sharing and creating new knowledge through the integration of individuals. However, communities of practice emerge in the social setting of the organization which means that varying impediments to their formation can exist 
(Roberts, 2006). Concentrations of power within the organization may lead to the enforcement of dominant knowledge and practices, such that some members can remain peripheral to the community (Roberts, 2006; Yanow, 2004). The trust and mutual understanding which facilitates the transfer of tacit knowledge within communities can also be undermined by hierarchical control (Coopey, 1998) and path dependencies in knowledge creation within the community of practice may inhibit more radical forms of innovation (Roberts, 2006). Within the multinational context in particular, the emergence of geographically dispersed communities of innovation can be inhibited by physical and temporal separation, as well as institutional and cultural differences, which limit their size and spatial reach (Roberts, 2006). These impediments to community formation and membership within the organization suggest that a consideration of context is important, both for researchers and managers, and that not all communities are equal with respect to knowledge sharing and creation. Prior research has also shown that these impediments do not necessarily prevent the emergence temporary communities, formed from previously isolated communities of practice, in order to pursue new opportunities (Lee and Williams, 2007).

The three components of LPP are inseparable in that each does not operate in a community of practice in the absence of the other. To understand the meaning and significance of LPP it is perhaps easiest to envision an individual entering a new community of practice. This individual possesses certain knowledge, skills and abilities which should enable him or her to legitimately participate in the community of practice, 
but lacks the socialization effects other members have already, or are in the process of gaining. Hence, this individual's participation is peripheral to the community, but moves towards full participation so long as their mode of interaction within the community is deemed legitimate. In short, membership within a community of practice is a learning process. The conceptual distance from peripheral to full participation is a continuum along which each individual's progress can be mapped. As the process of innovation is essentially a learning process, it cannot be taught in the traditional sense, but instead must be learned through participation, what Lave and Wenger (1991) referred to as 'situated learning'.

When a subsidiary gains an innovation mandate its members become participants in a community of practice to varying degrees, depending on the subsidiaries' level of integration within the MNE's overall innovation network. Due to the geographic, social, cultural and national institutional distance between the subsidiary and other affiliates, the natural flow from partial to full participation faces numerous impediments (Williams, 2010). Practice transfer can help to alleviate these impediments, but is also impeded by those same obstacles which encourage adaptation of practices. However, since variation is a necessary input to innovation, this should also provide opportunities for capability enhancement through selection processes operating in the MNE. In the following chapter, these and other concepts are incorporated in order to develop two descriptive models which motivated data collection and analysis. The first is an initial descriptive model of factors influencing practice adaptation and capability development. The second 
is a descriptive model depicting innovation practice transfer, comprised of adoption, adaptation and diffusion.

\subsection{Summary}

In this chapter, organizational knowledge, capabilities and practices were defined and characterized with reference to the literature on organizational routines. The community perspective on innovation, as situated learning, as well as the internationalization of innovation practices was also presented. This literature forms the context to which this thesis is intended to contribute. In the next chapter, descriptive models, derived from KBT and institutional theory, are developed in order to present the initial theoretical background position, prior to the collection and analysis of the data. 


\section{Chapter 4: Theoretical Background}

The purpose of this chapter is to develop initial descriptive models through synthesis of theory and empirical research pertinent to the transfer, adaptation and diffusion of innovation practices within the MNE. These models formed the basis for the interview protocol, included in Appendix 3, which guided the interviews conducted with MNE managers at both headquarters and subsidiaries.

The theoretical baseline for this research is drawn mainly from institutional theory, KBT and the micro-political perspective on intra-MNE relationships. As practice transfer and adaptation are all largely social phenomena, the variegated institutional pressures shape the processes through which the subsidiary develops innovation capabilities, which in turn have the potential to shape MNE capabilities. KBT provides a lens on the internal social context of the MNE in which knowledge and the related constructs of practice and capability development take a central role (Hymer, 1976; Kogut and Zander, 1992; Kurokawa et al, 2007). The micro-political perspective considers the role of subsidiary managers' motives, rationales, and initiatives which can lead to intra-MNE conflict (Becker-Ritterspach and Dörrenbächer, 2009; Delany, 2000), which in turn is likely to impact innovation practice transfer and adaptation within the MNE network. Within this section, factors affecting the practice transfer process, the extent and form of practice adaptations by foreign subsidiaries, and the diffusion of practices emanating from subsidiary adaptations are each separately examined. Factors 
are divided into those at the national level, organizational level, and characteristics of the practices themselves. Within these categories of the overall phenomenon of MNE innovation capability development, the initial descriptive model which guided and motivated the empirical investigation is derived. The research was not restricted to the variables included in this model, but it did provide a general framework for organizing questions and responses during the interviews.

In the first section, two descriptive models are presented. Descriptive models are conceptual frameworks which guide data collection and analysis (Miles and Huberman, 1994). They are specified at a sufficiently high level of analysis in order not to unduly constrain the types of variables which can be included during data collection and analysis. While some call for less structure prior to data collection (Glaser and Strauss, 1967), it can be useful in organizational research in order to avoid straying too far from the original intentions of the researcher (Miles and Huberman, 1994). In essence, descriptive models provide the 'bins' into which variables can be organized as the data are interpreted. The first descriptive model presented is the innovation practice lifecycle model which represents an ongoing, cyclical evolution of MNE innovation practices. The second model is a multilevel model of influences on the transfer of innovation practices, divided into the national, organizational, and practice levels of analysis.

Multilevel models enable greater understanding of phenomena which "unfold across levels in the organization" (Kozlowski and Klein, 2000), as well as across national borders (Hillman and Wan, 2005; Hitt et al, 2007; Williams and Ecker, 2011). 
Researchers of practice transfer in international settings have examined influences at the national and organizational levels of analysis (e.g. Geppert and Williams, 2006; Jensen and Szulanski, 2004; Kosotva and Roth, 2002; Luo, 2001; Morosini, Shane and Singh, 1998). However, researchers, to my knowledge, have not considered the influence of the nature of the practice to be transferred, nor the role of intra-MNE conflict on innovation practice transfer. Hence these factors, as well as context, were considered as potential influences on the overall phenomenon of innovation practice transfer and subsidiary capability development.

In the second section, an overview on the role of national institutions is provided in order to explicate the national level variables influencing practice transfer and the development of innovation capabilities of MNE subsidiaries for which there is precedence in the literature. Together, these topics serve to explicate the role of history and national level influences on innovation capability development within the MNE. In the next sections, organizational factors and practice characteristics are examined, which are posited to influence transfer. In the final section, a set of categories is developed for outcomes from the transfer process. Within this section, the revised multilevel model with the derived categories included is also presented.

\subsection{Descriptive Models}

Figure 4 depicts a descriptive innovation practice lifecycle model, incorporating MNE and subsidiary roles in the process. Following a long tradition within research, this model depicts linearly what is, in reality, a circular, iterative process, with the transfer of 
innovation practices to a foreign subsidiary as the starting point for the discussion. Lifecycle approaches to change involve relatively predictable stages which occur in sequence, brought about by forces internal to the system, in this case the organization (Van de Ven and Poole, 1995). However, the reader should not interpret the model presented as deterministic but instead think of it as a set of stages which may materialize at any given time, influenced by the role of agents.

The first stage, depicted in the upper portion of Figure 4, is the transfer of practices via headquarters to the subsidiary. The innovation practices are not necessarily within the boundaries of the headquarters, but nonetheless it is presumed it has some role to play in initiating and facilitating transfer. In the second stage, there is an ongoing process of adaptation and adoption of practices. Inevitably, some modifications will be made to practices. In the final stage, new and adapted practices are transferred to other units of the MNE, again via headquarters. However, it is also possible that modifications made to the practice are merely reflective of necessary local adaptations, which provide no benefit to the MNE as a whole, and thus do not warrant diffusion.

A critical function of the MNE in the practice lifecycle model is the selection amongst practice adaptations according to their potential value, and overcoming organizational inertia in adopting new practices. Although it is tempting to rate the value of a practice by the innovation yield resulting from its use, substantial causal ambiguity heightens the risk of making an attribution error. The possibility that similar outcomes may have been achievable through use of non-adapted practices remains unspecified. 
Furthermore, subsidiary managers may have little basis for the recognition that they have adapted practices, or may not disclose adaptations made in order to preserve the belief that they are following MNE directives.

Figure 4: Innovation practice lifecycle model.

\section{MNE HQ}

- Grants subsidiary mandate.

- Recognizes value of practices.
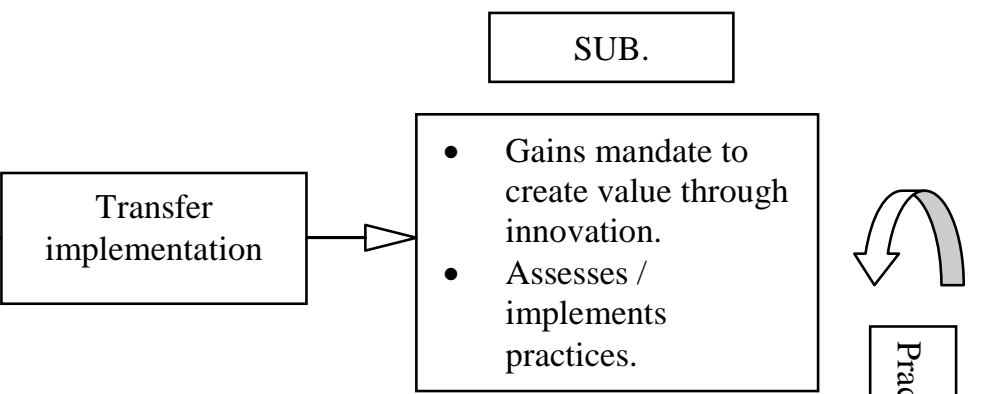

- Provides knowledge.

- Provides incentives.

- Monitors implementation.
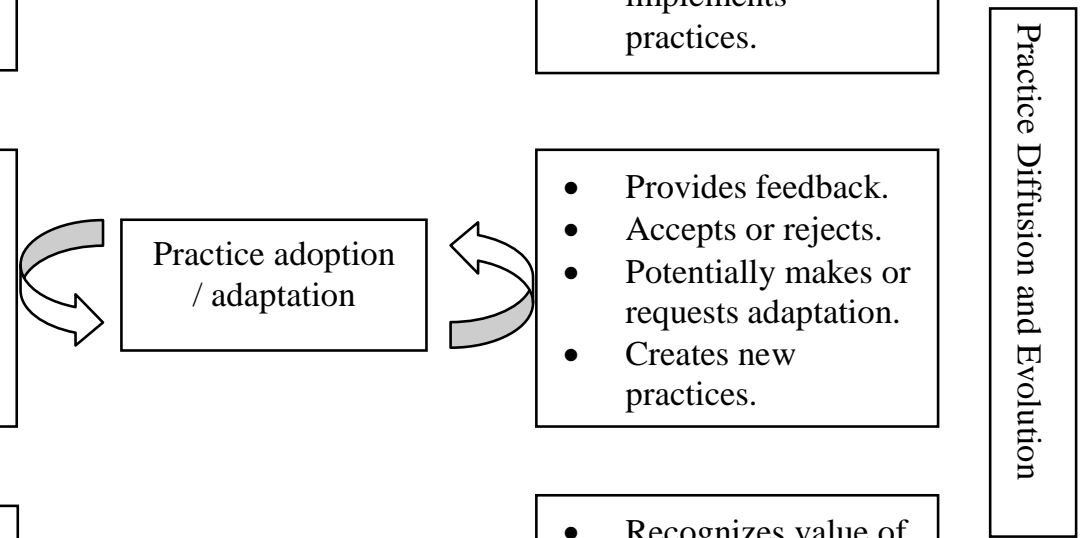

- Recognizes value of adapted/new practices

- May initiate transfer to other units.

Transfer implementation
- Recognizes value of adapted/new practices.

- Initiates transfer.

Figure 5 depicts the three levels of analysis deemed to influence the transfer of practices within the MNE. As MNEs operate established subsidiaries within multiple 
nations, they are exposed to numerous institutional environments, which can complicate the transfer of practices (Kostova and Roth, 2002). In accordance with KBT, the features of the social context within the MNE can facilitate transfer of innovation practices, amongst other resources (Gupta and Govindarajan, 1991, 2000; Kurokawa et al, 2007).

Figure 5: Multilevel descriptive model of influences on innovation practice transfer.

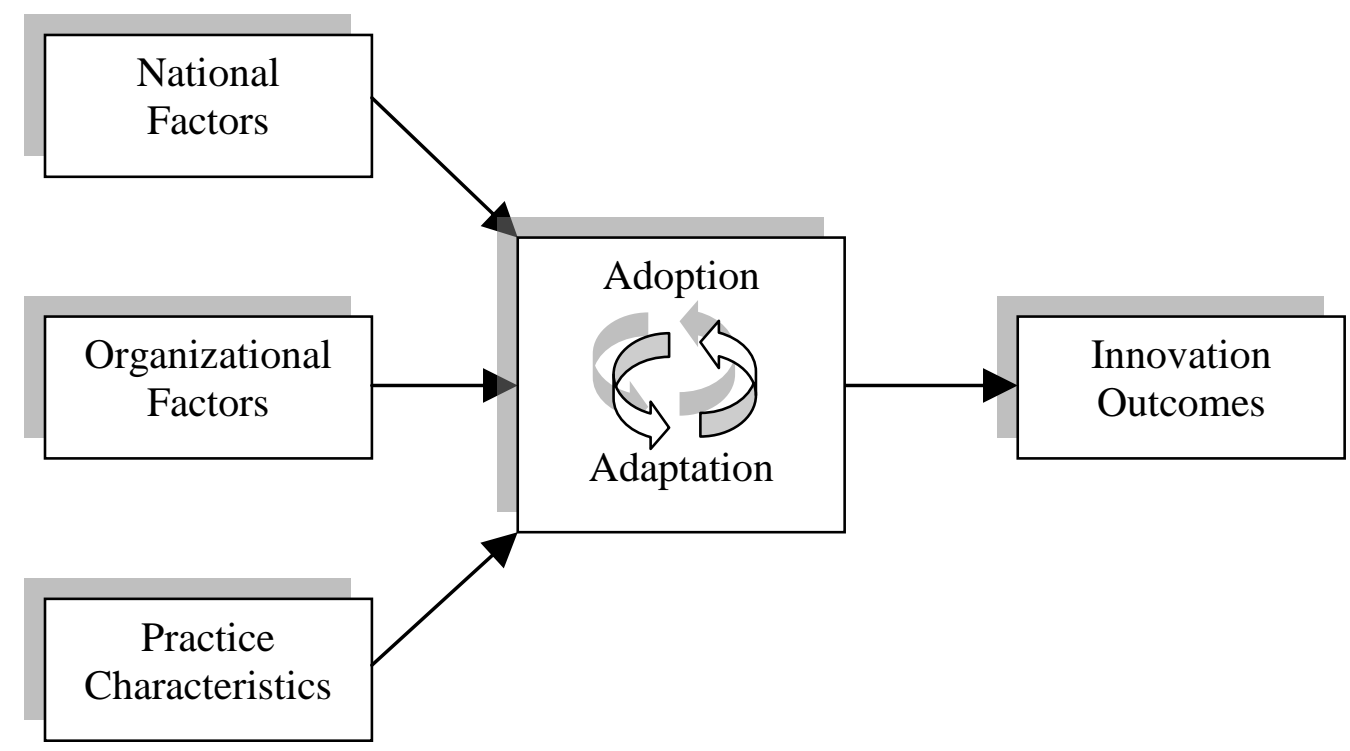

While factors at the individual level can also influence the adoption and adaptation of practices, this level was not considered for several reasons. First, reliably and validly assessing individual personality traits would require respondents to complete a survey, and given the low sample size inherent in case study research, this would not lead to generalizable results. Secondly, while differences amongst individuals within 
each subsidiary would lead to variable levels of personal adoption of practices, ultimately the practice must be implemented throughout the target organization. As such, decisions made by managers to implement practices are reflected across the practice recipient organization, and the effect of individual differences on this process would likely be nearly random. Finally, conducting a survey of all individuals within each MNE, or a representative sample, was not feasible given the resources available to conduct this research.

As discussed in Chapter 3, the ease with which practices are transferred, and the likelihood that they will be adapted in the process depends, in part, on the nature of the practice itself. Finally, the extent to which practices are adopted and, in some cases adapted, is posited to be one driver of innovation outcomes within the subsidiary, and MNE network as a whole. Each of the levels of analysis and outcomes are examined next, in order to develop the set of categories which focused the data collection and analysis.

\subsection{National Level Influences on Practice Transfer}

Although firms account for the majority of investment in innovation in any country, they do so in interaction within national systems of innovation (NSI) consisting of government, academia and other firms within their respective industries (Etzkowitz and Leydesdorff, 2000; Nelson, 1993). While the roles of each of these entities within NSI differ from country to country, in general, government provides funding to universities, start-ups, private researchers and research centers, public research institutes 
and consortia, and so forth, in order to stimulate innovation and economic growth (Carlsson, 2006). The role of universities, meanwhile, is generally to conduct basic research and train scientists and engineers, while firms carry on all these activities in addition to the commercialization and application of the collective outputs of the system. Interaction between these institutions result in interdependencies as, for example, national firms can substantially influence universities through funding which in turn can substantially shape the national competitive advantage of firms in that industry (FatasVillafranca, Sanchez-Choliz and Jarne 2008).

Of all MNE activities, innovation has historically been the least internationalized and, as a result, this activity is highly influenced by its home country NSI (Pavitt and Patel, 1999). Comparisons amongst the NSI of different countries reveal substantial idiosyncrasies in behaviour such as the higher propensity of the United States, in comparison to every other industrialized nation, to invest in very large, expensive research programs with high risk of failure (Walsh and Le Roux, 2004). Researchers have also noted that funding from the US government often tends to take the form of short term competitive contracts as compared to, for example, Denmark (e.g. Garud and Karnøe, 2003) and France (e.g. Walsh and Le Roux, 2004). NSI research has not collectively resulted in an agreed upon classification scheme for different approaches to funding innovation, nor is it likely that a 'best' configuration will emerge in the near future, although there is evidence that the responsiveness of national institutions to crises, competitive or otherwise, enhances the capacity of firms to successfully introduce radical 
innovations (Unger 2000). Overall, it is perhaps most constructive to appreciate that each NSI has evolved in a path dependent manner in response to various external events encountered by countries and the policy decisions made to address them.

One of the most recognizable distinguishing features of NSI is whether institutional arrangements are dominated by 'exit' or 'voice' logic (e.g. Hirschman, 1970). Exit logic involves short term contracts built on the logic of efficiency, in which firms simply discontinue partnerships with which they are dissatisfied, while voice logic entails building long term relationships and voicing concerns when dissatisfaction within the arrangement is encountered. Exit strategies are thought to enhance the pursuit and creation of radical innovation as firms are able to mitigate risk by changing partners (Unger, 2000). Hence, some variation is expected between MNE home and host countries in innovation practices involving partnerships and external sourcing.

Countries exhibiting different exit and voice characteristics, and their associated institutional environments, can be divided into liberal market economies (LME) and coordinated market economies (CME) (Hall and Soskice, 2001), which also correspond with pluralist and corporatist political economies (Schmidt, 1982; Hillman and Wan, 2005). LMEs, such as the US, are characterized by institutions which use enforced contracts, allowing firms to exit cooperative arrangements when not satisfied. Conversely, CMEs such as France and Germany tend to exhibit voice tendencies. As a result, LMEs tend to favour more radical or breakthrough innovation while CMEs tend to excel in industries characterized by incremental innovation (Hall and Soskice, 2001). 
However, this categorization scheme is not complete because it tends to focus exclusively on less recently industrialized nations. The institutional environments of the emerging markets (e.g. China, India, Brazil, etc.) are rapidly evolving, and it cannot be assumed that they will develop along the same paths as other countries. Hence, the LME/CME categorization scheme may be too narrow to fully capture the range of potential influences on cross border innovation practice transfer as MNEs increasingly allocate innovation mandates to emerging market subsidiaries. A more disaggregated approach to the influence of national institutions on innovation practice transfer may provide greater theoretical and practical insights.

The relationship between different NSI configurations and practice transfer is, at best, ambiguous. I am not aware of research which crosses these levels of analysis. However, empirical work on the internationalization of innovation systems has demonstrated that smaller countries tend to experience higher cross-border flows of scientific and technological knowledge than larger countries, and with more or less active filtering by country (Niosi and Bellon, 1994; 1996). At least some of this flow includes knowledge workers which represent flows of the most tacit forms of knowledge, including practices. Hence, some countries have developed an institutional environment which is more exposed to, and likely more accepting of, innovation practices formed elsewhere, while the practices of some countries have institutionalized over long periods of time, thus rendering them somewhat resistant to substantive changes. Within certain 
emerging, supranational industries such as biotechnology, it is possible for even institutional practices to be shared (Bartholomew, 1997).

Berry, Guillén and Zhou (2010) suggest additional cross national differences which are potentially relevant to innovation practice transfer including economic, financial, administrative, cultural, demographic, knowledge and geographic distance. All of these traits, and perhaps more importantly differences in them between the MNE home and host countries, should be considered as potential influences on the transfer of innovation practices. Additionally, one must consider the national differences between different subsidiaries in an integrated MNE innovation network, as communication, knowledge, and practice flows can and will occur horizontally in addition to vertically.

It is outside the objectives of the current research to map out all patterns of cross border practice flow and their antecedents. However, the interdependencies created through economic globalization are likely beginning to be partially reflected in the evolution of innovation practices. Despite this general trend, path dependencies in intellectual property regimes, education, research funding, and a host of other institutions remain nationally determined, and so differences amongst nations are likely to persist (Carlsson, 2006; Foray, 1995; Gregersen and Johnson, 1997; Nelson, 1992; Pavitt, 1998). These differences can be viewed both as an impediment to practice transfer, and as an opportunity for MNEs to select amongst a larger set of practices than a purely domestic firm. Pursuing such opportunities may prove valuable, but will still involve significant effort on the part of managers. Research to date has generally viewed the institutional 
differences between home and host countries an impediment to practice transfer, sometimes as a result of adaptation (e.g. Jensen and Szulanski, 2004; Kostova, 1999; Kostova and Roth, 2002).

Although NSI research is in the early stages of producing empirical evidence on the role of nations in shaping innovation practices, within international business research it is generally thought that national variables such as cultural and institutional distance between provider home and recipient host countries is an impediment to knowledge transfer (Ambos, Ambos and Schlegelmilch, 2006; Bhagat, Kedia, Harveston and Triandis, 2002; Kogut and Zander, 1993). Kostova and Roth (2002) found that only the cognitive domain of institutionalization, that is the extent to which practice recipients are familiar with the practice, positively impacts adoption. All three factors, regulatory, normative and cognitive, however, play a role in the extent to which the practice was internalized. However, their study focused only on quality management practices, and so it is unclear whether other practices would be influenced differently by the institutional environment. Providing further contribution, Jensen and Szulanski (2004) found that institutional difference between practice provider and recipient, measured as cultural distance (Kogut and Singh, 1988), increased the propensity for practice recipients to adapt practices before implementing them, which in turn impeded the transfer. These researchers take important steps toward expanding our knowledge of how national institutional environments impact practice flow, but are limited in their treatment and measurement of those antecedents. The goal of this thesis is to contribute to the 
understanding of how various facets of national institutions impact practice transfer and the development of innovation capabilities in foreign subsidiaries.

\subsection{Organizational Level Influences on Practice Transfer}

Knowledge based theory (KBT) provides an appropriate lens through which to study the transfer of innovation practices, as the critical assumption of KBT is that knowledge is the key value creating input for the firm (Grant, 1996; Kogut and Zander, 1992; Williams, 2009; Zollo and Winter, 2002). KBT views the organization as a source of knowledge creation, storage, exploitation and diffusion within an organized social community that is more efficient than the market (Kogut, 2000; Kogut and Zander, 1992; 1993). Ultimately knowledge resides with individuals within the organization. As KBT is a firm level theory, individuals' knowledge is considered to be embodied in the norms, rules and processes of the firm (Grant, 1996; March, 1991).

The more efficient an organization is at deriving value from its knowledge assets, the greater its competitiveness amongst other firms (Kogut and Zander, 1993; Nonaka, 1994). Hence, the ability of the organization to transfer practices from one unit to another is crucial (Miller et al, 2007; Tsai, 2001). Innovation practices are especially crucial for firms operating in industries where the underlying competition is Schumpeterian in nature. Schumpeterian competition requires firms to continually innovate, as the basis for value creation, and hence competitive advantage of the firm, is temporary in nature. The environment in which many MNEs operate is inherently Schumpeterian given the constant rise of new global competitors, industry convergence 
and decreasing product life cycles. The ability of the MNE to replicate and evolve practices across time and space therefore provides a source of competitive advantage.

Practice transfer is defined as the dyadic exchange of organizational routines and the knowledge they embody between a provider and recipient organization, or organizational unit (Szulanski, 1996, Williams, 2010). In this research, the transfer of innovation between any two units of the organization is considered. However, for the present discussion, the MNE headquarters is assumed to be the practice provider which initiates the transfer of innovation practices, and the recipient as a foreign subsidiary of that MNE. In this section, potential organizational influences on innovation practice transfer are considered. Consistent with prior research, practice adoption is viewed primarily as the process of institutionalization (e.g. Kostova, 1999; Kostova and Roth, 2002; Szulanski, 1996; Jensen and Szulanski, 2004). However, departing from prior research, the current study does not assume adoption to be a binary variable, nor is its focus limited to the difficulty of transferring practices.

According to KBT, organizations are superior mechanisms as compared to markets for the application, storage and diffusion of knowledge, which in turn is the primary source of value creation (Grant, 1996; Kogut and Zander, 1992; Zollo and Winter, 2002; Eisenhardt and Martin, 2000). Practices, by their ontological identity as routines, are the embodiment of organizational knowledge applied towards the production of value (Nelson and Winter, 1982). Transfer of practices which are deemed 
to be of particular value is one mode of enhancing the competiveness of the MNE (Kostova and Roth, 2002).

In summary, KBT presents a view of value creation by the firm which is particularly relevant to MNEs whose large size, possession of assets and geographic dispersion, provide a plethora of knowledge inputs. If the MNE continually develops its innovation capabilities, in accordance with Schumpeterian competition, it needs to possess the ability to diffuse practices, for the sake of efficiency and the integration of dispersed affiliates, and the ability to enhance its competency by exploiting the knowledge assets of those same affiliates. Innovation practice transfer, adaptation and diffusion are all contributing mechanisms to this process, but do not diffuse as readily as physical technology. Furthermore there is always a degree of doubt regarding the value of any given practice, as compared to unknown alternatives, due to path dependencies in its creation.

In the following sections institutional pressures, and in particular institutional duality, are considered as potential factors influencing innovation practice transfer. Next, the potential role of subsidiary innovation mandate dimensions is discussed. Following this, the influence that the quality of vertical (between headquarters subsidiary) and horizontal (between subsidiaries) relationships have on innovation practice transfer is considered. These relationships influence the motives of managers within different units of the MNE which can lead to internal competition, vying for enhanced mandates (e.g. Becker-Ritterspach and Dörrenbächer, 2009), and power differentials. These power 
differentials can lead to inefficient use of MNE resources, should agency problems arise (Mudambi and Navarra, 2004). Finally, the organizational requirements for innovation are presented (O’Sullivan, 2000).

\subsubsection{Institutional Differences}

Adaptation and development both refer to process and, as such, proceed according to the logic of one of four drivers of change designated as lifecycle, teleological, dialectic and evolutionary (Van de Ven and Poole, 1995). The lifecycle theory of change entails the unfolding of a process according to predictable stages. Teleological theory emphasizes coordination amongst parties interested in achieving a goal while the dialectical process results in change arising from negotiation and compromise amongst conflicted parties. Finally, evolutionary theory focuses on continuous change through variation, selection and retention.

Dialectical sources of change are, at least implicitly, the most focused upon drivers of practice adaptation in international transfers (Jensen and Szulanski, 2004; Kostova and Roth, 2002). Conducting business in a foreign market involves tradeoffs between local responsiveness and global efficiency. Some of the great benefits from conducting business internationally are the gains from scale economies and efficient asset allocation (Lawrence and Lorsch, 1967). At the same time, it is generally accepted that some degree of local responsiveness is required in order to successfully operate in foreign markets (Bartlett and Ghoshal, 1989; Luo, 2001; Morosini et al., 1998). Adaptation can enhance the legitimacy of an MNE from the perspective of national stakeholders, thus 
enabling the firm to overcome the liability of foreignness (Hymer, 1976; Zaheer, 1995). MNEs tend to encounter significant gaps in knowledge concerning the local environment after making the initial investment, and hence successful adaptation requires the ability to absorb local knowledge (Petersen, Pedersen and Lyles, 2008).

Achieving local responsiveness requires adaptation of products, services, and processes for the local market. Although much of the literature has primarily considered production and marketing practices, pressures exist to adapt nearly every practice. Answering the question of how much adaptation is enough largely depends on what is being adapted (Lawrence and Lorsch, 1967). Product adaptation can be achieved with market research and perhaps some trial and error. Herein lies the challenge for adapting innovation practices. Innovation is already difficult to achieve as the various processes of novelty generation are fraught with uncertainty, and efficiency is extremely difficult to assess without tangible outcomes (Adams et al, 2006). Adapting these processes aggravates the uncertainty of value creation through innovation even further. For example, managers attempt to create environments which foster innovativeness amongst employees through various means. These means are socially constructed and institutionally embedded. Cultural and institutional differences between the contexts of innovation practice provider and recipient may inspire adaptation of these means of motivation, but the outcomes cannot be determined ahead of time. This uncertainty could decrease the willingness of the practice provider to accept adaptations requested by the 
recipient. Resistance on either side of the transfer to accept or adapt practices provides an additional impediment to overcome in transferring the practice.

Adaptations have been conceived as having two types (Muchinsky, 1977; Roberts and O'Reilly, 1974). General adaptations affect the overall meaning of the practice while specific adaptations affect certain aspects of the practice, but overall meaning, that is the purpose of the practice, is unaffected. Prior research, concerned with generalizability, has examined the direct influence of institutional and cultural distances between providers and recipients of practices on adaptation, but has not delved deeply into how these differences matter. The research design used in here allows such inferences. Kostova and Roth (2002) found that cognitive and normative differences increased pressures for institutionalization, whereas regulatory differences had no apparent effect. However, that research was constrained to a single type of practice and may not generalize to all practices.

Regulatory regimes govern the manner in which labour is compensated and the relationship between basic research and industry. Hence, national regulatory differences between practice provider and recipient organizational units often will lead to necessary adaptations of the specific type for both external practices, such as partnerships, as well as internal practices. Cognitive differences refer mainly to differences in knowledge, awareness and the value of certain types of practice. Other pressures being equal, where the cognitive environment is favourable the practice should be transferred without much adaptation as subsidiary employees already have an appreciation for it. However, it is 
important that members truly understand the value of the practice for this to be the case. Being familiar with a practice without understanding its true value suggests that the practice has more of fashion or fad status within the cognitive environment of the subsidiary (Abrahamson, 1991). Where this understanding is absent, members may readily adopt the practice but unknowingly change its meaning through use. Finally, normative differences refer to differences in what is considered acceptable in practice provider and recipient environments. These differences, if they exist in general, are typically a result of cultural differences. Where a practice is deemed a poor fit, as may be especially the case in HRM practices where incentives effective in one environment have limited or even negative impacts in the recipient organizational unit, pressures for adaptation will exist. It has been shown that subsidiary decision making autonomy, which requires flexibility in the implementation of practices, is an important precondition for customer-oriented innovation (Foss, Laursen and Pedersen, 2011; Foss et al, 2009)

While difficulties in the transfer of knowledge present substantial impediments to practice diffusion, institutionalization of practices can potentially be even more difficult. According to institutional theorists, organizations adopt practices in response to a variety of influences, broadly classified as mimetic, coercive and normative, in order to gain legitimacy (DiMaggio and Powell, 1983; Meyer and Rowan, 1977; Scott, 1987). Mimetic influences are essentially an imitative response to uncertainty. Organizations may also adopt practices imposed upon them by a more powerful actor in the hierarchy (coercive) or because a general belief exists that certain practices are more acceptable 
than others within a particular social milieu (normative). Subsidiaries may adopt practices transferred from MNE headquarters in response to either normative or coercive pressures. The extent to which these pressures are experienced is a function of the manner in which the transfer is initiated and also the subsidiary's level of resistance.

Resistance by the subsidiary is caused not only by inertia but also by 'institutional duality' (Kostova and Roth, 2002; Morgan and Kristensen, 2006). This is in reference to the fact that subsidiaries need to respond to both the institutional pressures from a foreign headquarters and to the pressures within their own institutional environment. Just as organizations respond to institutional pressures in order to gain legitimacy, the organizational practice must gain legitimacy within the foreign subsidiary in order to become institutionalized. In the presence of institutional duality, gaining such legitimacy is ultimately more complicated. New practices may not integrate well with current practices, and may counter the commonly held understanding of how things are done in a particular social milieu. Under these conditions, there will be additional pressures to adapt the practice which results in greater challenges for institutionalization (Jensen and Szulanski, 2004).

\subsubsection{Subsidiary Innovation Mandate}

The transfer of practices is conducted in four separate, but potentially overlapping phases which are initiation, implementation, ramp up, and integration (Szulanski, 1996). Initiation involves all the processes which lead up to the decision to transfer a practice while implementation refers to the actual transfer of knowledge and routines. Once 
transferred, the value generation of the practice in the recipient organization is expected to be limited initially, and then to improve over time with use during the 'ramp-up phase' until it is fully implemented. Since it is not obvious that innovation practices will be transferred in all cases, aspects of the subsidiary innovation mandate which increase the likelihood that practice transfer will be initiated are examined.

To initiate innovation practice transfer, the active involvement of an agent is required. When subsidiaries are given an innovation mandate at inception, it is likely that initial project specifications will be provided through the MNE headquarters, and that boundary spanners will be involved in establishing the subsidiary. As boundary spanners are an essential mechanism for transferring practices across borders (Wenger, 2000), it is more likely practice transfer will be initiated in subsidiaries with innovation mandates from inception. Where a subsidiary is less integrated within the MNE network, however, it is less likely that boundary spanners will be involved. In mandates such as these, the objective may be to tap local knowledge and competencies that are nation specific, and hence there is less incentive to follow institutionalized practices. By this same logic, it is less likely that practice transfer will be initiated in a subsidiary with a mandate specialized to a geographic region or specific function.

Conversely, more integrated subsidiaries will have substantial interaction with other subsidiaries, thus increasing the level of boundary spanning activities. Finally, subsidiaries that are specialized will likely interact more with customers, industry partners, and other professionals according to industry membership than with affiliated 
subsidiaries. Hence, practice transfer may be less likely to initiate from specialized subsidiaries.

Most practice transfer is championed by someone within the provider organizational unit. In some cases, the champion may have an agenda to implement an innovation practice different than that previously institutionalized within the MNE. In these cases, the transfer agent becomes a change agent and the change in innovation practice thus follows a teleological processes. Hence, the champion can use the foreign subsidiary to develop a new or altered practice and use positive outcomes to legitimize the diffusion of this practice throughout the MNE (Anand et al, 2007).

\subsubsection{Micro-Politics and Internal Competition}

Micro-political pressures within the MNE arise from individuals' goals, and the actions they take to pursue them (Becker-Ritterspach and Dörrenbächer, 2009; Dörrenbächer and Geppert, 2009; March, 1962). A subsidiary's structural position within the MNE is subject to change with reductions or enhancement of mandates which can lead to intra-MNE competition for resources and attention from headquarters, thus

creating intra-firm conflict (Becker-Ritterspach and Dörrenbächer, 2009; Bouquet and Birkinshaw, 2008). Furthermore, subsidiaries with more strategic importance, and hence power viz. headquarters may be more likely to resist adopting practices from other parts of the organization (Geppert and Williams, 2006). In headquarters initiated practice transfer, for example, subsidiary managers' trust and dependence upon headquarters, as well as their identification with their own organization significantly influence practice 
adoption and internalization (Kostova and Roth, 2002). Hence, subsidiary power and autonomy are two influences on both the adoption and adaptation of innovation practices by subsidiaries. Conversely, trust and dependence upon headquarters both enable innovation practice transfer.

The quality of relationships amongst subsidiaries within the overall MNE network can also impact practice transfer due to differences in "the interests, rationalities and behaviors of top foreign subsidiary managers" (Dörrenbächer and Geppert, 2009). Subsidiary mandates evolve over time as their capabilities develop and strategic initiatives are undertaken either by headquarters or subsidiaries (Birkinshaw, 1996; Birkinshaw and Hood, 1998). The granting of an enhanced mandate to a particular subsidiary, such as outsourcing $R \& D$ to a foreign affiliate, often comes at the perceived or actual reduction of the mandate of another subsidiary, triggering strategic moves and competitive interactions within the MNE (Becker-Ritterspach and Dörrenbächer, 2009). These motives may lead to competition within the MNE as managers vie to increase the scope of their mandate and hence the strategic importance of their subsidiary. Also, in addition to the desire to expand the scope and scale of a subsidiary's mandate, managers also often perceive that failure to grow may be perceived by headquarters as a decline in strategic importance (Delany, 2000). Finally, given the size of many MNE networks, direct control by headquarters is often not feasible, and thus internal competition is often the main mode of governance (Cerrato, 2006). 
As innovation in the MNE typically requires integration and coordination amongst geographically dispersed subsidiaries (Burgelman, 1983; Carpenter et al, 2003), the quality of vertical relationships between subsidiaries and headquarters, as well as horizontal relationships between subsidiaries are important. While internal competition may enhance efficiency, it can also create integration problems, especially with respect to impeding knowledge transfer. Hence, internal competition for resources and attention from headquarters can act as an impediment to horizontal innovation practice transfer within the MNE innovation network. However, hierarchical control can reduce horizontal knowledge flow, as individuals subsequently perceive the activity as less valuable (Gooderham, Minbaeva, and Pedersen, 2011). Hence, there is a tension between integration through headquarters involvement and innovation practice transfer. Integration is difficult to achieve without the headquarters perspective on the overall strategy of the MNE, but too much involvement with practice transfer can reduce the extent to which individuals within the various subsidiaries share knowledge, which is crucial to successfully transferring innovation practices.

\subsubsection{Organizational Requirements for Innovation}

Aside from institutional differences between the environments of the innovation practice provider and recipient, and characteristics of a subsidiary's mandate and its evolution, there may be clearly many organizational factors which influence adoption and adaptation of practices. To focus this research, a classification scheme was used for 
variables pertaining to the organizational requirements for innovation (Carpenter et al, 2003; Lazonick, 2003; O’Sullivan, 2000).

The first of these requirements is financial commitment to innovation, which is the allocation of continual funding for innovation. The next is integration which is necessary to facilitate collective learning, a crucial component of innovation. The third is control of innovation, which refers to the allocation of decision making responsibilities for such matters as which projects should be initiated, continued, or discarded. According to O'Sullivan (2000), control over innovation is best allocated to those who understand the technology best.

In this section, factors which may influence innovation practice transfer were identified at the national and organizational levels of analysis, as well as the characteristics of the practices themselves. These are institutional differences, which are

particular to each practice provider-recipient dyad, characteristics of the subsidiary's mandate, and the organizational requirements for innovation, namely financial commitment, integration and control. Next, potential practice characteristics which may also influence the practice transfer process and outcomes are considered.

\subsection{Innovation Practice Characteristics and Transfer}

Transfer of organizational practices requires both the transfer of knowledge and the institutionalization of organizational routines. The success of any transfer attempt must be gauged against both these requirements. Several of the knowledge typologies in the literature converge on two generic types: tacit and explicit knowledge (Grant, 1996). 
Tacit or procedural knowledge is not codified and hence not considered as easy to transmit from knowledge provider to recipient (Kogut and Zander, 1992). Explicit, or declarative, knowledge is in some form such as manuals, patents, blueprints, and even personal communication, and hence is considered easier to transmit. This distinction is somewhat blurred in the case of practice transfer as each practice contains elements of both types of knowledge, to varying extents. MNEs most likely focus their efforts on transferring the codifiable portion of the practice, leaving the tacit portion to develop through constructivist learning processes. The extent to which a practice relies on tacit knowledge should impact the effort required and potential risk involved in transferring it.

Ceremonial adoption refers to the acceptance and institution of a practice in form only, without fully understanding the meaning of the practice, or not believing it to be valuable at all (Meyer and Rowan, 1977). It is less likely that a ceremonially adopted practice will produce the intended benefits as employees of the recipient firm will simply be going through the motions of the practice. Under these conditions, the practice becomes integrated into the operations of the subsidiary, but employees do not internalize its meaning or usefulness (Kostova and Roth, 2002).

A practice may be adopted ceremonially if substantial pressure from headquarters is experienced during the transfer process. It may also be a result of the extent to which the practice involves tacit knowledge, as employees of the adopting subsidiary do not have access to the historical and contextual factors which lead to the creation of the practice. Unless external mechanisms exist to maintain the practice, it is likely to be 
dropped. Where a subsidiary is integrated within the MNE innovation network, interaction with other units creates a social network. This social network creates normative pressures to maintain practices as integrated units expect and even require the outcomes those practices produce. Hence, a subsidiary may maintain practices for which it does not receive direct benefits, so long as those benefits enhance the operation of the overall MNE innovation network.

Figure 6: Multilevel descriptive model of influences on innovation practice transfer (revised).

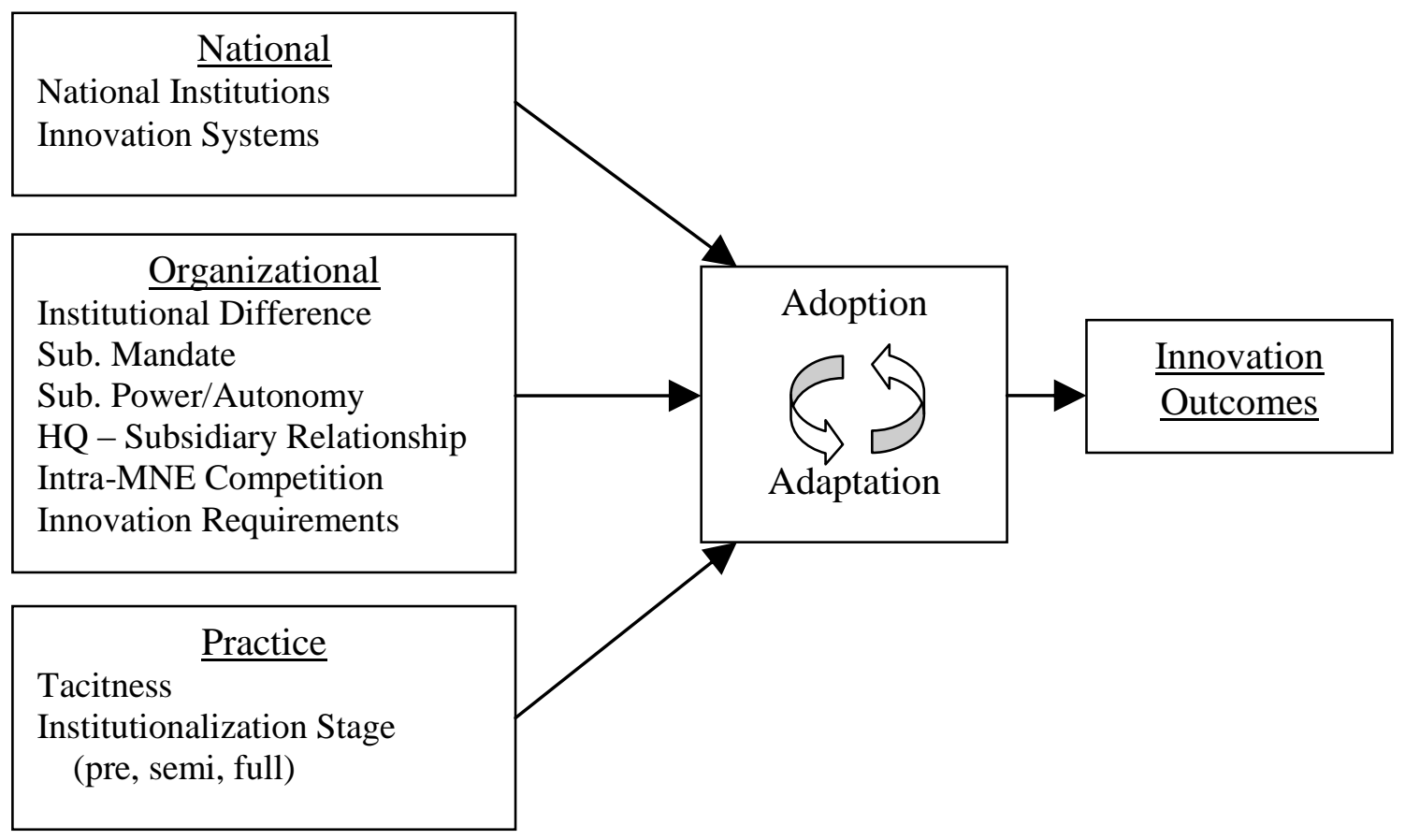

Practice transfer may also be influenced by the stage of institutionalization which the practice has reached (Kostova and Roth, 2002). These stages range from pre- 
institutionalization and semi-institutionalization to full institutionalization (Tolbert and Zucker, 1996). Practices at a pre-institutionalized stage are new and generally unknown within broader populations of relevant organizations, while semi-institutionalized practices have begun to spread throughout a population and fully institutionalized practices might simply be considered norms, and hence not actively questioned. Presumably, the less institutionalized the practice, the less legitimacy it will have accumulated, and hence the more resistance or adaptation pressure encountered when trying to transfer it to foreign subsidiaries.

In this section, characteristics of practices which may be factors affecting the transfer process were identified. The factors identified are the extent to which the practice involves tacit knowledge, the extent to which it is institutionalized, and whether it is engaged in with internal or external actors. In the preceding sections national and organizational factors were identified. The goal in this section was not to establish generalizations or a comprehensive set of variables, but rather a set of broad categories to guide this research. Figure 6 is a reproduction of the multilevel influence model (see Figure 5) in which these categories are included. The following section considers the possibility that events and conditions during the transfer process may influence the adoption and adaptation of innovation practices.

\subsection{Practice Adaptation and Capability Development}

During each of the transfer phases, the manner in, and extent to which the provider and recipient organizations interact influences both the process and potentially 
outcomes of the practice in the recipient firm. Involving members of the recipient organization in the initiation phase, for example, may lead to negotiations in which the recipient attempts to modify the practice before implementation begins (Geppert and Williams, 2006). Whether these modifications are beneficial can only be assessed by the outcome (Jensen and Szulanski 2004). In this section, factors which may influence the transfer process during its various phases are identified.

According to the lifecycle view, a practice changes in predictable stages. Given their ontological status as routines, practices will exist only so long as they are used. If the frequency of use declines below some threshold (Cohen and Bacdayan, 1994; Zellmer-Bruhn, 2003), or if the routine does not appear to have any impact, it is likely to fall into disuse. Hence, the only identifiable stages of the practice lifecycle are use and obsolescence. If a routine is not institutionalized, no organizational memory accrues, and hence the practice falls outside the attention sphere of organizational members.

During the ramp-up phase of practice transfer, recipients rehearse and attempt to improve the expected benefits. If expectations are not met, the practice will fall into disuse as new techniques are sought. Hence, practices will be discarded during the rampup phase prior to integration within the subsidiary if they are not engaged in frequently, there is no monitoring by someone adequately familiar with the practice, or outcomes are not consistent with expectations. However, it is not expected that disuse of an innovation practice by a subsidiary has any effect on the use within the MNE in general. Also, one caveat to the prediction based on monitoring is necessary. When an innovation practice 
does not lead to desirable outcomes from the perspective of recipients, which should occur relatively frequently as the causal link between any activity and innovation is often highly ambiguous, the subsidiary may ceremonially adopt the practice.

Adaptation of practices makes them more 'sticky' to transfer, meaning that additional costs and time may be involved, and at the extreme, adoption may not occur (Szulanksi 1996). However, as proposed in this research and in the international business literature in general, adoption may be necessary to enhance the legitimacy and effectiveness of the innovation practices in use. Adaptation is generally positive when it is of the specific type which does not affect the meaning of the practice but aids in fitting the practice to the subsidiary's local environment. Largely, the effect of adaptation on transfer depends mainly on timing. Adaptation which occurs during initiation and implementation should have a positive effect on the transfer as the practice is not widely used during these phases. But adaptation which occurs during the ramp up stage may stall the integration of the practice. Under these latter conditions, the practice may never come into use in the subsidiary.

The discussion to this point has focused entirely on unidirectional transfer of innovation practices from the MNE headquarters to foreign subsidiaries. The limitation of this view is that headquarters and subsidiaries play different roles in different MNEs (Delany, 2000). Subsidiaries exchange knowledge both with and without headquarters intervention (Ciabuschi, Dellestrand and Kappan, 2011; Gupta and Govindarajan, 2000; 
Van Wijk, Jansen and Lyles, 2008). Hence, innovation practices can also be exchanged within the MNE network with headquarters acting as a broker, or with no role at all.

In general, national institutional differences exert similar pressures on the transfer and diffusion of subsidiary innovation practices as already described. As well, adaptations that are made in order to fit a practice to a subsidiary's local institutional environment may serve little purpose in the MNE as a whole. However, where these transfers do occur, the type of adaptation or new practice transferred is often a function of the subsidiaries' mandate. First, when a subsidiary has a history of interaction with the MNE innovation network, it is more likely to share knowledge (Frost and Zhou, 2005). Integration and knowledge sharing places the subsidiary in close working contact with other subsidiaries in the MNE network, hence increasing the likelihood that specific adaptations to innovation practices will also be shared. This will not necessarily be the

case if the subsidiary remains peripheral or isolated from the network (Williams and Nones, 2009). However, if the subsidiary has a more specialized mandate, it may become a center of excellence (Frost et al 2002). As such, it also can become a source of 'best' practices which are new or generally adapted and may be transferred to and leveraged by other units as relevant.

\subsection{Innovation Outcomes}

The discussion to this point has considered the likelihood that innovation practices will be transferred to a foreign subsidiary upon receiving an innovation mandate. However, the question remains as to what role transferred practices will have 
in achieving that mandate as evidenced by the production of an innovation yield. More generally, the role that organizational knowledge, embodied in routines, has on new value creation is of most interest for this study. Amongst KBT research, there exist two competing views on this causal linkage (Felin and Hesterly, 2007). One school stresses the collective in locus of innovation (e.g. Eisenhardt and Martin, 2000; Kogut and Zander, 1992; Zollo and Winter, 2002) while the other asserts the primacy of the individuals comprising the organization (e.g. Grant, 1996; Simon, 1991). Felin and Hesterly (2007), citing recent advances in cognitive science as well as theoretical and methodological issues inherent in collective-based research, argue that the disproportionate emphasis on the organization is unwarranted. It can be argued that, especially in the case of innovation, it is individuals who account for the greatest advances in knowledge, but that the value created is a result of leveraging this knowledge which requires numerous organizational members and functions. Hence, the goal is not to assign heterogeneity in value created to different levels of analysis, but rather to examine the role of organizational processes in converting individual efforts into value.

In order to anchor an examination of practice transfer and innovation capability development, a set of outcomes by which these emergent and/or agent-driven phenomena can be evaluated is helpful. There are multiple categories of outcomes relevant to this research including those pertaining to process of transfer, practice adoption, practice adaptation, capability development, and ultimately the innovative yield of the subsidiary. 
Where the process is primarily guided by an agent or champion, as often would be the case in practice transfer, outcomes may be evaluated with respect to the intended goals of the initiator(s) of the process. The logic of making such an assessment is equivalent to that in assessing the institutionalization of a practice (Anand et al, 2007). This is also consistent with current research which suggests that practice transfer can be evaluated by a) whether or not a practice is adopted, and b) the extent to which an affiliate understands and appreciates the value of the practice for its intended purpose (Kostova and Roth, 2002). Another line of reasoning examines the extensiveness of the difficulty of transferring or developing practices and capabilities which represents a cost relative to the benefit obtained (Ethiraj et al, 2005; Jensen and Szulanski, 2004). In the extreme, high levels of difficulty preclude the transfer of the practices.

However, where there is friction produced in the transfer process as a result of conflicting organizational, institutional, social and cultural pressures, adaptation is undertaken in order to reconcile these differences through accommodation, negotiation, and so forth. In these instances, it may be more beneficial to view the outcome as the extent and manner in which a practice is adapted within the subsidiary, and potentially elsewhere. Another approach is to detail the process leading to resolution, if any. Understanding this process is valuable from a practical perspective, as it allows managers to enhance the efficiency of the transfer process.

Innovation yield, or performance, is difficult to capture and plenty of debate exists within the literature regarding its proper measurement. Much of this debate exists 
because various outcomes, such as patent counts, new product introductions and overall contribution to firm performance are all dependent upon factors such as industry, firm strategy, and, in the case of patents, characteristics of the national intellectual property regime. Furthermore, innovation is a learning process, and learning is difficult to measure. As subsidiaries are granted innovation mandates, outcomes can be compared to other affiliates and intentions of those granting the mandate. That is, the extent to which the subsidiary is achieving its mandate is a reliable indicator of its innovation performance, taking into consideration its development within the overall process of developing capabilities. Hence, yield in terms of product introduction, patents and so forth may be considered reliable indicators if compared to expectations. Ultimately, a comparison of performance related to expectations of $\mathrm{MNE}$ and foreign affiliate managers should prove insightful.

There is little empirical evidence in the literature regarding the linkage between practice transfer and value creation. Researchers have examined the transfer of practices within the organization, focusing primarily on barriers to transfer, or the 'stickiness' of the practice (e.g. Kostova, 1999, Szulanski 1996). Szulanski (1996) found that the most influential of these challenges were related to the nature of the knowledge itself, with less influence coming from motivational factors. These factors include the ability of the recipient to receive and incorporate new knowledge and the ambiguity of the link between the value generated from the practice, and the practice itself. Many of these challenges are likely to be magnified when practices are transferred to foreign 
subsidiaries. First, organizational practices at any given time are the embodiment of knowledge produced and exchanged through social interaction over the history of the provider organization, not the recipient (Brown and Duguid, 1991; Kostova and Roth, 2002; Lave and Wenger, 1991). As the recipient does not possess the same history, its routines may have evolved quite differently, creating fit issues with the practices sourced from the practice provider. This, of course, will be especially the case with subsidiaries which receive their innovation mandate well after their inception date. Furthermore, cultural differences between the provider and recipient are an additional barrier to knowledge transfer in general. Some work practices are culturally bound, and the difficulties of communication due to language differences are likely to increase with the complexity of the knowledge and routines transferred (Kedia and Bhagat, 1988; Lucas, 2006).

As is implied in the literature, managers initiate practice transfer because they believe it to be a worthwhile endeavour (Kostova and Roth, 2002). Hence, this research is not aimed at uncovering whether practices lead to value creation, but rather how they support innovation and capability development. Consistent with the view that knowledge is embedded in individuals but shaped through socialization, transferring innovation practices leads to new value creation by focusing employees' attention on organizational goals (Schelling, 1960) and nurturing an environment conducive to innovation. Hence, human resource management practices lead to new value creation through employee selection, retention and incentives, knowledge management practices facilitate idea and 
know-how sharing, intellectual property practices enable appropriation, and so forth. This innovative yield is above and beyond the efficiency gains arising from the consistency and predictability in action resulting from practice diffusion throughout the MNE.

The link between adaptation and innovative yield is likely more complex and multifaceted than prior research on practice transfer has empirically demonstrated. In general, adaptation complicates the transfer process, but this need not always have a negative impact on final results, such as innovative yield (Jensen and Szulanski, 2004). Making specific adaptations in order to respond to legitimacy pressures also aids in fitting the new practice to the environment of the recipient. However, there are two potential instances in which a negative pressure is exerted on innovative yield. First, when a practice is adapted such that its meaning changes, either because the recipient organization did not gain an adequate understanding of the value, or deemed it not to have much value, the most positive result would be that the practice transfer is ineffectual in helping the subsidiary enhance its innovative yield. Second, when the meaning of the innovation practice is not understood by the recipient organization, but it readily adopts the practice due to an otherwise favourable cognitive and normative environment, the resulting lack of adaptation leads to the same effect as a general adaptation which changes the meaning of the practice. Hence, the impact that innovation practices received by subsidiaries has on innovative yield depends on the type of adaptation, if any, which occurs during the transfer process. 


\subsection{Summary}

In this Chapter, two descriptive models were presented: the innovation practice lifecycle model, and the multilevel influence model. The multilevel influence model was further developed by identifying categories of factors at the national, organizational and practice levels of analysis. At the national level, categories of institutional environments which promote different styles of innovation were identified as potential influences on practice transfer and adaptation. At the organizational level KBT and institutional theory were employed to identify institutional differences, mandate characteristics, and their influence on the adoption, adaptation and innovation outcomes of foreign subsidiaries. From the micro-political perspective, subsidiary autonomy and power, intra-MNE conflict, and the quality of horizontal and vertical relationships were all deemed influential. These initial descriptive models helped in guiding the data collection and analysis phases of this study, and further developing an explanatory model. In the next chapter, the methodology and how it was conducted are described, and the four MNEs which comprise the cases for this research are introduced. 


\section{Chapter 5: Methodology}

This chapter first introduces the rationale for the qualitative design and analysis approaches which were chosen for this research. Next, case study epistemology is discussed, with particular emphasis on how it differs from the quantitative epistemologies more frequently employed in international business research. While case studies are somewhat more positivist in their epistemology than other qualitative designs (Langley, 1999), they do not follow the logic of variance methodologies which are intended to generalize to populations (Yin, 2009). Hence, this section on epistemology is included to clarify the nature of the intended outcomes, which is generalization to theory. Following this, the research design used to address the three research questions is discussed. Within this section, each of the data collection phases carried out is presented. Following this, the sample selection rationale for the four MNEs which were included in the research is discussed. Finally, the data analysis strategy and procedures used to develop the findings presented in the subsequent chapter are identified.

\subsection{Qualitative Design Rationale}

Case study methodology was chosen to address the research questions which investigate the linkages between innovation practice transfer, adaptation and their role in MNE innovation capability development. The case study approach is appropriate as it enables the researcher to discern between phenomenon and context (Yin, 2009). Furthermore, case study research is especially suited for studies which investigate process 
phenomena (Corbin and Strauss, 2008; Eisenhardt, 1989). Case study methodology is frequently used in empirical study of routines (e.g. Costello, 1996; Feldman, 2000; 2003; Feldman and Pentland, 2003) and has proven valuable in studying the emergence of knowledge-based practices (Anand et al, 2007).

Case study methodology allows researchers to determine the key constructs of the emergent theory and discern the relationships between them through interpretation of the data, so that in future research survey methodology can be used to further enhance the validity of the theory developed in the thesis (Eisenhardt, 1989). Innovation is a particularly context-bound phenomenon as the outcomes from novelty generation are not fully extractable from the historical and social processes which produce them, the organizational culture, and influences of the general environment. As with most studies of organizations, the researcher has no control over the behaviour of the research subjects which is required in experimental research (Yin, 2009).

While survey methodology is a rival candidate for this research, it is more suited to theory testing than theory building (Eisenhardt, 1989; Yin, 2009). In the context of this study, there is limited guidance for designing a survey as the key constructs of innovation practices and outcomes, as well as the relationships between them, are not concisely defined in prior research. Furthermore, interviewing multiple informants enhances the reliability of the conclusions regarding influences on the transfer process, thus reducing contamination of the case data due to managerial sense making (Weick, 1995). Also, the focus of this research was the process of innovation practice transfer, 
and had to take into account the differences between MNEs' approach to and stage within that process, for which cross sectional survey methodology is not able to provide reliable evidence (Corbin and Strauss, 2008; Eisenhardt, 1989). Hence, by using case study methodology it was possible to enhance the validity of construct definitions and the mechanisms through which they are linked in order to build a theory on the cross-border transfer of innovation practices.

\subsection{Case Study Epistemology}

Research methods can be broadly classified as either inductive, meaning that theoretical linkages are derived from data, or deductive, meaning that data is analyzed in order to test hypotheses specified a priori (Yin, 2009). Unlike the more rigorously defined research methods, case study methodology can and usually does encapsulate both approaches, as well as provide a framework for incorporating a variety of quantitative and qualitative methods. The design of this study necessarily includes both inductive and deductive epistemologies according to a logical sequence of theory formulation, data collection and analysis, theory testing, and theory reformulation. Theory generation is a repeated process which is first specified deductively, tested with each case within the study, and then re-specified in accordance with the results of each case. The goal of the theory re-specification is to incorporate findings inductively derived from the data and also to build theory on the role of practice characteristics, subsidiary mandates and national institutional environments in the relationships between innovation practice transfer and adaptation processes and their associated outcomes. The latter imperative is 
more fully explicated in the discussion on replication logic employed in the research design.

A key distinguishing feature of case study methodology as compared to other methodologies used in the social sciences is that data analysis techniques are not clearly defined, and many can be used successfully depending on the research questions and nature of the phenomena under investigation (Eisenhardt, 1989; Langley, 1999; Yin, 2009). The distinction between case study methodology and other methods can be made by contrasting it against survey methodology. While there is some variety in the analysis of survey data, the general approach is statistical, most commonly according to the principles of falsification. Inferences are generalized from a sample of units of analysis to a broader population. If the sample has been properly selected, researchers can claim that the observed relationships in the data hold true for the relevant population with a specified probability of drawing an erroneous conclusion.

It is primarily the nature of generalization which distinguishes case study data analysis from survey data analysis. In case study analysis, the goal is not to generalize to a broader population as in survey methodology but instead to generalize to a theory, which is iteratively generated by the researcher, using case replication logic (Parkhe, 1993; Yin, 2009). As such, it is incorrect to refer to cases as a sample, or members of a relevant population. Instead, each case represents a particular instance of a phenomenon which is to be explained by a theory generated by the researcher (Richards, 2005). As the data from each case is analyzed, in this case interview data for each MNE, the theory 
constructed by the researcher is tested and modified as necessary. Testing involves consulting with the data from other cases to see if explanations provided by the theory hold up to additional evidence. Modification specifically involves increasing the generality of the theory so that all the data collected 'fits', which is to say, does not demonstrate any conceivable exceptions to the theory constructed by the researcher. It is thus necessary for the researcher to return to the relevant literature on occasion, during analysis and theory building, in order to fit their theory also to existing theory.

If the evidence provided by each case is consistent with the theory, the theory is deemed supported. However, the relationships implied in the theory will often not be supported, at least in their entirety, and new observations may lead to apparent relationships not recently expected. Where multiple case studies are undertaken to address a research question, as is in the present study, replication logic is followed (Yin, 2009). This replication logic allows the researcher to adjust the theory generated according to new observations, and then retest in the context of a new case or with new informants. As case studies often inspire insights not previously considered (Siggelkow, 2007), case replication allows researchers to further test these insights rather than relegating them to future research. During the course of data analysis, each factor identified as an influence on innovation practice transfer, adaptation, capability development were considered as either direct or moderating influences. 


\subsection{Research Design}

Case studies are broadly classified as exploratory, descriptive, or explanatory (Yin, 2009). Exploratory research is conducted usually in the context of entirely novel research settings or phenomena about which little is known. Descriptive case studies are primarily concerned with ontology as they are conducted to determine the essential features of a particular aspect of a phenomenon or research context. The approach used in this thesis is explanatory, in order to understand how and why the transfer of innovation practices to foreign subsidiaries is variably affected by factors at the national, MNE, subsidiary, and practice level of analysis. Both exploratory and explanatory case studies can be used in theory building research. However, the former rely mainly on inductive reasoning while the latter use a deductive approach, or some combination of the two.

The research design employed in this thesis uses a multi-phased approach (Parkhe, 1993) which is depicted in Figure 7. The initiation of this research began with a broad review of the literature on the internationalization of innovation in order to establish an area of inquiry which was deserving of more scholarly attention. It was found that the primary focus of most research here was concerned more with patterns of internationalization, without delving deeply into management issues (e.g. Grandstrand, Patel and Pavitt, 1997). Much research was conducted at a high level using large samples and thus did not delve into the process of building innovation capabilities within subsidiaries, and the associated coordination and integration issues. Hence, an 
exploratory phase was undertaken to gain further insight into these and any other phenomena of potential interest.

Figure 7: Progression of research phases.

\begin{tabular}{|c|c|c|}
\hline Initiation Stage & Exploratory Phase & Multiple Case Study \\
\hline oic area & $\begin{array}{l}\text { Establish research } \\
\text { questions and context }\end{array}$ & $\begin{array}{l}\text { Replication within } \\
\text { and between MNEs }\end{array}$ \\
\hline
\end{tabular}

\subsection{Exploratory Phase}

Exploratory case studies are appropriate when the initial research questions are loosely specified, usually as a result of a focus on new and understudied phenomena (Yin, 2009). The primary goal of this phase was to gain a better understanding of what could be learned in the context of establishing innovation in foreign subsidiaries and then to generate appropriate research questions. During this phase, 23 interviews ranging from 30 to 60 minutes each were conducted with managers at both indigenous and multinational companies in India, China, UK and Canada from industries including consulting, telecommunications, consumer goods, software development and services, automobile design and manufacturing, energy, healthcare, and semiconductors. Audio recordings of each interview were made and transcribed when permitted. A summary of the interviews conducted, according to the industry of the MNE, the location of the 
interviewees, the home country of the MNE, and the scope of the applicable markets and innovation activities, is presented in Table 3.

Table 3: Interviews conducted during the exploratory phase of the research.

\begin{tabular}{|c|c|c|c|c|c|}
\hline Contacts & ${ }^{\dagger}$ Company & Industry & $\begin{array}{c}\text { Contact } \\
\text { Nation } \\
\end{array}$ & $\begin{array}{c}\text { Home } \\
\text { Nation } \\
\end{array}$ & $\begin{array}{c}\text { Market/ } \\
\text { Innovation }\end{array}$ \\
\hline 1 & $\begin{array}{l}\text { Telecom Co., } \\
\text { Canada }\end{array}$ & Telecom. & Canada & US & Global/Global \\
\hline 1 & $\begin{array}{l}\text { Pharma Co., } \\
\text { Canada }\end{array}$ & Pharma. & Canada & US & Global/Globa \\
\hline 2 & $\begin{array}{l}\text { SoftCo, } \\
\text { China }\end{array}$ & Software & China & US & Global/Globa \\
\hline 1 & $\begin{array}{l}\text { SemiCo, } \\
\text { China }\end{array}$ & $\begin{array}{l}\text { Semi- } \\
\text { conductors }\end{array}$ & China & US & Global/Globa \\
\hline 1 & $\begin{array}{l}\text { Telecom Co., } \\
\text { China }\end{array}$ & Telecom. & China & US & Global/Globa \\
\hline 2 & Lux Co. & $\begin{array}{l}\text { Mfg. \& } \\
\text { Retail }\end{array}$ & India & India & Global/Local \\
\hline 1 & T-Car & Automotive & India & India & $\begin{array}{l}\text { India \& } \\
\text { UK/Local }\end{array}$ \\
\hline 8 & IS Services & \begin{tabular}{|l|}
$\begin{array}{l}\text { Software } \\
\text { Services }\end{array}$ \\
\end{tabular} & India & India & Global/Local \\
\hline 3 & $\begin{array}{l}\text { ETF Co., } \\
\text { India }\end{array}$ & Diversified & India & US & Global/Global \\
\hline 1 & $\begin{array}{l}\text { Retail Co., } \\
\text { India }\end{array}$ & Retail & India & US & $\begin{array}{l}\text { US/ } \\
\text { US \& India }\end{array}$ \\
\hline 1 & $\begin{array}{l}\text { Consulting } \\
\text { Co., Canada }\end{array}$ & Consulting & Canada & India & Global/Global \\
\hline 1 & $\begin{array}{l}\text { Consulting } \\
\text { Co., UK }\end{array}$ & Consulting & UK & India & Global/Globa \\
\hline
\end{tabular}


One question typically asked of each respondent was, "How was that innovation carried out?", with respect to a particular example provided by the respondent. One response, by a senior engineering manager at ETF Co., India provided some particularly interesting insights. In response to the question, "How would you say this innovation came about? Was it something that was planned?", he responded with somewhat of an admonishment of the notion that innovation could be a 'process', or at least that people involved might not consider that to be an accurate or useful characterization:

"You can create innovation ecosystems, innovation practices, but where it becomes an issue is when you talk about innovation as a process. And when you talk about innovation as a process, then you have a goal, you have very defined steps to get to there. And many people might take issues with that [characterization of innovation]. But if you talk about innovation as a practice, and what are the ways to ensure that the right environment is there, that is [acceptable]."

The theme of environment was repeated by other members of ETF, India as well. For example, one engineer mentioned that "Management has to provide an environment wherein if people are thinking differently, people are challenging the status quo". The theme that ideas could be 'killed' if managers did not provide the right environment came up repeatedly during this site visit as well. The notion of environment came up at other research sites as well, such as the manager from IS Services Co., cited in Chapter 3 regarding the notion of status, esteem and aspiration of the members of the innovation team at that company. 
At SoftCo. China, one human resource manager mentioned the freedom that employees had to pursue whatever projects they were interested in:

Of course we would, as a company, want to see some technology transfer to our own product. But actually there is no pressure at all so we often joke that SoftCo. researchers are living a very good life. They can basically choose whatever they want to do and the company is very generous in term of giving them resources and freedom to do their own research.

I became interested in how such an environment was created, and how it could be effectively managed. Not all companies would necessarily have the resources to allow employees to pursue 'whatever they wanted', as in the SoftCo example. Nonetheless, it seemed that there should be a tension in managing this notion of freedom along with the organizational need for efficiency, integration, and profiting from innovation. Upon reviewing the literature again, the communities of practice perspective on innovation became a dominant theme in guiding the subsequent case studies. Likewise, KBT precepts substantially influenced the interview design, as it was clear that subsidiaries within the MNE network were often building upon techniques and knowledge gleaned through the internal innovation network.

The notion of 'practice' as it was used by the ETF Co manager above became a second emergent theme. The term is actually used in two ways by this manager. The first is to refer to the innovation as a practice ("if you talk about innovation as a practice"), and the second is with regards to innovation involving practices ("you can 
create...innovation practices"). I came to realize that the theme of "innovation as a practice' was similar to the theme of creating environments or communities which foster innovation. The second way practice was used by this manager seemed similar to the notion of 'best practice', or at least 'common practice'. Hence, there were certain ways of doing the work of innovation which were common to individuals within the organization. During many of the interviews, several examples of innovation practices were discussed. There were those based on patent searches to generate ways to solve problems, based on the 'theory of inventive problem solving' of Genrich Altshuller (ETF Co.), encouraging innovation through financial allocation (Lux Co.), engaging customers in problem solving (T-Car), portfolio management (IS Services Co.), amongst many others. Some of these practices were clearly in use across the entire MNE, and likely originated elsewhere in the innovation network, others seemed to be common within industries, diffused by consultants or certification institutes such as the Project Management Institute (PMI), and others seemed much more idiosyncratic to the organization.

In summary, the findings revealed that foreign subsidiaries of western MNEs generally followed innovation practices similar to, at least upon surface inspection, those of their headquarters. Evidence was also found that the development of innovation practices received substantial attention from management and often developed into idiosyncratic norms which shaped both interaction and the structure of innovation activities. Hence, I became interested in studying the phenomenon of innovation practice 
transfer and adaptation, and their role in capability development, along with the many management complexities involved in integrating, coordinating and controlling geographically dispersed innovation. This phenomenon is both timely, given the increasing involvement of foreign subsidiaries in MNE innovation networks, and highly relevant to strategy and international business research as innovation capabilities are one of the key cornerstones to competitive advantage. At this point, the relevant literature was reviewed in order to formulate research questions and selected a context, which is described in the subsequent section on sample selection rationale. This phase of the study was completed in August of 2010.

\subsection{Case Study Phase}

The third phase of the study was conducted using a multiple case study approach (Yin, 2003). Interviews were conducted with managers at four MNEs during the course of data collection which ended in May 2011. Where possible, managers in multiple business units were interviewed in order to compare perspectives and triangulate results. Each case was a single MNE and, within each, general and specific instances of practice transfer were examined. Questions were posed regarding the influence of national institutional factors, organizational factors, interaction with other subsidiaries within the MNE innovation network, as well as descriptions of innovation practices where possible. In addition, questions were posed regarding the outcomes of practice transfer within the MNE network, and capability development of subsidiaries. The goal of this final stage was to build theory and make refinements according to the evidence gathered. Ethics 
certificates for both the exploratory and explanatory phases of this study are included in Appendix 1. In Appendix 2, the letter of information and consent that was provided to each participant is presented.

During the final phase of the study, data was analyzed as it was collected. Transcripts of each interview were analyzed, noting specific questions to address in subsequent interviews with other informants both within and amongst different MNEs. This allowed refinement of the interview protocol in order to generate more focus on specific issues of interest.

\subsubsection{Sample Selection}

In case study methodology, the intent is to generalize to a theory, as opposed to population. Hence, sampling logic is purposive as opposed to representative (Eisenhardt and Graebner, 2007). The primary units of analysis for each case were practices transferred within the MNE. However, literal and theoretical replication logic (Yin, 2009) are applied within each MNE in order to enhance the generalizability of the findings, and to uncover differences derived from practice characteristics, subsidiary mandates and national institutional differences between headquarters and subsidiary. Within the MNE network, differences and similarities provide opportunities to extend and refine the emerging theory, and to further validate those findings. Likewise, comparing across cases allowed for refinement of theory based on differences between organizations, national environments and any other potential influences. 
Each MNE chosen for this research was substantially involved in innovation activity, as indicated by their industry membership. As the goal was to investigate the management of geographically dispersed MNE subsidiaries with global, competency creating, innovation mandates, large MNEs were selected, which are highly internationalized, and are located in industries in which value creation is highly dependent upon innovation. With few exceptions, MNEs already sampled in the exploratory phase all met these criteria. In addition, each had established foreign subsidiaries which possess innovation mandates. Based on these features, several MNEs were contacted for inclusion in this research. Contact information was obtained from personal contacts, as well as the Ivey Alumni Association, which retains the professional contact information of graduates from the Richard Ivey School of Business, University of Western Ontario. Table 4 lists some characteristics of the MNEs included in the sample and Table 5 lists the interviews conducted at each MNE.

Table 4: Characteristics of MNEs in the sample.

\begin{tabular}{|c|c|c|c|c|}
\hline & $\begin{array}{c}\text { Telecom } \\
\text { Co. }\end{array}$ & Aero Co. & $\begin{array}{c}\text { Software } \\
\text { Co. }\end{array}$ & $\begin{array}{c}\text { IT Services } \\
\text { Co. }\end{array}$ \\
\hline Employees & $70 \mathrm{~K}$ & $40 \mathrm{~K}(130 \mathrm{~K})^{\dagger}$ & $50 \mathrm{~K}$ & $160 \mathrm{~K}$ \\
\hline Sales (USD) & $\$ 40 \mathrm{~B}$ & $\$ 12 \mathrm{~B}(\$ 33 \mathrm{~B})^{\dagger}$ & $\$ 16 \mathrm{~B}$ & $\$ 8 \mathrm{~B}$ \\
\hline Internationalization & Extensive & Moderate $(75 \% \text { US })^{\dagger}$ & Extensive & High \\
\hline HQ & US & US & W. Europe & India \\
\hline R\&D & $12.5 \%$ & $(4.5 \%)^{\dagger}$ & $14 \%$ & $0.3 \%$ \\
\hline
\end{tabular}

\footnotetext{
${ }^{\dagger}$ Parent company figures; all figures approximated to disguise identity of the MNE.
} 
Table 5: Interviews conducted in the course of the research.

${ }^{\dagger}$ Telecom Co.

Aero Co.

Software Co. IT Services Co.

\begin{tabular}{|c|c|c|c|c|}
\hline Date & March 12, 2011 & March 2, 2011 & Feb. 18, 2011 & Jan. 6, 2011 \\
\hline Location & US & US & Canada & India \\
\hline Position & $\begin{array}{l}\text { Program Mgmt. } \\
\text { Office Manager }\end{array}$ & $\begin{array}{l}\text { Director, Eng. } \\
\text { Business Mgmt. }\end{array}$ & $\mathrm{VP}$ & Lab Head \\
\hline Duration & 52 minutes & 45 minutes & 24 minutes & 50 minutes \\
\hline Date & " March 18, 2011 & "March 30, 2011 & March 1,2011 & Jan. 11, 2011 \\
\hline Location & US & Latin America & US & India \\
\hline Position & $\begin{array}{l}\text { Program } \\
\text { Manager }\end{array}$ & Senior Eng. Manager & $\mathrm{VP}$ & CTO and VP \\
\hline Duration & 53 minutes & 59 minutes & 66 minutes & 44 minutes \\
\hline Date & & March 31, 2011 & April 7, 2011 & Jan. 11, 2011 \\
\hline Location & & China & Canada & India \\
\hline Position & & Senior Eng. Manager & Lab Head & $\begin{array}{l}\text { VP and Chief } \\
\text { Technology } \\
\text { Board Member }\end{array}$ \\
\hline Duration & & 45 minutes & 52 minutes & 44 minutes \\
\hline Date & & April 6, 2011 & ${ }^{\circ}$ April 14, 2011 & \\
\hline Location & & Eastern Europe & Canada & \\
\hline Position & & Senior Eng. Manager & Lab Head & \\
\hline Duration & & 35 minutes & 45 minutes & \\
\hline Date & & April 18, 2011 & ${ }^{\overline{ }}{ }^{\Delta}$ April 14, 2011 & \\
\hline Location & & US & Canada & \\
\hline Position & & Senior Eng. Manager & $\begin{array}{l}\text { Director of } \\
\text { Engineering }\end{array}$ & \\
\hline Duration & & 68 minutes & 45 minutes & \\
\hline Date & & May 2, 2011 & & \\
\hline Location & & India & & \\
\hline Position & & $\begin{array}{l}\text { Head, Marketing and } \\
\text { Product Mgmt. }\end{array}$ & & \\
\hline Duration & & 52 minutes & & \\
\hline
\end{tabular}

This is the same Telecom Co. as in the exploratory phase.

${ }^{\triangle}$ Two interviews conducted simultaneously at Software Co., April 14, 2011. $\ddagger$ Two interviews conducted simultaneously at IT Services Co., Jan. 11, 2011. 


\subsubsection{Data Collection and Analysis}

According to the replication logic involved in case study methodology, data collection and analysis occurred in tandem. Initial descriptive frameworks were used to guide the data collection during the execution of the case studies, and interview questions were adapted based on the findings in each subsequent round of data collection. This allowed for adaptation and refinement of the interview protocol which would not have been possible if all data were collected prior to conducting any analysis.

The primary data source consisted of interviews conducted with informants at each MNE. Upon conducting each interview, access to other suitable contacts was requested if the participants were willing to provide it. The interview approach used was partially based on ethnographic interview technique as this allowed interviewees to explain practice transfer and adaptation in their own words (Spradley, 1979). Where the researcher defines these terms on behalf of the informant, the credibility of the findings is greatly reduced (Guba and Lincoln, 1989). Hence, each interview began with questions related to the actual experience of managers in establishing transferring innovation practices within the MNE network, asking the interviewee for specific examples of the type of activities they themselves mention in the interview. The questions were then adapted using language consistent with that of the interviewee. This also allowed for the identification of other informants who were personally involved in the transfer process and management of other subsidiaries. The semi-structured interview protocol used is presented in Appendix 3. Prior to conducting interviews with each of the informants, 
numerous exchanges occurred via email. In most cases, the respondent requested and was provided with sample questions and descriptions of the interview protocol. These informants then sought clarity on any of the questions which they had regarding the nature of the research and how it might apply to their own personal experience. These exchanges occurred over a period of many weeks, and sometimes months. When the informant felt they understood the nature of the research and what would be asked of them, they proceeded to schedule the interview. These email exchanges improved the efficiency with which the interviews were conducted, and often were necessary to gain their consent.

During each interview, the participant was asked to explain the initial expectations for transferring innovation practices, and what outcomes were obtained. The participant was also asked about the various challenges that were faced in transferring practices, in terms of resistance from subsidiary employees if extant, learning challenges, difficulties in obtaining shared understanding of the purpose of the practice, and so forth. This stage of the interviewing was semi-structured and many probing questions were used to uncover the linkages between challenges, benefits and the national and organizational institutional elements which may influence these processes.

Table 6 provides a summary of innovation practice transfers discussed during the interviews, according to the sender unit, the recipient, and a basic characterization of the practice, organized according to each MNE in the sample. Note that many of the innovation practices discussed are idiosyncratic to the MNE, and hence do not 
necessarily have a specific name. Furthermore, in developing capabilities within subsidiaries with innovation mandates, innovation practices are often transferred as a 'suite', as opposed to individually. Hence, descriptions of each practice are more or less specific, depending upon the nature of the innovation practices discussed by each interviewee. In addition, the original source and intended recipient of each practice transfer is not known, as the process for diffusion appears to be more organic rather than centrally controlled.

Table 6: Innovation practice transfer discussed across four MNE cases.

\begin{tabular}{|c|l|c|c|l|}
\multicolumn{2}{c}{ Practice(s) } & \multicolumn{1}{c}{$\begin{array}{c}\text { Practice } \\
\text { Provider }\end{array}$} & \multicolumn{1}{c}{$\begin{array}{c}\text { Practice } \\
\text { Recipient }\end{array}$} & \multicolumn{1}{c|}{ Description / Rationale } \\
\hline \multirow{2}{*}{$\begin{array}{l}\text { Boards and } \\
\text { councils } \\
\text { meetings }\end{array}$} & HQ (US) & $\begin{array}{l}\text { All business } \\
\text { units globally }\end{array}$ & $\begin{array}{l}\text { Meetings of managers from across } \\
\text { the business units and labs to } \\
\text { negotiate and implement } \\
\text { innovation initiatives. }\end{array}$ \\
\cline { 2 - 5 } & $\begin{array}{l}\text { Crowd } \\
\text { sourcing }\end{array}$ & N/A & N/A & $\begin{array}{l}\text { New ideas generated and voted } \\
\text { upon by others within the MNE. }\end{array}$ \\
\cline { 2 - 5 } & $\begin{array}{l}\text { Distinguished } \\
\text { engineers }\end{array}$ & N/A & N/A & $\begin{array}{l}\text { Virtual (online) identification of } \\
\text { individual thought leaders to be } \\
\text { consulted for their knowledge. }\end{array}$ \\
\cline { 2 - 5 } & $\begin{array}{l}\text { Distributed } \\
\text { Teams }\end{array}$ & HQ (US) & $\begin{array}{l}\text { All business } \\
\text { units globally }\end{array}$ & $\begin{array}{l}\text { Assignment of geographically } \\
\text { dispersed individuals to project } \\
\text { teams based on expertise. }\end{array}$ \\
\cline { 2 - 6 } & $\begin{array}{l}\text { Identifying } \\
\text { reuse } \\
\text { opportunities }\end{array}$ & $\begin{array}{l}\text { Internal to } \\
\text { IT } \\
\text { organization }\end{array}$ & $\begin{array}{l}\text { Other } \\
\text { subsidiaries } \\
\text { within IT } \\
\text { organization }\end{array}$ & $\begin{array}{l}\text { Identifying new applications for } \\
\text { existing technology. }\end{array}$ \\
\cline { 2 - 5 } & $\begin{array}{l}\text { Centers of } \\
\text { excellence }\end{array}$ & HQ (US) & $\begin{array}{l}\text { All business } \\
\text { units globally }\end{array}$ & $\begin{array}{l}\text { Intention to distribute/integrate } \\
\text { innovation amongst different units. }\end{array}$ \\
\hline
\end{tabular}


Table 6 continued...

\begin{tabular}{|c|c|c|c|c|}
\hline & Practice(s) & $\begin{array}{l}\text { Practice } \\
\text { Provider }\end{array}$ & $\begin{array}{l}\text { Practice } \\
\text { Recipient }\end{array}$ & Description / Rationale \\
\hline \multirow{4}{*}{$\dot{\theta}_{\substack{0 \\
\dot{0}}}^{\dot{0}}$} & Design & HQ (US) & $\begin{array}{l}\text { All units } \\
\text { Globally }\end{array}$ & $\begin{array}{l}\text { All procedures related to new } \\
\text { product design. Required for Federal } \\
\text { Aviation Administration (FAA) } \\
\text { compliance. }\end{array}$ \\
\hline & $\begin{array}{l}\text { Design and } \\
\text { reporting }\end{array}$ & $\begin{array}{l}\text { Regional } \\
\text { HQ (India) }\end{array}$ & $\begin{array}{l}\text { China } \\
\text { Eastern } \\
\text { Europe }\end{array}$ & $\begin{array}{l}\text { Local practices for ensuring common } \\
\text { documentation and reporting of } \\
\text { design methods. }\end{array}$ \\
\hline & $\begin{array}{l}\text { Knowledge } \\
\text { sharing }\end{array}$ & HQ (US) & $\begin{array}{l}\text { All units } \\
\text { globally }\end{array}$ & $\begin{array}{l}\text { Formal training materials for all } \\
\text { aspects of the business. }\end{array}$ \\
\hline & $\begin{array}{l}\text { Project } \\
\text { management }\end{array}$ & N/A & N/A & $\begin{array}{l}\text { Project managers tend to be PMI } \\
\text { certified, although this is not a formal } \\
\text { requirement. }\end{array}$ \\
\hline \multirow{4}{*}{ 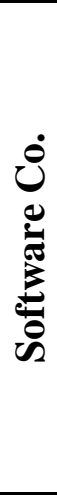 } & $\begin{array}{l}\text { 'Best' } \\
\text { practices }\end{array}$ & N/A & $\begin{array}{l}\text { Units } \\
\text { globally }\end{array}$ & $\begin{array}{l}\text { Brokered within the MNE amongst } \\
\text { the federated business units. }\end{array}$ \\
\hline & $\begin{array}{l}\text { Lean (agile) } \\
\text { programming }\end{array}$ & $\begin{array}{l}\text { HQ } \\
\text { (Europe) }\end{array}$ & $\begin{array}{l}\text { Labs } \\
\text { globally }\end{array}$ & $\begin{array}{l}\text { Initiative for software developers } \\
\text { using new techniques to reduce } \\
\text { software development time. }\end{array}$ \\
\hline & $\begin{array}{l}\text { Lead } \\
\text { generation }\end{array}$ & N/A & $\begin{array}{l}\text { Units } \\
\text { globally }\end{array}$ & Practices used to create new markets. \\
\hline & $\begin{array}{l}\text { Monitoring } \\
\text { practices }\end{array}$ & $\begin{array}{l}\text { Subsidiary } \\
\text { (not } \\
\text { specified) }\end{array}$ & $\begin{array}{l}\text { Subsidiary } \\
\text { (Canada) }\end{array}$ & $\begin{array}{l}\text { 'Dashboard' created in one location } \\
\text { implemented in another location } \\
\text { based on perceived usefulness. }\end{array}$ \\
\hline \multirow{5}{*}{ 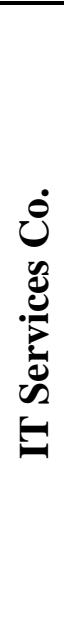 } & $\begin{array}{l}\text { Governance } \\
\text { practices }\end{array}$ & HQ (India) & $\begin{array}{l}\text { India } \\
\text { UK } \\
\text { US }\end{array}$ & $\begin{array}{l}\text { Measurement, reporting, } \\
\text { documentation practices negotiated } \\
\text { by technology board and } \\
\text { implemented globally. }\end{array}$ \\
\hline & $\begin{array}{l}\mathrm{R} \& \mathrm{D} \\
\text { branding }\end{array}$ & HQ (India) & $\begin{array}{l}\text { Labs } \\
\text { globally }\end{array}$ & $\begin{array}{l}\text { Branding creates perceived new } \\
\text { value. }\end{array}$ \\
\hline & $\begin{array}{l}\text { R\&D } \\
\text { partnerships }\end{array}$ & HQ (India) & $\begin{array}{l}\text { Labs } \\
\text { globally }\end{array}$ & $\begin{array}{l}\text { Partnerships entered into with } \\
\text { customers to develop new } \\
\text { capabilities. }\end{array}$ \\
\hline & $\begin{array}{l}\text { Technology } \\
\text { transfer }\end{array}$ & HQ (India) & $\begin{array}{l}\text { Labs } \\
\text { globally }\end{array}$ & $\begin{array}{l}\text { Transfer of new R\&D to business } \\
\text { units for commercialization. }\end{array}$ \\
\hline & $\begin{array}{l}\text { Project } \\
\text { management }\end{array}$ & HQ (India) & $\begin{array}{l}\text { Labs } \\
\text { globally }\end{array}$ & $\begin{array}{l}\text { Formal stage classifications for } \\
\text { projects }\end{array}$ \\
\hline
\end{tabular}


Additional data pertaining to the industry and firm in question were gathered from secondary sources such as annual reports and company websites, as required, to improve understanding of contextual factors. These data gave additional insights into the general and business environments in which the MNE operates. Furthermore, this secondary analysis helped to discern the phenomenon from the context, as managers sometimes over-emphasize idiosyncratic events in their discussions which, while they do represent an account of actual events, are not representative of their most typical experiences with the phenomenon in question.

All interview transcripts were stored and analyzed with the assistance of $\mathrm{NVivo}^{(}$ version 9 software. Analysis of the data began with open coding of each transcript, keeping in mind both the research questions and the descriptive frameworks presented in Chapter 4. While some prefer a more grounded approach, a more structured approach was opted for, as particular research questions had already been specified, and the phenomenon was deemed too complex to be addressed efficiently through a purely inductive approach (Miles and Huberman, 1994). The coding was not completed in a single, linear fashion but instead as new codes were established prior transcripts were recoded accordingly. In addition to open coding, annotations and memos were used to store and build upon initial thoughts. As coding proceeded, themes representing a particular variable, construct or important aspect of the phenomenon were organized into collections or 'tree nodes' (Bazeley, 2007). 
As the coding scheme for the data became increasingly complex and saturated, comparisons were made across cases on different nodes. At one point, a summary table of the basic qualities of each node, or variable, across each case was produced. The overall purpose of this analytical technique was to reduce the data into more manageable and theoretically relevant sets. It also permitted the formation of linkages between different nodes, which would eventually represent relationships between variables. Brief case summaries of each MNE are provided in Appendix 4. Through this process, structure was imposed on the interview data, in order to derive theory (Richards, 2005), which is presented in the following chapter. 


\section{Chapter 6: Subsidiary Capability Development}

In this and the subsequent chapter, theory is developed to address the research questions concerning innovation practice transfer, capability development, adaptation and diffusion. In this chapter, the role of innovation practice transfer in developing subsidiary innovation capabilities is examined. Propositions are derived from the data, as well as from an examination of existing literature relevant to innovation practice transfer, including KBT and institutional theory. However, as the case data revealed substantial differences in the characteristics of each MNE innovation network, as well as practice transfer processes commonly used, an overview of the four cases is first presented in order to provide important contextual information for the subsequent theory development.

\subsection{Overview of the MNEs Included in this Research}

Table 7 lists some key characteristics of each MNE network including the dominant innovation process, MNE innovation network and control structures, subsidiary innovation mandates within the innovation network, and innovation cycle time within the respective industries of each MNE. In addition, the most predominant modes of innovation practice transfer within each MNE are listed. The typology of innovation processes is from Bartlett and Beamish (2011) which consists of local for local, center for global, locally leveraged and globally linked. As the MNEs chosen for inclusion all serve global markets, mainly consisting of other MNEs and domestic businesses, none of them 
were substantially engaged in local innovation for local markets (i.e. 'local for local'). Likewise, as the MNE networks are all geographically dispersed, 'center for global' processes are not applicable, although given the early stage of innovation internationalization for IT Services, the majority of its innovation is currently conducted according to this mode. The two remaining types of innovation processes are locally leveraged processes which are carried out in foreign subsidiaries to serve global markets, and globally linked innovation which is carried out by an integrated group of geographically dispersed subsidiaries.

The innovation network typology employed is from Zander (1999) which classifies innovation networks according to the extent that redundant or diversified innovation capabilities are distributed internationally. Dispersed innovation networks have high degrees of both redundant and diversified capabilities distributed geographically. Internationally duplicated networks have a high degree of distributed redundant capabilities, and a low degree of diversified capabilities. Conversely, internationally dispersed networks are characterized by low levels of redundancy and high levels of capability diversification amongst geographically distributed affiliates. Home centered networks possess low degrees of internationalization along both dimensions. 
Table 7: MNE Innovation, control, subsidiary mandate, industry innovation cycle and innovation practice diffusion characteristics.

Telecom

\begin{tabular}{|c|c|c|c|c|}
\hline $\begin{array}{l}\text { Innovation } \\
\text { Process } \dagger\end{array}$ & Globally Linked & Globally Linked & Globally Linked & $\begin{array}{l}\text { Locally } \\
\text { Leveraged }\end{array}$ \\
\hline $\begin{array}{l}\text { Innovation } \\
\text { Network } \uparrow \dagger\end{array}$ & Dispersed & $\begin{array}{l}\text { Internationally } \\
\text { Duplicated }\end{array}$ & Dispersed & $\begin{array}{l}\text { Predominantly } \\
\text { Home Centered } \\
\text { but moving } \\
\text { towards } \\
\text { Internationally } \\
\text { Diversified. }\end{array}$ \\
\hline $\begin{array}{l}\text { MNE } \\
\text { Structure } \dagger\end{array}$ & $\begin{array}{l}\text { Coordinated } \\
\text { Federation }\end{array}$ & $\begin{array}{l}\text { (Tightly) } \\
\text { Coordinated } \\
\text { Federation } \\
\end{array}$ & $\begin{array}{l}\text { Decentralized } \\
\text { Federation }\end{array}$ & Centralized Hub \\
\hline $\begin{array}{l}\text { Subsidiary } \\
\text { Innovation } \\
\text { Mandate }\end{array}$ & $\begin{array}{l}\text { Leverage } \\
\text { technology and } \\
\text { capabilities }\end{array}$ & $\begin{array}{l}\text { Design } \\
\text { according to } \\
\text { HQ } \\
\text { specifications }\end{array}$ & $\begin{array}{c}\text { Leverage } \\
\text { capabilities }\end{array}$ & $\begin{array}{l}\text { Develop new } \\
\text { technology and } \\
\text { transfer to } \\
\text { business units }\end{array}$ \\
\hline $\begin{array}{l}\text { Innovation } \\
\text { Cycle }\end{array}$ & Fast & Slow & Fast & $\begin{array}{l}\text { Incremental - } \\
\text { Fast } \\
\text { Breakthrough - } \\
\text { Slow }\end{array}$ \\
\hline $\begin{array}{l}\text { Innovation } \\
\text { Practice } \\
\text { Transfer }\end{array}$ & $\begin{array}{l}\text { Organically } \\
\text { Diffused }\end{array}$ & $\begin{array}{l}\text { Centrally } \\
\text { Administered }\end{array}$ & $\begin{array}{l}\text { Brokered } \\
\text { Centrally } \\
\text { Administered }\end{array}$ & $\begin{array}{l}\text { Centrally } \\
\text { Administered }\end{array}$ \\
\hline
\end{tabular}

$\uparrow$ Adapted from Bartlett and Beamish (2011). $\dagger \dagger$ Adapted from Zander (1999).

The subsidiary mandates provided in Table 7 refer only to those subsidiaries discussed or from which managers were directly interviewed in the research, and hence to which innovation practices had been transferred. Hence, other subsidiaries within the MNE not discussed in this research may play different roles, and some of the subsidiaries 
included had additional mandates such as manufacturing (Aero, Latin America), sales and service (Software, Canada and Telecom, US). The innovation cycle time refers to the relative rate at which new innovations are brought to market within the industries represented by each of the MNEs. Finally, the typology of innovation practice transfer modes revealed in the case data includes (A) centrally administrated, from HQ to subsidiaries, (B) brokered, from one subsidiary to another intermediated by a manager who may or may not be affiliated with either unit, and (C) organically diffused, directly from one subsidiary to another. Only the most predominantly mentioned transfer modes are listed here. All three modes of transfer may exist within each MNE innovation network to varying degrees.

A few patterns within these sets of characteristics are worth noting. Innovation practice transfer within less centrally controlled MNE networks tends to involve less involvement from HQ. While this is not surprising, it is worth noting that in both Telecom and Software, the innovation cycles are quite fast. At Software, the only innovation practice transfer administered by HQ was lean software development, with the stated goal of reducing product development time. Hence, although not originally considered in the design phase of this study, industry may play a role in how innovation practices are diffused within the network. Faster cycle industries may involve more decentralized MNEs out of a need for responsiveness, not necessarily to local environments, but to the evolving needs of customers and new underlying technologies. In the case of Aero, innovation practices are centrally administered because they have 
been developed over the course of decades from HQ and must ensure that products developed for the aerospace industry are compliant with FAA regulations. At IT Services, the rationale for centrally administering practices is likely associated with the early stage of development of its international innovation network. At this time, only two foreign subsidiaries have been established and the priorities mentioned by both the CTO and a director involve establishing a common set of operational and reporting practices, and R\&D branding.

Finally, of the three MNEs with globally linked innovation processes, only Aero's network is characterized as internationally duplicated. As the process and form of the innovation network may appear to be inconsistent, some explanation is warranted. Although subsidiaries at Aero are all linked, in that each new product developed involves globally dispersed teams, the capabilities each possesses are duplicated from Aero's home country, the US. Although this can be interpreted as an attempt to economize on engineering, given that factor costs are different in the subsidiary local nations, the Director of Engineering in the US made a point of indicating that these locations were chosen for eventual market access. Hence, developing product design capabilities, similar to those of the US site, in order to ensure FAA compliance, can be viewed as a necessary precursor to serving local markets. As the MNE realizes cost savings in the process of accessing these markets (Maskell et al, 2007), the initial investment is justified in the short term. In order to serve local national defence markets in particular, substantial local presence is also necessary. 


\subsection{Innovation Practice Transfer and Capability Development}

Evidence gleaned from the case studies provided insight into how practice transfer influences subsidiary capability creation. The process of innovation practice transfer occurs over a period of time and coincides with the development of subsidiary capabilities. In essence, the knowledge dynamics and shared context (Nonaka, Toyama and Nagata, 2000) created by innovation practice transfer can motivate subsidiaries to actively seek knowledge from existing sources within the MNE. When a subsidiary is granted an innovation mandate through, for example, inclusion on a new product development project, seeking knowledge from existing internal sources aids in fulfilling the mandate efficiently.

In order to appreciate the role that innovation practice transfer plays in creating knowledge dynamics and shared context, it is important to view practice transfer and capability development as neither static nor sequential events. They are both dynamic and potentially, but not necessarily, mutually influential. Furthermore, innovation practice transfer involves the establishment of know-how sourced from one area of the organization in another, and this know-how consists of both tacit and explicit components. Both are necessary in order for a subsidiary to develop the capability, but the tacit component is not transferred so much as it is developed. The purpose of this section is to identify mechanisms, evidenced in the case studies, by which transfer of the explicit aspects of practice enable the development of the tacit components in the foreign subsidiary. 
Capabilities are developed over time, typically evolving in a path dependent manner from existing capabilities, or through acquisitions of firms with capabilities not previously present in the acquiring MNE (Birkinshaw and Hood, 1998). In accordance with the view of practices and routines discussed in Chapter 2, innovation practices transferred from one area of the organization to another can aid subsidiaries in developing new capabilities by providing the existing process knowledge, or know-how, that they embody. Indeed, it is largely assumed in existing practice transfer literature that what is being transferred is of high value or even strategic importance to the overall MNE, and hence should be diffused as widely as possible (Jensen and Szulanski, 2004; Kostova and Roth, 2002; Yu and Zaheer, 2010). While I concur with this assumption in general, the case data allowed a closer examination of what is actually being transferred, as clearly a practice cannot be transferred like a document can, and also to establish what the managers' motivation for initiating the transfer.

After analyzing the data by considering what was being transferred in each case, it became evident that innovation practice transfer is, as expected, not straightforward nor easy to achieve (Gertler, 2003), and that the transmission of know-how was not the only role that practice transfer plays in developing subsidiary capabilities. In what follows, I examine the role that practice transfer plays in aiding the subsidiary to obtain the tacit knowledge required to build product development capabilities.

In all cases, practice transfer actually involves the transfer of knowledge of two general types. The first is knowledge which subsidiary employees would use to 
accomplish a task, while the other group was related to procedures, which essentially consist of rules and regulations which are not oriented towards a particular goal. Here it is important to note that although the purpose of practice transfer is to share know-how, the actual process of transfer cannot directly achieve this, because know-how is always at least partially tacit (Nonaka and von Krogh, 2009). Hence there is a need for individuals in the innovation practice recipient subsidiary to develop some components of the knowhow themselves.

Two of the key themes emerging from the data, related to capability development, were identified as use of organizational knowledge and timing of its transfer. Use refers to the practical application of transferred knowledge, while timing refers to having access to knowledge sources as the capability was developed. The importance of use is illustrated by the following quote from a subsidiary manager in Aero, Eastern Europe, one of the several emerging market subsidiaries to receive design practices from the US HQ:

The lowest management usually gets used to using the process, and it was difficult to explain to the managers that our people learn relatively quickly, and need to move forward. So it's not possible to have daily meetings and not to give people more responsibility ... they get used to using processes and repeating the same processes again and again, and the people are learning and would like to get more responsibility and higher level of work. This was very difficult for our American partners to understand. 
The reference to "getting more responsibility" suggests a heightened degree of impatience to gain a more advanced mandate from HQ. Hence, this subsidiary manager was highly motivated to obtain knowledge, which was done at that subsidiary through interaction with engineers in the US HQ where these capabilities had been developed. A key issue highlighted by this manager was that the training on Aero design practices provided by engineers at the home location in the US was appreciated, but that the provision of an enhanced mandate was necessary in order to build capabilities. Hence, the timing of the provision of the codified portion of the innovation practice created a motivation to put that practice into use.

Additional evidence from the case studies demonstrates the dynamic nature in which capabilities and innovation practice transfer enforce one another in recipient subsidiaries. The formal training provided by HQ engineers was not sufficient to complete the subsidiary's mandates, but rather there was an ongoing need to access these sources of knowledge during the progression of designing airplane components. The training provided a general appreciation for the processes, and was enough to enable the subsidiary to begin to develop the design practices, but subsidiary engineers continued to access knowledge from HQ engineers in order to develop the tacit components of the practice. In numerous instances, having access to required knowledge sources, both codified and tacit, was cited by subsidiary managers as a critical enabler of airplane component, and hence capability, development. The following quotes were typical of Aero subsidiaries: 
At the beginning it was every day communication via phone. "What did you do?", "What problem do you need to solve?", and so on. So [communication] was a very important part of mentoring and knowledge transfer. Right now we have meetings on a weekly basis.

(Engineering Manager, Aero Co., Eastern Europe)

We have a very good relationship with American team. So every time we encounter some technical problems or engineering problems we can consult with the U.S. team, whether it's the managers or the product people.

(Engineering Manager, Aero Co., China)

In the first quote, the manager of the Eastern European subsidiary highlights the role that access to HQ engineering knowledge played in developing capabilities. Initially HQ engineers provided daily mentoring and monitoring in order to track the progress of the subsidiary in fulfilling its responsibilities, but this interaction declined as the subsidiary gained competencies in using the practices, and HQ gained confidence in these competencies. Hence, interaction between HQ and the subsidiary was frequent in the early stages of developing the capabilities, and then declined as that tacit knowledge was developed. Likewise, the manager from the Chinese subsidiary refers to the availability of HQ engineers to provide knowledge in order to solve problems as they arose as an important driver of capability development. Hence, initiation of innovation practice transfer by HQ provided the motivation for subsidiaries to develop capabilities, but having access to knowledge sources as they put these practices into use was the critical enabler of capability development over time. 
The theme of timing was also evident in the IT Services case, but the context is somewhat different. Here, formal innovation practices were developed several years after the establishment of research labs throughout India, and these practices were then transferred to subsidiaries in the US and UK which were established later. The Indian subsidiaries had individually developed innovation practices within each lab, and hence their formalization involved some degree of codification. This process of formalization involved some negotiation, and hence interaction amongst the labs. This was enabled by developing a formal technology office board which consisted of the upper management, including the Chief Technology Officer (CTO), and the head of each lab. The manager of one lab in India characterized the process of formalizing practice as follows:

Practices are shared by doing them, and the processes are established and defined. At most there will be emails exchanged from time to time as the practices evolve.

You don't have all the practices in place in the very beginning, so you start creating practices.

This manager speaks of the emergence of innovation practices from within the Indian lab network, which initially were more tacit and confined to individual labs, but later codified in order to establish commonalities. By establishing these commonalities, labs could be monitored more closely, and could share knowledge more easily. Hence, this establishment of common innovation practices promoted use of knowledge from within the MNE innovation network, and the timing of interaction aided in the 
formalization process, 'as the practices evolved'. However, overseas labs were established much later than those in India, and hence were not initially included in negotiating innovation practices. Instead, these practices were transferred to the labs as they were established. This was achieved by transferring someone from within the IT Services innovation network to act as head of the labs in the US and UK. The value of having someone established in the organization as the foreign lab head was that it aided in developing the tacit knowledge of the other labs. As stated by the CTO:

[The processes in the foreign labs] are the same processes which a lab in, Mumbai, or Pune, or Chennai will follow. The same practices and same structures apply to [the US and UK labs] as well. For the purposes of the soft transfer of the intangibles, the founding head of the lab is an IT Services person who has spent time in research and development before they have taken on the leadership position in the overseas lab.

Hence, the transfer of innovation practices from India to the overseas labs was primarily achieved through the use of an expatriate manager as the source of the tacit component of those practices. In this case, the 'soft' practices referred to establishing relationships with various research institutions in the local environments, such as universities, as well as with industry, with research and development processes, and the establishment of the lab's mandate. The transfer of these practices promoted the use of organizational knowledge. The timing of the transfer of each set of innovation practices was in accordance to the priorities of IT Services when setting up the lab. These priorities according to the CTO were, in order, establishing connections to the local 
academic institutions, hiring researchers locally, and establishing the mandate of the lab. Hence, through timing the transfer of separate sets of innovation practices, the lab sequentially developed its capabilities in accordance with the priorities of top management.

At Software and Telecom, MNE structure influenced knowledge dynamics due to a higher degree of decentralization of innovation than in the cases of IT Services and Aero. At Software, instances of innovation practice transfer discussed, with the exception of lean software development, were somewhat ad hoc and opportunistic. Subsidiaries were encouraged to adopt practices by employees who regularly visited these subsidiaries, but the decision to adopt was left to the subsidiary management. The autonomy of subsidiaries in making these choices hence resulted in non-adoption in some instances, and adaptation of the practices in others. These issues are dealt with in the subsequent section on innovation practice adaptation, in which the role of micro-politics in adapting innovation practices is explored further. In the case of Telecom, the strategy of developing capabilities through acquisition resulted in a continual need for integration within the subsidiary network. Therefore, sharing of innovation practices was also somewhat uncoordinated. As stated by a manager in a Telecom subsidiary in the US:

There really isn't a concept of [practices] coming from one place and going to another. It's really a cross platform sharing of ideas and best practices.

I think we're getting more deliberate about [selecting amongst practices] and better at that, because we do have so many good ideas that come through that we need to focus on the right one at the right time for the right purpose. 
Hence, this manager notes that timing and purpose of the innovation practice are both important in order for innovation practices to be adopted by other units within the MNE network. As coordination is not as centrally controlled within this MNE, developing a common set of practices is challenging. The reference to 'getting more deliberate' suggests that someone must act as an initiator of innovation practice transfer, in order to promote the use of organizational knowledge.

In summary, both use and timing can be construed as components of knowledge dynamics, that is, the interaction between sources of knowledge, such as product documentation and engineers in other units, and the structural configuration of individuals responsible for innovation (Nonaka et al, 2000). Use is important in enabling the development of tacit knowledge through learning. As practice transfer involves the transfer of knowledge from one area of the organization to another and use of that knowledge, innovation practice transfer will aid in developing subsidiary capabilities through the development of tacit knowledge associated with explicit organizational knowledge. Timing serves a similar purpose, as knowledge which is gained when it is needed is more likely to lead to learning, and hence capability development. In the case of timing, it is not simply the availability of organizational knowledge, but rather that knowledge recipients have incentive to 'pull' knowledge from senders. Under these pull circumstances, the knowledge recipient is better able to articulate the type of knowledge that is required by explaining in the context of a problem he or she has encountered. In 
essence, the unique patterns of knowledge dynamics created in innovation practice transfer enable subsidiaries to develop capabilities through the practical application of organizational knowledge.

Proposition 1a. Innovation practice transfer enhances subsidiary capability development by promoting use of available knowledge resources.

Proposition 1b. Innovation practice transfer enhances subsidiary capability development by promoting access to applicable knowledge when it is to be practically applied.

Case evidence also suggested that innovation practice transfer improves knowledge flow from sender to recipient. It is primarily the existence of a more established social context within the organization that is cited as the reason that organizations are superior to markets in knowledge sharing (Grant, 1996; Nonaka et al, 2000). Contexts are interpretations made by individuals concerning the situations in which they find themselves (Augier, Shariq and Vendelø, 2001). According to this definition, contexts cannot be 'shared', as they are an individual interpretation, but through interaction, these contexts can become similar amongst individuals engaged in common pursuits. For the sake of simplicity, these shared interpretations are referred to here, similar to Nonaka et al (2000), as shared context which is meant to be understood as 
similarities amongst individual interpretations of context. Shared context thus enhances the ability to share knowledge as they constitute similar frames of reference which direct understanding. The literature on communities of practice also stresses the importance of shared purpose, experience, expertise, and sense of belonging as enablers of knowledge sharing (Brown and Duguid, 1991; 2001; Wenger, 1998; Wenger et al, 2002). However, the quality of the social context within organizations is likely to vary such that some organizations will share knowledge more freely than others. Knowledge can be a source of power, and hence independence amongst subsidiaries in an MNE network (Andersson, Forsgren and Holm, 2007), and this can create barriers to knowledge transfer. Likewise, communities of practice may not naturally develop across different business units, and across geographic boundaries (Lee and Williams, 2007) and therefore capabilities existing in one area of the firm may not easily transfer to other subsidiaries.

In order for communities to form amongst geographically dispersed or co-located subsidiaries, interaction amongst individuals within different subsidiaries is a necessary, although not sufficient, prerequisite. Even when interaction exists, individuals in business units which could potentially act as knowledge sources may not have sufficient incentives, or even perceive disincentives for sharing their knowledge, as expressed by an Aero manager in Latin America:

(Sometimes there is) understandable resistance from the domestic market to transfer knowledge into (the emerging market) region. Obviously, they [perceive] the risk of losing jobs, the risk of saying "now they can do what 
I am doing." Definitely, that's been a challenge and a concern that we try to address and are still addressing with some US sites.

Essentially, the problem faced by managers in developing subsidiary innovation capabilities is one of encouraging knowledge sharing between disparate entities which would not otherwise interact. As mentioned in chapter 2, subsidiaries with mandates that integrate them with other business units are more likely to share practices. However, evidence from the cases suggests that these are not necessarily independent processes, nor that they need to proceed in that order. So long as mutual interdependencies are created, motivation to share knowledge which would help build subsidiary capabilities is more readily exchanged (Foss and Pedersen, 2002). For Telecom, this is achieved using globally distributed teams:

'Somewhere else based' is almost ubiquitous to the conversation [concerning sources and recipients of practices] or to knowledge sharing. So imagine 100,000 people sitting all over the world, there really isn't, there used to be, but there really isn't anymore a concept of coming from one place and going to another.

(Senior Program Mgmt. Office Manager, Telecom Co., US)

At IT Services, innovation takes different forms including incremental and breakthrough, as well as co-innovation with customers. The focus of the foreign and domestic labs is on developing new knowledge which may then be applied to business problems identified by customers and business units in order to generate new value. The case of IT Services presents a counterpoint to the use of globally distributed teams which, 
in part, is a result of the limited extent to which innovation activities are currently distributed. In this case, a central management body has been created to manage the establishment and sharing of practices amongst research labs:

People are told what to do because the head of the lab has to be a member of the corporate technology board, and that's where budgets are asked for, and processes are established.

(Lab Head, IT Services Co., India)

Here, there is less integration amongst the research labs which are intended to feed into the business lines. As a result, practices are not directly transferred between units, but rather established centrally. The result, according to this manager, is not ideal because the labs are working somewhat independently and thus not 'doing' the practices together, which suggests far less integration.

In Aero, the primary knowledge source, apart from the codified knowledge base, is located in the US based engineering operations. Hence, the use of teams lead by the US created mutual interdependencies which, in turn, would necessitate knowledge transfer to build innovation capabilities. As demonstrated by the following quote from a Aero subsidiary manager in Eastern Europe, working in global teams creates interdependencies, but as capabilities develop, the frequency of communication is reduced.

Our people here are assigned to experienced project engineers or groups in the United States and usually the metrics manager provides technical mentoring and knowledge transferring to our site. Right now, because we 
have some know-how, we are able to [participate in] more teams. And we have relatively bigger ownership of the projects and so communication is not as frequent anymore.

Overall, the cases suggest that practice transfer within the MNE network creates mutual interdependence amongst subsidiaries. These interdependencies in turn aid in overcoming barriers to knowledge transfer which might otherwise exist as a result of micro-political, geographic, and potentially cultural barriers. Mutual interdependence thus creates incentives for the establishment of communities of practice, which in turn enhance knowledge sharing and consequently subsidiary capability development. By establishing mutual interdependencies amongst subsidiaries first, existing and potential barriers to knowledge sharing are reduced. Initiating practice transfer amongst subsidiaries creates these mutual interdependencies by creating a focal point (Schelling, 1960) around which contexts begin to converge.

Proposition 2. Innovation practice transfer enhances mutual interdependency amongst subsidiaries which fosters the development of communities of practices, which in turn motivates knowledge transfer and thus aids in the creation of subsidiary innovation capabilities.

Shared context also enhances mutual understanding, which in turn can hasten the flow of knowledge to subsidiaries when and where needed, in order to help it establish 
innovation capabilities. Practices are context dependent and shaped by forces over time and therefore cannot be fully replicated in a subsidiary. However, it is possible that sharing practices amongst subsidiaries in the MNE network may help to establish a shared context to the extent that knowledge flow is enhanced. Such a context would likely possess prominent features of the business units from which practices originate.

One mode of creating shared understanding through practice transfer is demonstrated by the Aero case, as cited above ("usually the metrics manager provides technical mentoring, knowledge transferring to our site”). This demonstrates the importance of using common metrics amongst various subsidiaries in order to establish shared understanding. The metrics used to assess performance are common amongst subsidiaries, and are mainly focused on promoting engineering efficiency, productivity, and capability development:

We use all kinds of metrics. Yield is one that my team monitors for the organization census. Seeing how well you're developing around the world, you might look at how many people are in each location. We take an inventory on a regular basis of the capabilities we have in each location, in the engineering group, and where do we need to build what capabilities in the future, and put in actions to address those gaps --

We also look at fill rate on a particular program, that our engineering resources fill the needs of a program, in particular. Obviously, financial performance, are people doing things under the cost they're supposed to. (Director, Aero Co., US)

The use of metrics used to monitor and assess the performance of each development site is very common across the different subsidiaries. Engineering yield, in 
particular, was one metric mentioned by nearly every location included in the sample. For example:

One is yield or efficiency. That is the ratio between direct working net worth versus, divided by the actual payroll. That is how we measure yields.

(Engineering Manager, Aero Co., Latin America)

In order for subsidiaries to become more efficient, in terms of their engineering yield, they would need to ensure that most of their engineers' time was spent on tasks directly billable to a project. In other words, they would need to be more involved in projects and would have to have enough projects to keep engineers busy, and thus integrated with the US operations as well as other subsidiaries. Hence, this common language surrounding metrics is one factor which helps to create a shared context, in which different engineering units become integrated through the sharing of common practices.

Another driver of shared context is the use of communications technologies to coordinate activities, ideas and knowledge flows amongst individuals in the MNE. Indeed, the primary assumption is that virtual teams, or communities of practice, can develop aided by communications technologies (Kimble, Li and Barlow, 2000). However, I argue, based on evidence in the cases that the manner in which the technology is used influences the extent to which a shared understanding is created. That is, the context with respect to the existence of various communication tools and 
techniques may be a type of shared context, but the extent to which the technologies truly integrate the activities of disparate individuals within the MNE depends upon how they are used, and what sort of uses they enable.

Given that this study was focused on the exchange of practices and the extent to which communication technologies are now used amongst innovative organizations, many examples of use were recorded during the data collection. Tools ranged from those that have long been in use and widely diffused across most industries, such as email and instant messaging, to those which are now colloquially referred to as 'social networking tools'. Here are a few examples of communication technologies used, in the words of the respondents:

Yes, we have meetings on a regular basis where folks are not necessarily joining the call, but we're recording it. The time difference is a little bit of a challenge, but we do a lot of asynchronous collaboration where we have recordings from all the different meetings. We actually have a type of collaboration tool. I can create a community there and identify all of the people in that community, and they become part of that sharing where we have wiki blogs, and discussion forums and file sharing and video recording.

(Senior Program Mgmt. Office Manager, Telecom Co., US)

Knowledge transfer and knowledge sharing is a big priority for us. We've been experimenting with a few things, like (proprietary name omitted) is one tool, it's probably like a Twitter tool, where you can type in certain things, ask a question, anyone around the world on that network can answer it.

Also we use a lot of things like Wiki pages and SharePoint sites that share information around product development or different practices, business processes around the world you know seamlessly. Knowledge sharing is a big deal for us internally.

(VP, Aero Co., US) 
The other part of the story is to try and get hold of problems, areas that require innovation, back from the different parts of the world into a central repository. In this case we call it (proprietary name omitted), which collects problems and possible solutions. So a lot of the infrastructure is available to try and get at things.

(VP, IT Services, India)

These communication technologies help to overcome the difficulties of interaction across time and space, but it is also helpful to categorize them as enabling either the 'pull' or 'push' of knowledge transfer through a network. While pushing knowledge across a network is likely desirable from a strategic perspective, allowing individuals the ability to pull the knowledge as necessary helps to create shared time and space, which in turn helps subsidiaries to develop capabilities. During the earlier stage of this research, managers at one Indian conglomerate described a central repository in which individuals from across the many businesses could post solutions to problems that they had discovered. In this early incarnation of the portal, use was not as high as managers had hoped. Over time, practices were adapted so that managers at the various businesses would instead describe problems they faced in their business, in order to seek any relevant advice. By changing the manner in which the technology was used, from pushing to pulling of knowledge, the degree of usefulness was notably increased. Hence, while communication technology enhances the ability of geographically and temporally dispersed subsidiaries to share knowledge, it is the sharing of practices concerning the use of that technology which is more likely to create shared understanding. 
A third major component or prerequisite for shared understanding is common language. In this case, language refers not simply to the words, but to the contextual meanings they are assigned within an MNE. If subsidiaries within an organization have different practices, then it becomes difficult to establish this common language, as actors will interpret the words of others according to local uses of the terms. Hence, transferring practices can create this shared language, where meaning is negotiated. This was especially evident in the case of Telecom Co., which primarily establishes new subsidiaries through acquisition, rather than greenfield investment:

We are definitely big about transferring major processes so that, that we're all sort of working in a similar fashion. So that when we do get together and have to work across business units or whatnot, we're still able to talk the same language.

(Senior Program Manager, Telecom Co., US)

In instances where practices are not transferred, subsidiaries are slower to develop capabilities, at least with respect to integration within the context of the MNE innovation network:

There are other major acquisitions that we've taken on such as (company) They've been on board about a year, and they're still going through a lot of growing pains. They don't stick to processes and they don't stick to deadlines and the way things work and whatnot.

(Senior Program Manager, Telecom Co., US)

The use of common metrics amongst subsidiaries, common practices regarding the use of telecommunication technologies, and the establishment of common language 
all serve to promote the establishment of common, or shared, context amongst geographically dispersed subsidiaries. Shared context, in turn, enhances mutual understanding and knowledge flows, and ultimately the development of capabilities by subsidiaries. Practice transfer is positively associated with the creation of shared context, but the extent to which it does so, as evidenced by the above examples, is influenced by the extent to which practices are shared. Practice sharing refers to the extent to which practices are distributed across the MNE network. Distribution of practices differs from diffusion in that the former has the effect of requiring subsidiaries in the MNE innovation network to coordinate their activities, thus enhancing organizational integration, a principle requirement for innovation (O’Sullivan, 2000).

Proposition 3. Practice sharing amongst subsidiaries in the MNE innovation network enhances the extent to which practice transfer creates shared context, which in turn enhances mutual understanding and hastens innovation capability development.

\subsection{Summary}

In summary, innovation practice transfer aids in subsidiary innovation capability development due to the unique knowledge dynamics it creates and through the creation of shared context which enhances mutual understanding and hence knowledge flow. The relationship between practice transfer and the creation of shared context is enhanced by 
the extent to which practices are shared, or distributed across different subsidiaries in the innovation network.

In terms of knowledge dynamics, practice transfer aids in knowledge sourcing during the process of building tacit knowledge in the subsidiary. In addition to helping individuals locate the knowledge they need, the timing of the knowledge request in proximity to when it is to be used for a practical purpose also aids in building tacit knowledge, and hence capabilities. In addition, subsidiaries that share similar practices are better able to exchange information due to interdependencies and the creation of shared understanding, which makes the interpretation of tacit knowledge easier. 


\section{Chapter 7: Diffusion and Adaptation of Innovation Practices}

In the previous chapter, the role that innovation practice transfer can play in establishing capabilities in MNE subsidiaries has been examined. In this chapter, three distinct processes through which practices diffuse throughout the MNE are identified. Following this, factors which influence innovation practice adaptation are discussed.

\subsection{Modes of Diffusion}

Three modes of diffusion, central administration, brokering, and organic diffusion, were identified in the MNEs which substantially impacted the extent to which innovation practices are adopted and the potential adaptations that are made to them in the process. These influences, as well as others which emerged from the data are examined in the subsequent section. It is not likely, nor evident, that any of the four MNEs included in this research employ a single mode of diffusion, but it is possible that some modes are more dominant than others.

The case of Aero Co. best illustrates the use of central administration of practices. Central administration of innovation practices involves the corporate or regional HQ as the initiator of the transfer process. This mode of diffusion entails the transfer of what would likely be termed 'best' practices, throughout the MNE network. Of all the cases, the innovation practices at Aero are the most established and rigorously defined, owing in part to the high level of industry regulation and also the lengthy period of time over which these had been institutionalized. However, IT Services also used central 
administration of practices even though the attempt to formalize them was in an early stage of development:

It's a new thing for us because software development is something we have been doing for forty years, research we've been doing for 25, 30 years, but we only started trying to formalize [research and development] in the past couple of years.

(Lab Head, IT Services, India)

Hence, while central administration of practices may be more likely when practices have evolved and become highly institutionalized in one area of the firm, it is more likely that this mode of transfer is used when there is a desire to formalize innovation through common processes, metrics, and reporting structure. As innovation is a highly uncertain and risky endeavour, especially in the context of leveraging local knowledge resources for global markets, HQ can use these common metrics and reporting to compare amongst subsidiaries. In the case of IT Services, these comparisons could be made to longer tenured labs in India. Without this formalization, HQ would have less insight into the development of the foreign subsidiaries, and be provided with fewer opportunities to leverage local knowledge through combination with its established capabilities. In this way, the MNE has better access to information from the subsidiaries with which to guide and direct strategy. This control may be desirable in both the Aero and IT Services cases as integration is more important than local responsiveness when serving global markets. 
The second identifiable mode of diffusion is brokering, and is evident mainly in the case of Software Services Co. Brokering here specifically refers to the transfer of innovation practices through an intermediary, from one subsidiary to another. However, the underlying concept is similar to that of boundary spanning in which influential individuals transfer knowledge within and between organizations (Kostova and Roth, 2003; Mudambi and Swift, 2009; Tushman, 1977). While Software used central administration to diffuse major changes in the way innovation was achieved, there was also evidence of brokering which entails diffusion of practices from one location to others through a common intermediary, which in this case would be an individual who works with several subsidiaries:

I have an operations person who works in Japan. He works virtually, actually, lives here in [the US]. He talks daily to multiple people, multiple centers and multiple disciplines. He'll find different things out from somebody in Shanghai and say, "Hey, listen, have you spoken to Kim over in Korea about this because they're doing something similar". (VP, Software Co., US)

According to the propositions developed in the first section of this chapter, the creation of mutual interdependencies amongst MNE subsidiaries and business units enhances knowledge flow, and ultimately capability development in a focal subsidiary. However, in the absence of these mutual interdependencies, innovation practices may diffuse throughout the network through brokering. 
So they may, at their discretion, choose to adopt those best practices and that knowledge transfers over to them. The challenge of our company is to get that knowledge shared with their colleagues in other regions and other market units. For example you might have somebody from India who comes up with a great idea and they don't regularly speak to someone in Brazil, so what we try to do is broker the information so that it could be syndicated and, of course, made more valuable to the corporation.

(VP, Software Co., US)

Brokering occurs in most organizations to some extent, but Software is organized as a somewhat decentralized federation, and hence there is less interaction between different units than would be the case in Aero. So while major new initiatives would occasionally be centrally administered, other potentially valuable practices would be unknown by headquarters. Likewise, individual units within the federated structure are not necessarily aware that practices they are using are unique and potentially valuable to diffuse. Hence, brokering is available in order to overcome the structural barriers to innovation practice transfer.

Proposition 4. Innovation practices diffuse through brokering when structural barriers to communication inhibit either central administration or organic diffusion.

Finally, within any organization, there will be differences amongst practices used by different subsidiaries and business units separated by function, business line, geography and so forth. Telecom, partially as a result of its acquisition strategy, houses 
numerous different practices. It has developed the boards and councils structure to address this heterogeneity and hasten the rate of innovation. It also uses communication technology in order to source and rate ideas and practices from throughout the organization. The CEO also has attempted to create a competitive atmosphere in which different ideas compete.

There's a general willingness to share, and the interesting thing there is [the CEO] has made it very clear that he wants people at [Telecom] who are willing to do that, who are willing to compete but to share at the same time and be a family, first and foremost. And made it very clear that folks who are not interested in doing that, albeit they may be extremely talented, in order for [Telecom] to move forward, we need them to be here. And then created that environment to the point where folks that are not as interested in that have started to leave.

Organic diffusion also occurs in Software during meetings of different lab heads. In these meetings, managers have an opportunity to share practices implemented at their own labs. If a lab manager feels that they might be valuable in their own organization, they will actively seek advice on establishing it in their own.

When [managers meet], for example, let's say somebody came up with a dashboard. We basically say, "This is what we're doing in my location." And if we feel that it's good for our location we work with whoever created it and say, "How did you do it?" And we roll it out in our location. So those are the types of best practices that we share.

(Lab Head, Software Co., Canada) 
It is not clear that organic diffusion is the result of a broader strategic initiative or structural configuration. However, as evidenced above, adoption of innovation practices requires both that potential recipients are made aware of the existence of the practice, and that they deem it to be valuable, which in turn is a function of how performance is assessed within that subsidiary. If subsidiaries are assessed according to common metrics and meet at regular intervals, then practice sharing will likely occur more frequently. Hence, it is possible for HQ to indirectly promote sharing of practices within the MNE innovation network.

Proposition 5. Organic diffusion of innovation practices occurs when managers and employees communicate regularly such that potential recipients are made aware and recognize the value of practices implemented in other subsidiaries.

\subsection{Innovation Practice Adoption and Adaptation}

As discussed in Chapter 3, adaptations to innovation practices are posited to occur in response to differences in national institutional environments between source and recipient of the transfer, as well as organizational factors. While adaptations can, and often will occur gradually over time, the approach here follow others (e.g. Szulanski and Jensen, 2006; Yu and Zaheer, 2010) by specifically examining intentional adaptations following teleological or dialectical change processes. Evolutionary or lifecycle 
approaches or unintentional change are not considered, as the data would not allow a rigorous analysis of these issues.

National level factors which affect practice transfer are regulatory (i.e. legal/political), normative (i.e. cultural) and cognitive differences between practice providers and recipients. In addition to institutional differences, the organizational factors considered during analysis were the level of integration of the practice recipient within the MNE innovation network, and the extent of its specialization. The practice characteristics of degree of tacitness and extent of institutionalization were proposed also to be influential on innovation practice adaptation.

In examining how practices are adapted, it is helpful to construe them as multidimensional with adaptation occurring along one or more of these dimensions. The conceptual dimension of a practice refers to its rationale for adoption, and intended use (Reger et al, 1994; Yu and Zaheer, 2010), while the social dimension is concerned with the assignment of roles for individuals engaged in the practice, and the technical dimension refers to the particular techniques and processes embodied by the practice ( $\mathrm{Yu}$ and Zaheer, 2010). While each practice possesses all three dimensions, the extent to which any of them may be adapted depends upon the pressures that drive the change.

In examining specific instances of innovation practice adaptation, as discussed by interviewees, a number of other themes beyond those originally considered emerged. In addition, some of the potential influences originally considered, such cognitive differences between home and host countries, were not apparent. Table 8 summarizes 
themes which were apparent, and indicates the cases in which they were observed. In each case, Table 8 indicates the attributions which respondents indicated as the cause of adaptations to innovation practices discussed. The one exception is the influence of industry regulation at Aero which made any but the slightest of adaptations intolerable. Whereas prior research on practice transfer generally considers institutional pressures leading to adaptation, the strength of these regulations had the opposite effect. As stated by a VP from Aero HQ:

We drive the same process across [the entire] network and do not make exceptions to do something faster, because having someone learn something faster, but not learning it the right way that it's compliant is not acceptable in the business we're in. If you think about the flight management system of an aircraft, you can't have an India team doing their own thing, or China team develop differently than the rest of the group.

The attributions of innovation practice adaptation made by respondents are grouped into regulatory pressures, normative pressures, and organizational, subsidiary and practice related factors, primarily according to level of analysis. In each case, the absence of evidence concerning any of the factors does not imply that pressures did not exist within the organization, but instead indicates respondents either were not aware of instances in which these pressures lead to adaptation, or that the pressures lead to nonadoption. In Software and Telecom in particular, subsidiaries will often choose not adopt practices, and this is likely because the modes of diffusion are organic or brokered as 
identified in the previous section. Pressures for adaptation at each level of analysis are next considered.

Table 8: Attributions of innovation practice adaptation indicated at each MNE.

\begin{tabular}{|c|c|c|c|c|}
\hline & Aero & Software & Telecom & IT Services \\
\hline \multicolumn{5}{|l|}{ Regulatory Pressures } \\
\hline National Regulation & $\mathrm{X}$ & $\bar{X}$ & & \\
\hline Industry Regulation & $\begin{array}{c}\text { Prevents } \\
\text { adaptation }\end{array}$ & & & \\
\hline \multicolumn{5}{|l|}{ Normative Pressures } \\
\hline Culture & & $\mathrm{X}$ & & \\
\hline \multicolumn{5}{|l|}{ Organization } \\
\hline Product innovation cycle & & $\bar{X}$ & & \\
\hline Structure & & & $\mathrm{X}$ & \\
\hline \multicolumn{5}{|l|}{ Subsidiary } \\
\hline Local business requirements & $\bar{X}$ & $\bar{X}$ & & \\
\hline Resources & $\mathrm{X}$ & $\mathrm{X}$ & & $\mathrm{X}$ \\
\hline Path dependencies & & $\mathrm{X}$ & & \\
\hline Tenure & $\mathrm{X}$ & $\mathrm{X}$ & & \\
\hline Autonomy & & $X$ & $X$ & $X$ \\
\hline \multicolumn{5}{|l|}{ Practice } \\
\hline Institutionalization stage & & $\mathrm{X}$ & & \\
\hline Perceived value & & $\bar{X}$ & $\mathrm{X}$ & $\mathrm{X}$ \\
\hline
\end{tabular}

\subsubsection{Regulatory Pressures}

A primary finding from the data is that regulatory pressures are not always the result of national institutions, but sometimes supranational institutions applying to global industries such as aerospace. Regardless, regulatory pressures are powerful incentives to 
adapt practices which are not compliant. The main regulatory pressures faced by Aero Co. in transferring its practices to foreign subsidiaries were the need for FAA compliance in product design and testing, and technology export restrictions. The FAA regulations were globally enforced, while technology export restrictions were sometimes specific to individual countries. Product design practices thus stressed the technical dimension, as procedures would need to be rigorously defined and regulated. As would be expected under these conditions, adaptations to product design and testing practices were generally not permitted, as doing so would require seeking FAA approval. However, where practices were in conflict with local national regulations, they had to be adapted. For example, technology export restrictions were reported by a manager in Latin America as a primary reason for adapting practices transferred from the US:

A typical regulation that we all face at least in Latin America, and these are not our regulations, is how to manage the import-export of goods from the US. We must comply with those. For some US sites, it is a headache because we could say that it is easier to send a certain type of project within the US with a US supplier than sending that project here because of the border crossing.

In these cases, the conceptual dimension and the social dimension were unaffected by the regulatory pressures, but technical adaptations were required for compliance purposes. Regulatory pressures were also reported by Software in transferring practices to some sites in Europe. The source of these adaptation pressures were compliance with 'worker's counsel', or the unions which had established 
regulations to which any new practice would need to comply. As stated by one VP in the US who was a broker of practices:

I've done quite a bit with people in Germany and Austria and the issue we have there is that a lot of decisions that affect the workers have to go through worker's counsel. For example, you can't record calls. Many of the things that work in other countries don't work there because of the worker's counsel agreement. Or if they do, they sometimes take three to four months of review, and then you end up with that regionalized [adaptation]. You try to keep your constants but the variables are all over the playground.

At Software, these issues specifically affected not the conceptual dimension, but rather the social and technical dimensions. As some components of practices would not be acceptable because they involved tasks or activities which were not permitted under the worker's counsel agreements, they would have to be changed substantially, or the practice transfer would need to be abandoned. Hence, national and industry regulations prove to be powerful forces for adaptation for the social and technical dimensions of innovation practices, but not the cognitive dimension.

Proposition 6. Differences in national regulatory environments between innovation practice providers and recipients result in increases in adaptation to the social and technical dimension of transferred practices. 


\subsubsection{Normative Pressures}

Overall, there were limited examples of major changes to innovation practices, along any dimension, as a result of national cultural differences. However, this is most likely because at both Software and Telecom, there was not always a very strong requirement that a practice be adopted. At Aero, these pressures were much stronger, and tended to override normative pressures. Failure to comply with FAA regulations would render subsidiaries unable to contribute value to the MNE. In addition, organizational culture likely played a role in the extent to which communication between subsidiaries was hampered or improved. Given the professional nature of the functions represented in this research, it is likely that there were similarities across the subsidiaries with respect to engineering and software development practices, for example. These similarities may have produced an organizational culture which was somewhat more common amongst subsidiaries, thus reducing the effect of national cultural differences, where applicable. Nonetheless, cultural communication styles sometimes created difficulty in reaching understanding between the different subsidiaries:

The cultural differences between [Latin America and India] were definitely an obstacle in the beginning. People from India are used to saying yes at every single request, at every single question that I was asking them even though they disagreed with it.

(Engineering Manager, Aero Co., Latin America) 
These cultural differences did not apparently alter innovation practices substantially. However, this may be more a result of the overriding regulatory pressures presented by the FAA and national authorities. If there were greater latitude for adaptation of practices, they likely would have been less formally defined over their institutional history. If a dimension of innovation practices was expected to be affected by cultural differences, it would likely be the social, and to a lesser extent, the technical dimension. Indeed, this may be the reason why setting up research labs in foreign countries involves a substantial amount of learning and adaptation, as expressed by a VP at IT Services in India:

We have been thinking of setting up [a lab] in Latin America. There, the culture is very different. The same is true of China. The difficulty with that is that, while there is no shortage of bright people, it's how do we adapt to the culture, the environment, and come up with meaningful challenges, meaningful characters for each of these locations. So, some of the things that [we] perhaps talked about, is the amount of thinking that goes in before setting up the lab, rather than after setting up the lab, the timeframe, the gestation period, the processes that we have to go through.

Hence, cultural differences provide pressures for adaptation of innovation practices, especially with respect to the social and technical dimensions. Where these pressures exist, they will likely lead to greater levels of adaptation where opposing pressures are not greater. At Software, cultural differences were cited as a reason why it would often be difficult to complete a transfer. It is important to note that, due to the brokering role played by many who attempted to initiate transfer, there was not a 
requirement that the practice be adopted. Hence, if the potential recipient of the transfer was unconvinced, they could simply ignore the advice to adopt new innovation practices. Where this was most strongly evidenced was during practice brokering between the US and Japan, as stated by a VP in the US:

When they accept something, when they see there's a real true business value that works in their society, they will gobble it up and they'll be the best at it. They'll at least strive to be the best, but you have to really prove to them that this does have value, just because it comes from up above doesn't mean that they're going to go ahead and run with it, because what they're doing is usually working pretty well. They know their society better than everyone else, and it hasn't changed over the years. They'll say, "yes, I agree, thank you very much," get on the airplane, go home and they revert back to their old ways.

This failure to implement an initiated practice transfer can be attributed to recipients' unwillingness to internalize it. If the recipient does not internalize the practice, and there is no incentive to at least ceremonially adopt it, then practice does not transfer. Hence, adaptation pressures emanating from national cultural differences impact social and technical dimensions. Where potential recipients are unconvinced of the value of the cognitive dimension, the result is more likely to be a failure to adopt the innovation practice.

Proposition 7. National cultural differences between innovation practice providers and recipients result in increases in adaptations to the technical and social dimensions of transferred practices. 


\subsubsection{Organizational Pressures}

Organizational pressures impacting innovation practice transfer cited by respondents primarily involved the speed of the innovation cycle, and the structure of the organization, especially that of the innovation network. MNEs which operated in faster cycle industries, such as Software, acknowledged that when establishing a new subsidiary, it was difficult to transfer a standard set of innovation practices, as these were constantly evolving:

The development of technology is an intensely, quickly moving process. The way you develop technology now may be very different in two year's time, and setting up a lab can be a long term process in itself. By the time you set the lab up, the technology that you're using and developing on may well have changed itself. We quite regularly change how the developer's code, and the technology that they use. So you can't plan this year for something that's going to happen in 2013.

Given the nature of this industry, central administration of practices is required, but constantly challenged as technology and software development techniques change frequently. Hence, a degree of organic diffusion may be desirable, as it is more efficient. However, this may also lead to many adaptations of practices, and hence inconsistencies throughout the innovation network.

While the structural elements of integration and specialization were not specifically attributed as the cause of adaptations within each MNE, some evidence was nonetheless inferred. At Aero, for example, the degree of integration amongst 
subsidiaries is quite high, as each project is carried out at multiple sites. As evidenced by the fact that adaptations to the ERP system requested by Aero Latin America had to be reflected throughout the overall organization, this integration increased resistance to adaptations of the technical dimension of practices:

We were told by the SAP implementation team $90 \%$ of the system is standard, your $10 \%$ is going to fit your requirements. In some instances we went against the standard because it didn't fit the business requirements of the local unit and we had to justify to the implementation team. [They told us] this is going to impact the operations of all sites if we decide to go this way. In the end, the business case was approved and we did not follow the standards.

Telecom, according to one manager in the US, had become less centralized over time as it grew, and made many acquisitions. Efforts were being made to integrate different subsidiaries, but due to the acquisition strategy used, there remained a fair degree of separation amongst them. As a result, there were far fewer standard innovation practices as might be observed in Aero. This lack of integration made driving common practice challenging:

Definitely there are different ways of doing things. We are still a milliondollar start-up, so there's entrepreneurial ways of doing things all over the place, but we're trying to wrangle that in a little bit. (Senior Program Mgmt. Office Manager, Telecom Co., US) 
Likewise, although projects involved multiple sites at Software, the extent of integration amongst the different subsidiaries was limited by the software development process and federated structure. At Software, although the subsidiaries were not as integrated as those of Aero, major global changes in software development practices were driven by headquarters, which essentially transferred the conceptual aspect of this development paradigm, leaving details of the social and technical implementation up to each subsidiary. This offers further support for the negative relationship between integration and technical adaptation of innovation practices, and further suggests that integration is negatively related to adaptations of the social dimension of the practice:

It could become bottom up, but [an initiative like lean development] initiative has to come top down. If you want to do it around the world it definitely has to come top down, so that everybody in all the locations would sing from the same sheet. (Lab Head, Software Co., Canada)

Finally, at Telecom, ideas are shared in a competitive format. Different subsidiaries, which operate with a fair degree of autonomy and have limited shared history and context, propose different ways of doing things and the 'best' are chosen. However, as each idea is likely to be interpreted within the context of a particular subsidiary's mandate and history, the conceptual dimension is left open for interpretation. Hence, like the social and technical dimensions, the conceptual dimension of a practice is likely to be more highly adapted when subsidiaries are less integrated within the MNE 
network. This latter point is also consistent with the finding that conceptual adaptations are made very early during the transfer process (Yu and Zaheer, 2010).

Proposition 8. Integration between innovation practice providers and recipients result in lower levels of adaptation of the technical, social and conceptual dimension of transferred practices.

Although highly integrated, the subsidiaries at Aero are also somewhat specialized in that each has a particular area in which they focus their capability development. For example, flight controls are a specialty of the Eastern European unit while India is the primary test site outside of the US. However, the degree of specialization is not as high as in the case of the research labs of IT Services Co. which each have their unique "character" defined by the knowledge and venture capital resources in their location. This character is further made unique by the fact that they are often managed by an individual with a unique set of capabilities and expertise.

It appears that higher degrees of specialization limit the extent to which common innovation practices can be implemented across different subsidiaries. At IT services, the practices which are implemented tend to involve the operational and reporting aspects surrounding how a lab is run. These practices are negotiated by the technology board which includes the heads of each lab. Once the practices are transferred to the labs, there are substantial pressures for adaptation along technical and social lines. Hence, adaptations to the conceptual dimension of the practice occur prior to transfer, and due to 
high degrees of specialization in the labs, there is substantial adaptations made to the technical and social dimensions.

At Aero, limited specialization amongst different subsidiaries results in limited levels of adaptation to innovation practices. Hence, specialization tends to increase the extent to which the technical and social dimensions of each innovation practice are adapted, but may have no effect on the conceptual dimension. As alluded to earlier, once practice transfer has commenced, it is more likely that the technical and social dimensions will face adaptation pressures than the conceptual dimension. However, if a practice is designed to address a certain aspect of innovation, such as how the capabilities of each lab are assessed, then adaptations to the technical dimension can lead to difficulties in interpretation. Overall, the conceptual dimension of practices does not appear to come under adaptation pressure as a direct result of specialization.

Proposition 9.
Specialization between innovation practice providers and
recipients result in increases in adaptation to the technical and
social dimension of transferred practices.

\subsubsection{Subsidiary Pressures}

The majority of specific instances of adaptations made to innovation practices during transfer mentioned by respondents resulted from characteristics of the intended recipient subsidiary. This is expected, as it is the subsidiary which typically initiates adaptations. However, given the structure of the various MNEs, the extent to which 
adaptations are made is largely a function of the volition of the subsidiary to adopt the practice, and hence latitude to make adaptations. This in turn is evidenced by the modes of innovation practice diffusion predominantly found in each of the MNEs. With organic diffusion, subsidiaries have the greatest latitude to adapt practices while when centrally administered, there is an expectation that adoption will occur, and hence corporate or regional HQ will be more involved in monitoring implementation, and any adaptations made.

The fit of a practice to the local business requirements was cited by both Aero, as in the case of the ERP system mentioned in the previous system, as well as Software. At Software, there were two instances in which fit to local business requirements were mentioned by respondents. A lab manager in Canada was discussing the extent to which they adopt practices from subsidiaries in other geographic locations. The occasion for this was in the context of meetings of lab heads in which practices would be discussed:

If we feel that it's good for our location we work with whoever created [the practice] and say, "How did you do it?" And we roll it out in our location. So those are the types of best practices that we share. And the other thing you have to realize, for example, we have Brazil and Russia, the emerging countries and then we have the other established countries so we have different needs. But needless to say that there's some stuff that's being done in Brazil, India, or China that we take and vice versa.

Hence, if a particular innovation practice appears to fit the needs of the local business environment of subsidiaries at Software, there is greater likelihood it will be 
adopted. But due to the different needs, the subsidiaries have great latitude for making adaptations to that practice. The example above is an instance of organic diffusion. The effect of local business requirements on brokered practices was given by a VP in the US:

The value that standardized processes bring to the local areas is many times totally at odds with the value that is perceived from the global perspective. You have the global people looking at a particular process for lead handover and routing. And you have the local people looking at $i$, and it's totally disjointed because of the business situation on the ground as well as the requirement to produce a certain amount of revenue from particular sources.

Hence, while the initiator of practice transfers sees the apparent value of the practice, it is not so apparent from the perspective of the intended recipient. In both cases, the key factor is the cognitive dimension of the practice, from which it derives its value. Interestingly, this does not necessarily lead to lack of adoption in all cases, but in many cases it leads to adaptations through which the value intended by the practice sender is actually lost. The VP above referred to such instances as "phantom best practice' transfer, meaning that the practice was adopted but no value was realized.

Two adaptation attributions related to the evolution of the subsidiary were identified as resources and path dependencies. Due to the distributed nature of innovation practices, a variety of roles are ascribed to individual participants. In many cases, subsidiaries do not have adequate human resources to replicate all of these roles. Furthermore, given that many practice transfer attempts occur in the presence of already 
established practices, there is often a lack of fit experienced. As stated by a VP at Software in the US:

You think you want to adopt a particular practice, but in all practicality it's impossible, because you don't have the head count. You don't have the infrastructure. You don't have the training, the history, the culture, et cetera, so it's a phantom best practice. We weren't all built at the same time in mirror images of each other.

At IT Services, resources were also an impediment to transferring practices to overseas labs in the US and UK. The issue here was that the costs were much greater, and hence the labs employed only about a tenth of the employees that Indian labs did. The result is that the mandate of the foreign labs is different from the domestic labs, and hence there is different emphasis on different types of practices. As stated by one lab head in India:

The function of the overseas lab is sometimes a little different than the ones that we have in India in the sense that they're a little less volume in terms of research, just because of the cost issue, and a little more go to market, connect with customer, that kind of work. So there's a different balance of activities in those labs. But that's a conscious decision because setting up labs in the UK and the US has a cost issue and one can't have hundreds of people over there, so we have a smaller number of researchers.

The examples above suggest that transfer of practices to a subsidiary within a substantially different context can be unsuccessful. However, lack of resources actually 
inspired an adaptation to testing practices which provided substantial benefits at Aero. Hardware required for testing stage of components was often scarce in India, as products were sometimes delivered late. Shipping additional hardware test units from the US site would not improve the situation, as the length of time required to apply for a technology export license would exceed the time allotted to run the tests. Engineers in India suggested that hardware simulators be developed by their unit and used in place of the actual hardware. The US site had to be convinced of the merit of this endeavour, as it would require them to convince the FAA that the new test systems were compliant:

The U.S. and the India team worked together to develop a simulator and it was the U.S. team's responsibility to provide all of the documentation, and all of the execution data to FAA to make sure they are certified. Both teams realized that this would really be a major benefit for the subsequent programs because every person now has either a desktop or a laptop, and could run the test at their desk. (Engineering Manager, Aero Co., India)

Hence differences in resources can create an impediment to innovation practice transfer, and can lead to adaptations that may or may not add value to the subsidiary or MNE as a whole. The key difference illustrated in these cases is the active involvement of both the practice provider and recipient in adapting the practice in accordance with the actual resources available at the subsidiary. However, the overriding forces in the case of Aero were the need for compliance and the tight integration between subsidiaries and HQ. Hence, when a particular practice is adapted in order to fit the local resource and 
business environments of a subsidiary, technical and social adaptations will be made, but not cognitive adaptations. Where the resources or local business needs are inadequate to realize the value of the practice, it will be ceremonially adopted only.

Finally, the tenure and autonomy of subsidiaries played a role in the extent to which practices would be adapted. The most recent geographic regions in which MNEs have made substantial investments in competency creating subsidiaries is Asia. With regards to tenure, newer subsidiaries are either less able or less inclined to adapt practices. The cases of IT Services and Software provide contrasting evidence of this. At Software, adaptations were less tolerated by HQ in newer subsidiaries, as stated by one VP in the US:

By the time we got to Asia/Pacific, we had a pretty well buttoned up set of processes that were accepted across the board.

Overseas subsidiaries of IT Services were established in the context of the early stages of formalizing innovation practices amongst the Indian labs. Hence, although not nearly as tenured as other subsidiaries within the innovation network, they were still able to influence the development and implementation of these common practices. In order to preserve the cognitive, value-adding dimension of the practices, various labs were permitted to 'trial run' different practices so that their value could be determined. The 
CTO of IT Services explains the process of monitoring the establishment of labs as follows:

We give them time to actually get going. The formal review process might actually start 6 months or a year after the lab has been established so that they have time to get used to the framework. After that, by 3 to 6 months from now, they will have to at least start showing progress against the practices that they have not adopted yet. And then the process improvement suggestions start coming in from them as well. They say that "the global process is fine here, but this is where we have a problem". And then we adapt the process as appropriate.

The actual process through which adaptations are considered as to their appropriateness is explained by a lab head in India:

There's a group within the CTO organization which is responsible for taking feedback from everybody, and what they'll do is pilot more than one approach with the labs which propose them, maybe run that for a year, and then share the feedback at the technology board meetings regularly, which are quarterly actually, and at some point of time that feedback sharing session will get one lab saying "well it looks like what you're doing is better than what we're trying to do, so let's adopt yours."

Hence, adaptations to innovation practices are generally accepted in the short term, but are constantly evaluated. In essence, lab managers have to prove the value of the adaptations that they suggest against common metrics. Hence, just as in the case of the fit of practice to local business requirements and resources, the primary determinant for the acceptance of an adaptation is the perceived value, in accordance with the metrics used to evaluate the subsidiary. 
The above evidence also suggests that a subsidiary's tenure within the innovation network influences the extent to which adaptations will be made to practices. Autonomy of a subsidiary is partially a function of its tenure, but also of the integration of the MNE innovation network ${ }^{2}$. Telecom had altered its command structure from hierarchically controlled to more of an integrated network structure in order to try and hasten innovation, reduce the production of redundant technologies, and increase the extent to which practices were shared amongst its many acquired subsidiaries:

We've transitioned from a command and control type of organization into an organization that is still hierarchal in some ways, and still is somewhat siloed in terms of business units or into enterprise function. What we've done is we split the leadership into something called boards and councils. (Senior Program Mgmt. Office Manager, Telecom Co., US)

This less centralized structure essentially created more awareness amongst the subsidiaries as to what innovation practices were being used. Through this awareness, it then became possible to compare and select amongst practices. As with much of the evidence cited above, the perceived value of each practice is the primary criterion by which adaptations are made:

Sometimes we find the direction that we're taking others might not agree with, and then maybe there is a better way of doing it, of dealing with the overall scope and schedule of a project or cost for that matter, if there is a better way of doing things, if there is a new transformational way of

\footnotetext{
${ }^{2}$ Subsidiary power is a frequently cited influence on autonomy within the literature as well. However, it was not possible to directly disentangle these two variables from the data. Given the structure of each MNE included in this research, autonomy is correlated to the characteristics of the innovation network.
} 
solving the same problem they're trying to solve, then this is a workforce that's flexible enough to listen to that input and make changes if necessary.

(Senior Program Mgmt. Office Manager, Telecom Co., US)

At IT Services, research labs had originally worked independent of each other.

Hence different innovation practices had developed within each. It was only with the formation of an oversight board that the adoption of common practices became a priority, likely to aid that board in monitoring and comparing amongst subsidiaries:

For example, we didn't have this technology board organization until 2006. We had 4 or 5 research labs at that time that were operating fairly independently and then we formed an organization to essentially manage the process. Then the processes started getting established over time and obviously they evolved. At the present moment it's a fairly informal set. We are trying to make it more formalized, naturally there's resistance from researchers who don't like it to be that formalized. There are people who want to make it very formal, like a software development process. There are research teams and lab heads who, like myself, who say let's make it a bit more informal. So this give and take is there, at some point in time it evolves the practice, each lab will start doing this slightly differently, the best practices will get shared after a year or two, and we will evolve a common practice which seems to be an acceptable compromise to everybody. That's the way it evolves.

(Lab Head, IT Services, India)

Hence the autonomy of labs lead to the creation of informal practices at IT Services and, through the desire to promote common practices, a board was created to share knowledge and priorities, and negotiate the ultimate form of these practices. Although the overseas labs were more recently established than the others, they could 
participate in the evolution of these practices as their heads were also members of the recently established board. Both Software and IT Services provide evidence that the extent of adaptation of innovation practices is positively related to the tenure of the focal subsidiary within the MNE innovation network.

The evidence pertaining to subsidiary specific factors suggests that the degree of fit with subsidiary resources and path dependencies, local business requirements, and ultimately the tenure and autonomy of the subsidiary within the innovation network all increase the extent to which innovation practices will be adapted during transfer. The strong moderating effect is subsidiary autonomy as it affects the extent to which adaptation is tolerated. These adaptations will be made primarily to the social and technical dimensions of the practice, and less so to the cognitive dimension, as perceived usefulness implies acceptance of this dimension. The probability a practice will be adopted by a subsidiary is directly related to this perceived value in subsidiaries with greater autonomy. Hence, an attempt to adopt a practice which does not fit with subsidiary resources, history and local business requirements will more likely be ceremonial, and perhaps eventually discarded.

Proposition 10a. Differences in local business requirements, resources and path dependencies between practice provider and recipient enhance the extent to which adaptations are made to the social and technical dimensions of innovation practices. 
Proposition 10b. Subsidiary autonomy and tenure are positively related to increased adaptation of the social and technical dimensions of innovation practices.

Propositions 10c. Adoption of practices by a subsidiary which do not fit the local business requirements, resources or path dependencies within that subsidiary are more likely to be ceremonial, and eventually discarded.

\subsubsection{Practice Characteristics and Innovation Practice Adaptation}

Finally, the two characteristics of the innovation practice, the extent to which tacit knowledge must be developed and the level of institutionalization, were considered moderators of the relationship between national and organizational level factors. In addition the perceived value of the practice was found to be a major determinant of whether the practice would be adopted amongst subsidiaries in a more loosely coordinated network. The role that perceived value of the practice played in the decision to adopt it was articulated in the previous section on subsidiary-specific influences.

The degree of tacitness increases the extent to which innovation practices are adapted due to national or organizational differences between provider and recipient subsidiaries or business units. Conversely, the extent of adaptation when transferring innovation practices decreases as the practice becomes more institutionalized. This was evident from the Software VP's comment regarding the fact that practices were 'buttoned 
up' by the time they established some of the subsidiaries in the Asian region. More institutionalized practices likely have a more developed explicit characteristic, and are more deeply ingrained in the organizational context. Aero provides another clear example of highly institutionalized practices and how they are more easily transferred to and less adapted at each subsidiary. Conversely, practices at Telecom are more open to adaptation given that extent of institutionalization across the organization as a whole is limited.

Proposition 11a. Degree of tacitness of the innovation practice is positively associated with the extent to which all three dimensions of the practice will be adapted in response to organizational and national differences between provider and recipient subsidiary or business unit.

Proposition 11b. Stage of institutionalization of the innovation practice is negatively associated with the extent to which all three dimensions of the practice will be adapted in response to organizational and national differences between provider and recipient subsidiary or business unit such that pre-institutionalized practices are most susceptible to adaptation while fully institutionalized practices are the least. 


\subsection{Summary}

The purpose of this chapter was to develop theory regarding diffusion of innovation practices and to establish conditions under which adaptation is more likely or likely to be more extensive. Three modes of innovation practice diffusion were identified (central administration, brokering, and organic diffusion) and the conditions which may lead to their existence within the MNE were proposed. The importance of these three distinct modes of transfer is that they provide varying latitude to subsidiaries in making the decision to adopt practices, yet also allow the structural barriers amongst less integrated subsidiaries to be overcome. With regards to the forces for adaptation, it was proposed that national differences in regulatory, normative and cognitive environments, as well as the organizational factors of integration and specialization, promote adaptation of the conceptual, social and technical dimensions of practices to varying extents. In addition, several subsidiary-specific factors influencing adaptation were identified through analysis of data across the four MNEs. The tacitness and degree of institutionalization of the practice were proposed to moderate the relationships between higher level influences and the adaptation of innovation practices. Implications of these propositions are discussed in the following chapter. 


\section{Chapter 8: Discussion}

Transferring practices within the MNE allows for the exploitation of valuable, often strategic knowledge of the firm (Bartlett \& Ghoshal, 1997; Kogut, 1991; Kostova, 1999; Kostova and Roth, 2002). The results of this study further this notion, and reveal important linkages to capability development at the subsidiary level. Practice transfer improves coordination and efficiency within the MNE network (Kostova, 1999) and, according to the propositions developed in this research, plays an important role in strategy implementation. In this chapter, the theory developed in the previous chapter is discussed with a greater interpretation of the results in order to derive implications for managing the MNE innovation network. First, is considered the role that practice transfer plays in shaping the social context of the MNE in order to enhance knowledge sharing. This section advances the notion that mutual interdependency within the MNE network is a key mechanism underpinning the development communities of practice. In the following section, the identified processes of innovation practice diffusion are presented in further detail. Each is illustrated by the case data, and implications for the coordination of various forms of MNE innovation network, at various stages of evolution are derived. In the third section, implications of the adaptation and evolution of innovation practices are derived. Finally, emerging themes on micro-politics in the MNE innovation network, and their implications, are discussed in the context of the Aero case. While micro-political forces arising from internal competition can play both positive and 
negative roles in any organization, the case of Aero in particular highlights some potential difficulties MNE managers may face during the internationalization of innovation networks. While it is generally desirable that managers are motivated to develop the capabilities of their subsidiaries, having those attempts blocked can lead to 'impatience'. Impatience, in turn, can create pressures on the subsidiary to seek alternate sources of knowledge.

\subsection{The Shared Context of the MNE and Knowledge Integration}

Tacit knowledge is not simply transferred from one individual to another, but must be learned and acquired as subsidiaries develop the capabilities required to contribute to the MNE innovation network. Yet, as proposed in this research, tacit knowledge is developed through subsidiaries' motivation to use organizational knowledge, especially as it is directly applied to a practical application. While these knowledge dynamics (Nonaka et al, 2000) enhance the rate and effectiveness with which a subsidiary develops the requisite tacit knowledge to participate in the MNE innovation network, these conditions are further enhanced by creation of shared context.

Shared context refers to commonalities in contextual interpretations amongst potential innovation practice providers and recipients, and enables capability acquisition through the development of tacit organizational knowledge to use practices for the purposes they were intended. Shared context furthermore enhances the efficiency and effectiveness of knowledge transfer, but is developed in conjunction with the practice transfer process, as the more tacit components of practice are developed by recipient 
subsidiaries, or negotiated amongst practice sharing subsidiaries. Hence, shared context and practice transfer are mutually reinforcing.

Shared context facilitates the transfer of knowledge through the development of common metrics and the use of interactive communication technology (ICT), which enables both the push and pull of organizational knowledge (Pedersen, Petersen and Sharma, 2003). The use of common metrics amongst different subsidiaries within the MNE innovation network provides necessary incentives for subsidiaries to develop their capabilities in accordance with peers within the MNE innovation network. ICT provides a common platform different subsidiaries can use to interact, share ideas and obtain organizational knowledge. The propositions developed in Chapter 6 are summarized in Figure 8 .

Figure 8: The role of practice transfer in subsidiary capability development.

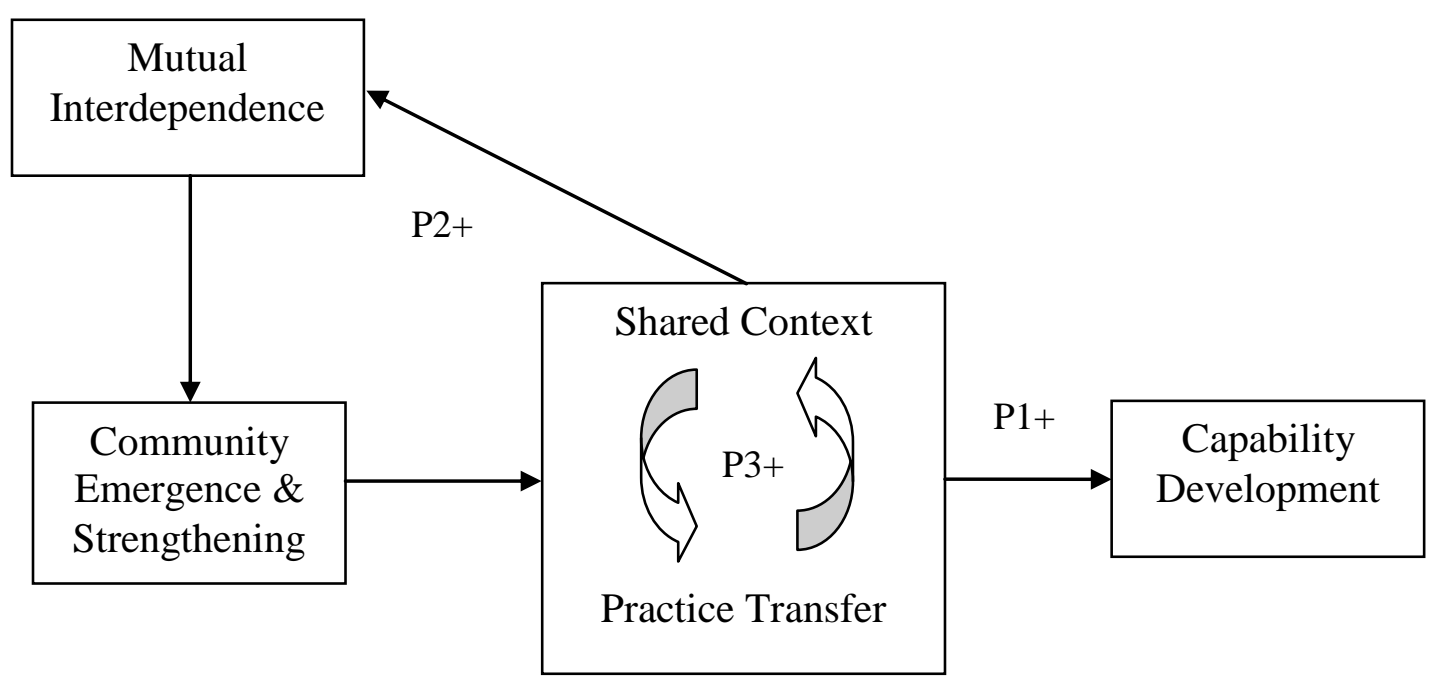


In order to develop capabilities, subsidiaries require organizational knowledge. Using common metrics enhances the motivational aspect of absorptive capacity, as metrics provide a signal as to the value of knowledge for a subsidiary (Cohen and Levinthal, 1990; Minbaeva et al, 2003). Finally, ICT also aids in knowledge transfer by increasing the availability of knowledge, but perhaps more importantly by allowing knowledge to be sourced as it is required in practical application. For example, IT Services used an internal website to share knowledge amongst different labs. They adapted this ICT so that formal practices identified as 'best' within the innovation network would be readily identifiable and most easily noticed by users of the database.

Shared context aids in developing subsidiary innovation capabilities, and is enhanced if communities of practice emerge. The community of practice perspective suggests that innovation is enhanced by a sense of belonging by its members which provides the necessary sharing and integration of knowledge resources (Brown and Duguid, 1991; Lave and Wenger, 1991). Brown and Duguid (1991) suggest that managers can play a role in the formation and shaping of communities of practice, while others have suggested that hierarchical control can diminish the effectiveness of these communities by undermining the environmental conditions that provide the sense of belonging that underpins the functioning of the community (Hislop, 2003; Lee and Williams, 2007; Orr, 1990, 1996).

International innovation practice transfer requires transfer of codified knowledge, in the form of operational procedures, as well as the development of tacit knowledge by 
the recipient subsidiary in order to be successful. Empirical research has suggested that hierarchical involvement in knowledge transfer process diminishes its efficiency and effectiveness (Ciabuschi et al, 2011, Yamin, Tsai and Holm, 2011). The case data revealed some evidence which helps resolve this apparent conflict between the notions that hierarchical control can both enhance and diminish the functioning of communities of practice and knowledge sharing within them. By indirectly being involved in innovation practice transfer, by creating conditions which enhance mutual dependency amongst subsidiaries, the motivation for sharing knowledge increases, goals are aligned, and hence capabilities are developed more readily within subsidiaries.

As a counterpoint to the characterization of a community of practice, in this instance arising from the integration of subsidiaries within the MNE innovation network, significant barriers to knowledge transfer remain. In the Aero case, these barriers included intercultural communication impediments, motivation to withhold unique knowledge, and internal competition within the MNE network. At Software, subsidiaries unable to perceive the value of innovation practices were less likely to even attempt to adopt them. Intercultural communication impediments diminish understanding between culturally dissimilar subsidiaries, thus reducing the ability to transfer knowledge effectively. Also, where an innovation practice provider has little interest in the outcome of the process, they may be less available to assist the recipient subsidiary during the process of implementation as problems are encountered. Finally, competition between subsidiaries for enhanced mandates can potentially reduce the sense of belonging and 
trust which underpin the functioning of communities of practice. While according to KBT the organization is superior to the market with respect to knowledge sharing and integration, not all organizations are equal in that respect. As a result, variance in the rate of learning and its associated performance outcomes amongst organizations will exist. In essence, knowledge may transfer and be more easily integrated within communities of practice, but variation in the extent to which these positive benefits are realized will persist.

As proposed in Chapter 6, the creation of mutual interdependence can mitigate these consequences by overcoming impediments to knowledge transfer which in turn diminish the theoretical returns from lateral coordination. Mutual interdependency refers to the requirement that subsidiaries coordinate their efforts in order to complete innovation projects in a timely and effective manner. The community of practice perspective suggests that these mutual interdependencies amongst members will arise as communities form, along with the associated increase in trust and sense of belonging. However, especially in the case of MNE innovation networks, the creation of mutual interdependence should occur within close temporal proximity to the transfer of practices. Hence, hierarchical control is valuable in establishing these mutual interdependencies by establishing the design of workflow within the MNE innovation network. This was achieved at Aero by providing the new foreign subsidiaries with mandates to participate in global design teams, originally mentored by engineers in the US. Hence, subsidiaries were motivated to enhance their capabilities by seeking knowledge from their US 
counterparts, and engineers in the US were inclined to assist those subsidiaries in order to ensure projects were completed on time, and in compliance with FAA regulations.

Thus, while communities of practice are useful for integrating knowledge resources, it is the existence of mutual interdependencies which underpin the emergence of the community social structure, amongst previously isolated entities within the broader network. These mutual interdependencies may arise as a result of ambiguities in the technical and social dimensions of practice, but membership of newer subsidiaries within the innovation network will be impeded by established communities of practice (Hislop, 2003). Hence, by creating mutual interdependence through, for example, the establishment of integrated global teams and product mandates, hierarchical control can create this necessary precondition to community formation. In essence, mutual interdependency enhances the diffusive capacity of subsidiary practice donors, primarily through the creation of incentives which influence individual behaviour.

This section discussed the mutually reinforcing nature of innovation practice transfer and the creation of shared context amongst subsidiaries within the MNE innovation network, which in turn influences subsidiary capability development. This discussion highlights the role that intra-MNE environmental conditions enhance capability development. Further to this, it was proposed that mutual interdependency is a highly influential precondition for the emergence of communities of practice, which in turn enhance the development of shared context and knowledge flow between subsidiaries. This implies that hierarchical control is valuable in setting up the initial 
conditions which reduce impediments to knowledge flow, namely through the establishment of mutual interdependence within the innovation network.

\subsection{Modes of Diffusion and Innovation Network Characteristics}

Prior research on practice transfer has primarily been conducted in the context of HQ initiatives (e.g. Jensen and Szulanski, 2004; Kostova and Roth, 2002). However, the data analyzed in this research revealed other processes through which innovation practices diffuse amongst subsidiaries without formal HQ involvement, and often on an ad hoc or opportunistic basis. When innovation practices diffused through brokering, present in all instances in the case data, there was no formal requirement that subsidiaries adopt the practice. As stated by a VP at Software: "[subsidiaries] may, at their discretion, choose to adopt those best practices and that knowledge transfers over to them." Organic diffusion of innovation does not involve an intermediary, but happens sporadically as different subsidiaries communicate, identify practices, and consider adopting them. Again there is no requirement that each subsidiary actually adopt the practices. They will do so only if individuals predict valuable outcomes.

Figure 9 illustrates the processes of central administration, brokering and organic diffusion of innovation practices. The necessary precondition for any transfer is either corporate or regional HQ initiative or, in both brokering and organic diffusion, the existence of heterogeneous innovation practices within the MNE innovation network. Central administration of practices bypasses inter-subsidiary communication by centralizing communication and incentives for adoption. This mode of diffusion 
represents the majority of innovation practice transfer at Aero where HQ mandated engineers in the US to share with subsidiaries in order to enable diffusion of a common set of compliant practices and capabilities. This does not imply that inter-subsidiary communication didn't exist, but that it was not a precondition for diffusion. Instead, inter-subsidiary communication was enabled subsequent to innovation practice sharing.

Figure 9: Processes of diffusion of innovation practices amongst subsidiaries.

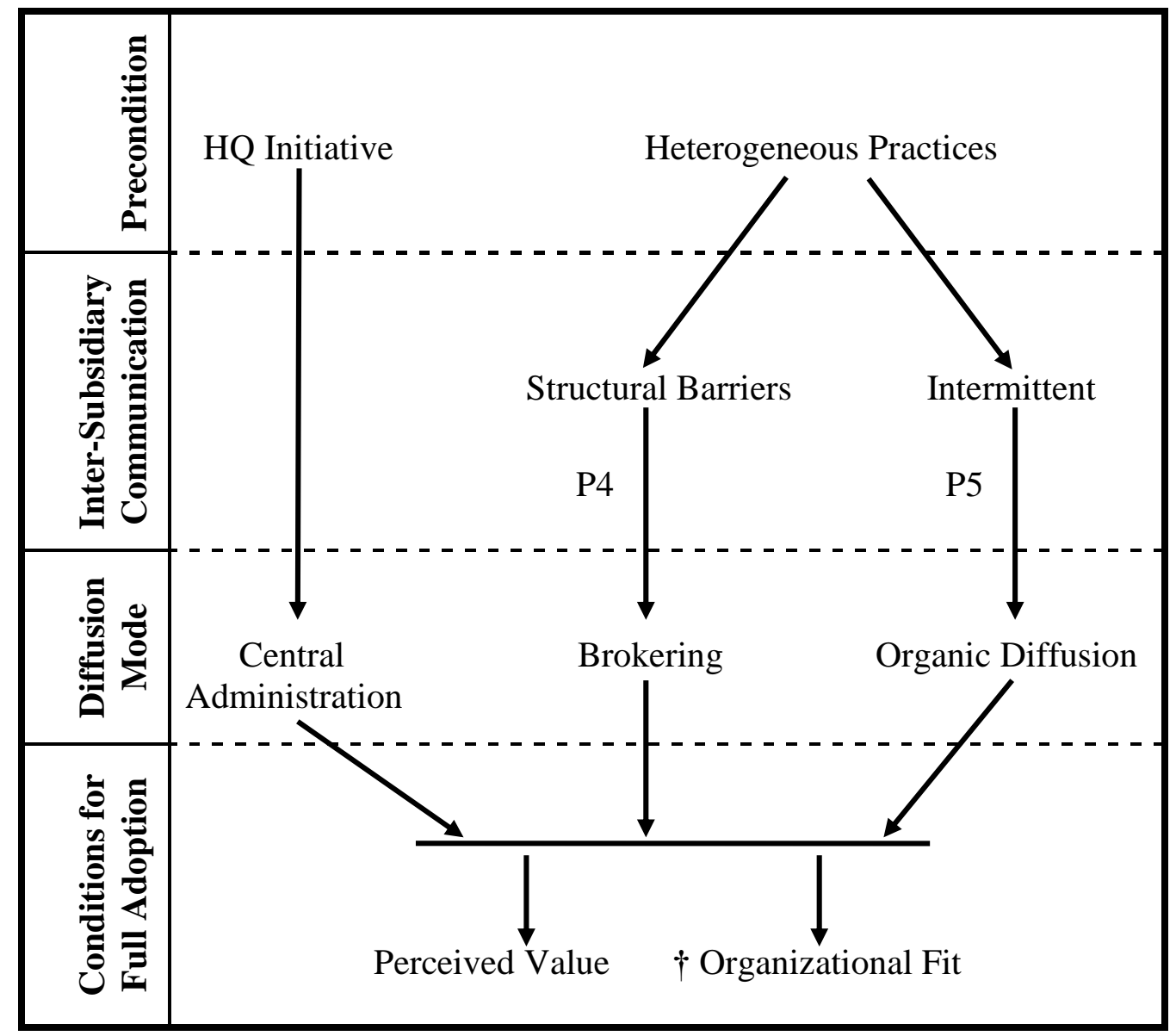

$\dagger$ Business requirements, resources, and path dependencies. 
Unlike Aero, at IT Services inter-subsidiary communication was first structured through the formation of a board comprised of lab heads and upper managers, in order to establish and diffuse a common set of practices amongst dispersed subsidiaries. The key difference between IT Services and Software, with respect to central administration of practices, is the relative tenures of subsidiaries within the innovation network, and hence the extent of their capability development. However, the evolutionary path may be similar. As IT Services develops and establishes common practices throughout labs, future initiatives may be lead by HQ, with involvement of the technology board.

The loosely federated structure of Software creates structural barriers to communication amongst subsidiaries. However, intermediaries can act as innovation practice brokers by identifying valuable practices in one subsidiary, and attempting to initiate transfer to another. A VP at Software referred to these brokers as the "give a damn people". Also at Software, meetings of lab heads created intermittent opportunities to share innovation practices, without the involvement of an intermediary, creating organic diffusion where potential adopters saw fit.

Finally, at Telecom, frequent acquisitions made in order to gain access to new technologies, and the capabilities which had developed them, created forces acting against coordination and integration amongst dispersed subsidiaries within the innovation network. The resulting structure created a context in which managers of a focal subsidiary were often unable to detect the patterns of innovation practice flow. As stated by one manager in the US: "there really isn't a concept anymore of coming from one 
place and going to another. It's a cross platform sharing of ideas and best practices". While various measures had been introduced to increase integration, such as the boards and councils and idea sharing supported by information technology, the most salient mode of innovation practice diffusion remained organic.

In all cases, the perceived value of innovation practices, their fit to subsidiary business requirements, path dependencies and resources were all important factors limiting the extent of adoption. Centrally administered practices were accompanied by a heightened expectation that subsidiaries would adopt them, and hence it was more likely that HQ could play a role in adapting innovation practices to subsidiary-specific factors, and could provide additional resources as warranted. As HQ was only indirectly involved in brokering practices, and not at all in organic diffusion, subsidiaries would often simply choose not to adopt innovation practices, where there was little or no perceived value, or to adapt them in the presence of subsidiary-specific factors which limited their fit. In the latter case, the innovation practices were ceremonially adopted, and may eventually have been discarded.

The various modes of innovation practice diffusion have implications for coordination and integration within MNE innovation networks. While all of these MNEs have potential to realize the value of the transnational perspective on MNE strategy and structure, their evolutionary paths can create forces against the formation of a tightly integrated network. At Aero, the network remains tightly coordinated at this time, although there is already evidence that micro-political dynamics amongst subsidiaries 
will become more difficult to manage in the future. These dynamics are detailed in the final section of this chapter. In more loosely federated structures, such as Telecom and Software, HQ has a role to play in innovation practice transfer, even when it is occurring between subsidiaries. Brokers can be used to diffuse innovation practices, but if their attempts are not accompanied by an expectation that the subsidiary will adopt, then some efforts will not effect change. Hence, it is important that brokers adequately understand the subsidiary specific factors which lead to the creation of practices in one subsidiary, and the factors which create barriers to adoption in potential recipient subsidiaries. In addition, in order for adoption to occur, subsidiary managers need to perceive the value of the practices. Therefore, the extent to which these innovation practices help to improve performance, according to the metrics against which the subsidiary is evaluated, must be made clear. In some cases, this may involve creating new metrics, in others it means adapting the practices so that they address existing metrics. For Aero this is easier, as failure to achieve compliance results in negative value creation by a focal subsidiary. For Software this is more difficult because the federated structure is a result of a perceived need for subsidiary autonomy to address local business needs.

Finally, organic diffusion is an efficient mode of innovation practice sharing, but there is always the risk that what gets shared is not consistent with the MNE's overall strategy. Again, metrics can play an important coordinating role. If subsidiaries are evaluated according to similar metrics, then innovation practices are more likely to fit a focal subsidiary's needs and resources. Where corporate or regional headquarters 
endorses and monitors common sets of metrics for each subsidiary within the innovation network, practices more readily flow to those subsidiaries that can extract value from them.

\subsection{Adaptation and the Evolution of Innovation Practices}

Following $\mathrm{Yu}$ and Zaheer (2010), the adaptation of practices was examined with regard to their three dimensions. The technical dimension consists of the various processes and techniques associated with it, the social dimension is concerned with the allocation of roles and responsibilities amongst individuals engaged in the practice, and the conceptual dimension is concerned with the overall purpose of the practice. While these authors were concerned with the order of adaptation of the three dimensions during the process of practice transfer, this research builds upon this by proposing the manner in which different institutional differences, subsidiary mandate characteristics and the nature of the practice influence the extent to which adaptation pressures are likely to be present. Figure 10 summarizes the propositions related to practice adaptation developed in the previous chapter. In this section, some of the implications of these propositions are discussed.

The technical dimension of practices is relevant for innovation in that it specifies the extent to which different members of a MNE innovation network are following similar processes. The social dimension is important for the integration of knowledge assets required for innovation. Adaptations to the social dimension are not necessarily detrimental to the operation of a community of practice, but can impede coordination 
amongst different subsidiaries if these differences are not understood. Finally, the conceptual dimension is typically the first component to be adapted during practice transfer ( $\mathrm{Yu}$ and Zaheer, 2010), and hence it is important that implications of the adaptation be fully understood before further steps in the transfer process are taken. For example, in the case of Aero, conceptual adaptations were not tolerated, due to the regulatory compliance requirements in the aerospace industry.

Figure 10: Adaptation pressures on innovation practices.

Institutional Differences

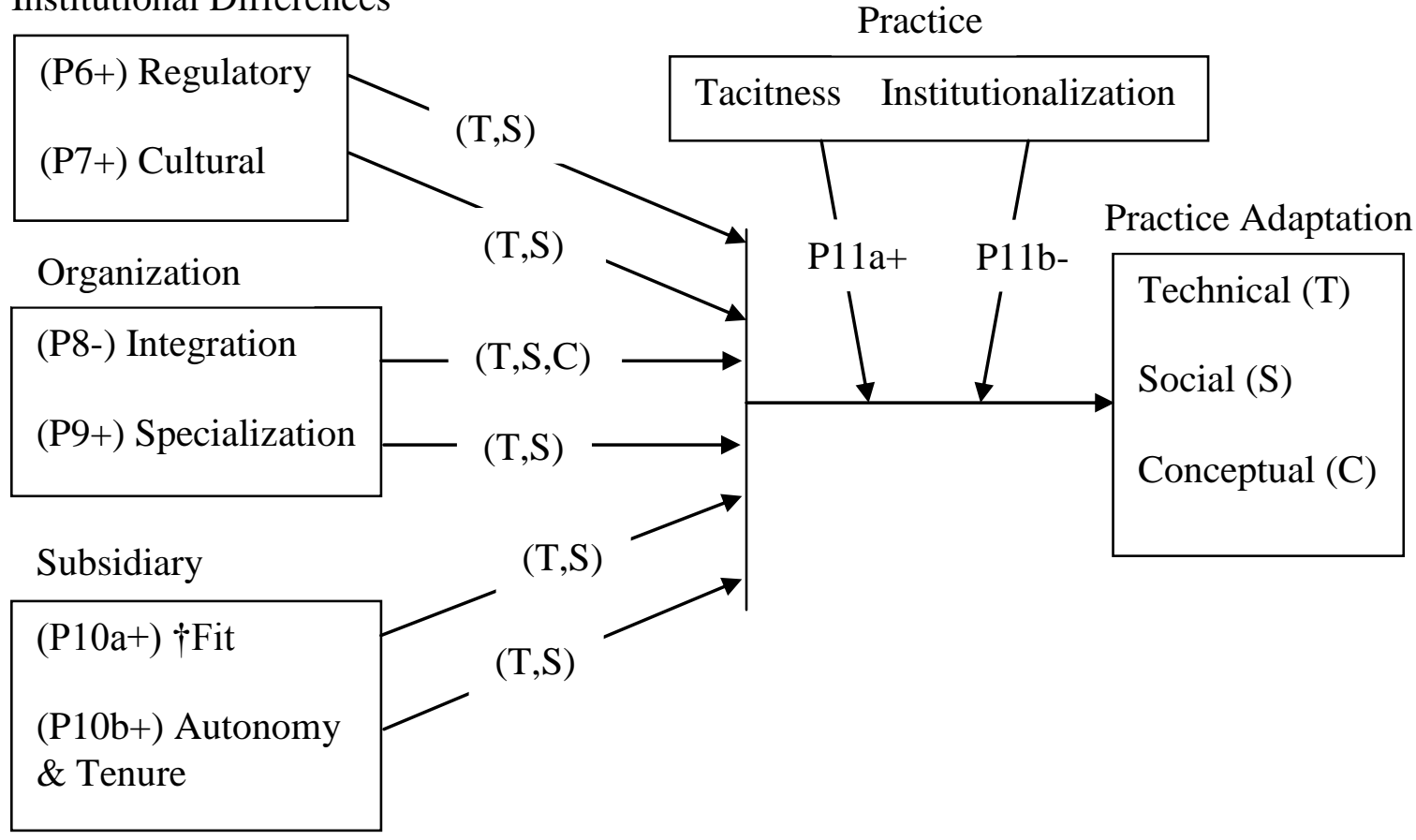

$\dagger$ Business requirements, resources and path dependencies. 
With regards to adaptation to the conceptual dimension of innovation practices, only the integration of a subsidiary within its innovation network is proposed to produce the greatest adaptation pressures. Recalling that practices are a result of contextually bound institutionalization pressures, their perceived importance and relevance within another nation may be lessened. Within less integrated innovation networks such as Telecom, different subsidiaries may become aware of innovation practices within the MNE network, but do not have the historical context within which they were created. Hence, prior to implementation, the practice can take on a new conceptual dimension as the recipient subsidiary reinterprets it and gives it new meaning.

As mentioned in the previous chapter, conceptual adaptations are typically less desirable as success would be difficult to determine, and coordination and integration amongst different units within the MNE innovation network would be difficult to achieve. As evidenced in the Software case, where the initiation of practice transfers to Japanese business units were initially ignored, cognitive differences between the provider and recipient can result in a failure to begin the transfer process. In situations where integration of subsidiaries is not the goal of practice transfer, or when adoption is not initiated and monitored by headquarters, such adaptations may provide substantial benefits to the adopting business (e.g. Yu and Zaheer, 2010).

With regards to the social dimension of innovation practices, the most substantial adaptation pressures are proposed to result from differences in both the regulatory and cultural environments. As evidenced in the case data, the work processes of subsidiaries 
are influenced by cultural differences with regard to the assignment of roles and responsibilities. While these differences may slow down the transfer process, as individual roles and processes are negotiated, it should not prevent adoption. Practices may need to be adapted to the management style and monitoring systems inherent in a particular national context, but these changes will be easier to achieve than changes in the organization itself. Consistent with Yu and Zaheer (2010), social and technical changes will tend to cascade, in that changes in one dimension produce inconsistencies in the other dimension. While this creates forces for dialectical change which would impede the process, it does not greatly inhibit the transfer of practices as in the case of pressures for changing the conceptual dimension. In terms of improving the transfer process, those initiating transfer should expect these differences and be prepared for them. As discussed in the preceding section, creating conditions of mutual interdependency prior attempting practice transfer will motivate both provider and recipient subsidiary and business units to negotiate the social and technical dimensions of innovation practices. Adaptation to the practices at the recipient subsidiary need not be reflected in all units in most cases. In cases where adaptations do need to be reflected more globally, as in the Latin American subsidiary of Aero, there will likely be more resistance, and the subsidiary initiating the adaptations will likely need to take a greater role in establishing them.

Adaptations to the technical dimension of innovation practices are also proposed to be influenced by regulatory and normative pressures. Technical changes are presumed to be least substantial in terms of magnitude and scope. Adaptation pressures on the 
technical dimension would not likely affect the conceptual dimension of a practice, although they will most often be mutually influential with adaptations to the social dimension. As a result, these two impede the transfer process, but mainly in a manner which influences only the recipient subsidiary. In the Software case, such adaptations are likely as centrally administered innovation practices were initiated by headquarters, but finally implemented locally. Hence, it was more important to establish the conceptual dimension of the practice than to ultimately dictate the implementation of the technical dimension. Conversely, adaptations to the technical dimension of practices were met with greater resistance at Aero, largely as a result of the late stage of institutionalization of the practices and the high integration amongst subsidiaries.

By definition, highly integrated subsidiaries more readily share knowledge and function with greater mutual interdependence. Adaptations of practices amongst these integrated networks can follow both teleological and dialectical processes. Dialectical processes of adaptation result in mutual adjustment between subsidiaries in which incompatibility between existing practices creates coordination difficulties. Teleological change processes can occur when practices do not exist within a particular subsidiary and can be driven by either the recipient or provider. In both cases, the level of integration within the MNE innovation network will be enhanced under the precondition of mutual interdependency and lead to less adaptation of practices. Less integrated subsidiaries are less likely to exchange practices and more likely to adapt any that are adopted because the dialectical pressures which lead to negotiation are not present. Conversely, highly 
specialized subsidiaries are more likely to adapt practices, as the function they provide within the MNE innovation network is more unique. Subsidiary specialization entails differences in work practices, and fewer interfaces with other subsidiaries. As a result, the value that new innovation practices provide to the specialized subsidiary is not directly comparable to other subsidiaries within the network, and thus may be adapted in accordance with performance metrics.

In Software and Telecom, there was less of an expectation that subsidiaries must adopt innovation practices from other subsidiaries either directly, or through an intermediary. Hence, subsidiaries first considered the potential value of adopting the practice, and where it was not clear that it would provide benefits, given local business requirements, it would simply choose not to adopt. Where there was perceived value, lack of fit of the innovation practice to local business requirements, resources and the development path of the subsidiary impeded the implementation, leading to adaptation of the social and technical dimensions. In some cases as reported by the VP of Software, this lead to ceremonial adoption in which the benefits of the innovation practice were not obtained.

Finally, the level of tacit knowledge present in an innovation practice increases the extent to which institutional and organizational differences create pressure for change. A greater level of tacitness creates more difficulty for subsidiaries attempting to implement practices, as this requires greater interaction with the practice provider, and decreases the temporal proximity between accessing and applying knowledge. Stage of 
institutionalization of a practice is proposed to decrease adaptation pressures in that less institutionalized practices are more open to adaptation. This is partly because less institutionalized practices are less codified, and hence likely contain more tacit knowledge, but also because the social resistance towards adaptation is greater. Clearly, practices at Aero, for example, were highly institutionalized, and highly codified. At Telecom, the strategy of acquiring and integrating firms necessarily lead to differences in practices, which may have been highly institutionalized within one subsidiary but much less so at the level of the overall MNE innovation network. In the former case, pressures against adaptation would be greater and practice transfer would be less impeded. In the latter case, that pressure would be higher as subsidiaries became more integrated. In both cases, creating conditions of mutual interdependency amongst subsidiaries would ease the transfer of practices.

To this point, the discussion on innovation practice transfer has been consistent with KBT in that adaptation is considered an impediment to practice adoption. However, adaptation can be desirable as better ways of doing things may be discovered in the process. Largely, the extent to which adaptations will be desirable depends on the level of innovation the MNE wishes to encourage. In both the Aero and Software cases, the strategic focus was on more incremental innovation while Telecom and IT Services focused on both incremental and more breakthrough levels of innovation. While, all things equal, adaptation creates more friction and slows the process of practice transfer, the extent to which it does so is reduced through the creation of mutual interdependency 
within the MNE innovation network which hastens the emergence of communities of practice, which in turn enhances knowledge sharing through the creation of shared context. Hence, whether adaptation is desired or not, these conditions improve the practice transfer process in general.

\subsection{Subsidiary Impatience and Institutional Duality}

The difficulty of coordinating and controlling internationally dispersed networks of subsidiaries has long been considered a key challenge for MNE managers, and a topic of interest amongst researchers (Andersson et al, 2007; Doz and Prahalad, 1981; Ghoshal and Bartlett, 1990). In this thesis, the role of innovation practice transfer has been highlighted as a mechanism for increasing shared context, and thus knowledge transfer. In addition, the importance of performance metrics has been stressed here, in providing signals to subsidiaries in terms of the value of adopting innovation practices either through direct, indirect, or no involvement at all of HQ. Distributed power amongst subsidiaries in the MNE network can create competition for enhanced mandates, and a desire for independence (Asakawa, 2001; Birkinshaw and Hood, 1998). Subsidiaries may also use their power for engaging in undesirable behaviour from the HQ perspective, such as rent-seeking (Mudambi and Navarro, 2004). The micro-politics of competition amongst subsidiaries can therefore be used to enhance efficiency, but can also result in value-destroying behaviours.

The extent to which micro-political behaviour was reported amongst the subsidiaries in this research was fairly limited. However, this can at least partially be 
explained by the effect of social desirability bias. A lab head at Software in Canada was asked whether competition existed amongst subsidiaries for enhanced mandates. This was confirmed. However, this manager also denied that such competition impeded knowledge transfer, as illustrated by this exchange:

Interviewer: Does the fact that you're essentially in competition with other labs ever get in the way of sharing practices and knowledge?

Lab Head: I would say, I've been here four years, I would say no, because there's a location strategy and there are certain guidelines. I have critical mass. You have 85, 90, 100, 120 people in one line of business, that's critical mass.

Competition amongst labs is therefore partially based on resources and location, and the advantages they provide. Of course, if a lab did not have 'critical mass' in terms of capabilities and resources, it follows that it would be more inclined to compete directly for enhanced mandates, and the resources required to fulfill them. In the case of Aero, the subsidiaries located in the emerging market regions did not have critical mass given their limited tenure within the innovation network. Most of the subsidiaries had only been in operation for about six years, and the capabilities in the US HQ had been developed over a period of decades.

Aero is an example of a firm in a very mature industry, which has only recently engaged in a more aggressive international expansion into emerging market regions where growth in defence spending is high. The institutional pressures faced by Aero 
necessitated tight control, and thus learning by subsidiaries was monitored carefully before enhanced mandates were granted:

We drive the same process across all the network and do not make exceptions in order to do something faster, because having someone learn something faster, but not learning it the right way so that it's compliant is not acceptable.

(VP, Aero, US)

As discussed previously, the subsidiary manager at Aero in Eastern Europe expressed a degree of impatience with regard to gaining enhanced mandates. Impatience, as it is used here, can be construed as a reaction by subsidiary managers when their mandate is enhanced more slowly than their perception of the development of the subsidiary's capabilities. Where a subsidiary's pursuit of an enhanced mandate is impeded, managers may bargain more aggressively. While none of the emerging market subsidiary managers would acknowledge the existence of internal competition, a senior engineer from the US who had been involved in ramping up the capabilities of the labs stated otherwise:

Between the three of them (Eastern Europe, China, India), each country feels they should be getting all the work and we should be doing all the work in their country. They ask: "Why are we doing so much in India? We could be doing this in Eastern Europe". The Eastern European subsidiary resents that their senior leadership is all in India.

Hence, there are substantial discrepancies between the accounts given by the emerging market subsidiary managers, and the engineer in the US who frequently worked 
with them. The evidence suggests that internal competition is more strongly present in the initial stages of subsidiary competence development. In addition, this manager provided evidence of the institutional duality Aero encountered in expanding into China. A state-owned aircraft manufacturer in China had recently decided to undertake the design of an aircraft, and had contracted Aero to produce some of the components. According to the US engineer:

We got a specification from [China] for the APU, for the Auxillary Power Unit which is where they put the air power management system. We recognized this specification. It was like they got it from somebody else and they tried to market it off. And I don't know which air framer they got it from, but they got it from a US air framer.

Although aerospace was a mature industry, it is still relatively new to China, and the state-owned company was also apparently impatient to enhance its capabilities in aircraft design. The Chinese subsidiary was thus established in the context of competing institutional settings. The first of these was the institutional environment of Aero, which had learned over decades to design in accordance with FAA regulations, and the local context in which these regulations were not as established. The extent to which Aero's subsidiary in China was affected by this institutional duality was not discussed by any of the respondents, but clearly it indicates a challenge for MNEs in technologically advanced, mature, and highly institutionalized industries in expanding internationally. Inflexibility in the implementation of practices reduces learning opportunities (Petersen 
and Pedersen, 2002). Substantial learning is required in order for the MNE to both access the local market, and maintain its legitimacy in the industry.

\subsection{Summary}

Innovation practice transfer is an important part of building subsidiary competency within the MNE innovation network. This chapter discussed the role of shared context in easing knowledge flow and how the transfer of innovation practices can begin this process. Here, creating initial conditions of mutual interdependency was also posited to be a highly beneficial precondition to the formation of communities of practice which in turn increase the extent to which that context is shared. This links notions from the community of practice perspective to KBT in that it clarifies the role of headquarters in aiding the emergence of communities. Three modes of innovation practice diffusion were also discussed. The extent to which each of these is present in the MNE innovation network depends upon the administrative heritage (Bartlett and Beamish, 2011), and the stages of internationalization. Hence, it is important to consider innovation practice transfer in the context of industry and organizational characteristics.

This chapter also presented a discussion on the extent to which institutional differences, MNE innovation network and subsidiary-specific factors, and the tacitness and stage of institutionalization of innovation practices create adaptation pressures on the various dimensions of each practice. Finally, in examining the evidence on micropolitical forces within the MNE, it was suggested that these forces decline as subsidiaries gain enhanced mandates, that newly tenured subsidiaries may be impatient to prove their 
capabilities, and that institutional duality may provide a more difficult environment for internationalization within mature, highly regulated industries.

\section{Chapter 9: Conclusion}

This chapter provides a summary and conclusion of this thesis. The contributions to practice transfer research, KBT, and the internationalization of innovation are first presented. Following this is a discussion of future avenues for research which are suggested by the findings of this thesis. Limitations to the present research are discussed next, followed by proposed implications for management practice. Finally, a conclusion to this thesis is provided.

\subsection{Contributions}

This thesis was undertaken to contribute to a growing field of research on how firms coordinate the innovation activities of foreign affiliates (Zander, 1997) through an examination of the transfer and evolution of innovation practices. The initial stance, as depicted in Figure 4 of Chapter 3, was that knowledge is embodied in routines, which form the practices by which organizations create value. However, with respect to creating new value, something must change within this process, and individuals in the organization are sometimes motivated to do so (Anand et al, 2007). Indeed, it was found that it is only through human agency that such changes are first initiated, and then institutionalized within the firm. The extent to which those changes are guided towards 
value creation is dependent upon the socializing forces of collectives which are present outside as well as inside organizations.

This thesis contributes to both KBT and institutional theory by examining the processes of practice transfer and adaptation, their contribution to subsidiary innovation capability development, and the factors influencing those processes. The study also provides bridging mechanisms between the two theories by examining how national institutional factors influence capability development in the subsidiaries of a MNE. The case of Aero, for example, illustrated that the creation of geographically distributed mentoring structures in which subsidiaries developed the highly institutionalized innovation practices of the parent company in the US. The MNE can therefore act as an efficient mechanism through which even highly institutionalized capabilities can be transferred effectively. In cases such as Software and Telecom, where the innovation network is more loosely federated, the flow of potentially valuable innovation practices is influenced by institutionalized relationships amongst subsidiaries and performance metrics.

The majority of research in this vein has examined national institutional influences at a macro level of analysis, suggesting that they complicate the practice transfer process (e.g. Jensen and Szulanski, 2004; Kostova and Roth, 2002). The research design allowed a closer analysis of these phenomena in order to examine the extent to which institutional differences, organizational factors and practice characteristics create forces in favour and against adaptation of various practice 
dimensions. Adaptation may not merely be a necessary by-product of mandating foreign subsidiaries to innovate (Jensen and Szulanski, 2004). Adaptation provides the MNE with an opportunity to renew and replace routines, as the transfer process is part of the path dependent development of capabilities.

The research contained within this thesis was undertaken in order to extend the general literature into the context of cross border innovation practice transfer. This setting is unique in that the types of organizations included all follow a strategy of producing new value through innovation in an international setting. Prior work on the cross border transfer of practices has focused primarily on manufacturing practices such as total quality management, just-in-time, etc. which are primarily focused on improving the efficiency. The context of this research provides unique insights as the practices examined are used primarily for conducting and coordinating activities related to innovation. As such, they represent strategic capabilities which can be quite idiosyncratic to MNE strategy and structure. In addition, the strategic value of innovation capabilities tends to evolve over time and with it the practices which underpin them. Thus, this context is especially useful for investigating the causes and modes of practice adaptation and diffusion.

An additional contribution is made to the notion of diffusion of innovation practices within the MNE network. The data revealed processes other than HQ initiatives which lead to the diffusion of innovation practices with the geographically dispersed innovation network of the MNE. Central administration refers to the initiation of practice 
transfer amongst all relevant subsidiaries and business units, while less hierarchically controlled modes include brokering and organic diffusion. An awareness of these processes, and the conditions under which they occur, provides managers with an opportunity to guide and direct the flow of innovation practices. It was suggested that metrics used to evaluate innovative subsidiaries provide signals used to evaluate the potential value of the practice. Practices which address these metrics are more likely to be adopted, but there often remains the challenge of fitting them to subsidiary-specific resources and local business requirements. These considerations must be made by HQ and innovation practice brokers if the practice is to be fully adopted and internalized by a recipient subsidiary.

This thesis also contributes to KBT by better explicating the creation and role of shared context and community in the transfer of organizational knowledge. KBT posits that the very reason of existence for some, if not all firms, is its ability to exploit and diffuse knowledge. While it has generally been assumed that this is due to the creation of shared context or, from the communities of practice perspective, the desire for membership by individuals within the organization, less attention has been given to overcoming the impediments to forming this shared context. In this thesis, innovation practice transfer has been found to play a role in creating this shared context, through mechanisms such as common language and performance metrics. Furthermore, it has been proposed that the presence of mutual interdependencies amongst subsidiaries within the MNE innovation network underpins the formation of community. This implies that 
when individuals in geographically dispersed subsidiaries rely on one another to complete their responsibilities, they will communicate more frequently, and exchange knowledge more readily. Hence, although researchers have shown that hierarchical involvement in knowledge transfer tends to inhibit knowledge transfer, the propositions developed here suggest that HQ can play a role in creating some necessary preconditions for integration and coordination.

\subsection{Future Research}

This research has focused on innovation practice transfer in the unique setting of innovation intensive MNEs. Prior research has examined the process of adaptation of practices in the manufacturing setting ( $\mathrm{Yu}$ and Zaheer, 2010). Innovation requires substantial integration and coordination amongst disparate units within the MNE innovation network. This requirement for integration suggests that adaptation to innovation practices could prove detrimental or at least burdensome to those organizations undertaking it. However, the organizational capability to continually adapt and improve practices has strategic merit, and would likely evolve slowly over many years. Hence, future studies employing longitudinal case based methodology are warranted to investigate the process of innovation practice evolution, its antecedents, and outcomes.

In addition, this research developed theory concerning the role of shared context, its antecedents, and its role in developing subsidiary capabilities. This closer examination was warranted in order to clarify the nature and influence of shared context, 
which the KBT literature often assumes to underpin the value creation of the firm. Future research can use the results of this research as a starting point for the development of survey instruments to validate and extend these propositions. Research conducted according to this objective could provide more generalizable results and thus allow KBT theorists to better articulate the underlying mechanisms by which organizations achieve superiority over markets in the generation, exploitation and diffusion of knowledge. Furthermore, research in this area could provide more implications for the management of knowledge and mechanisms for overcoming impediments within the organization.

The increasing interdependencies amongst national economies brought on by globalization have created a renewed interest amongst scholars in the integrating and coordinating role of MNE headquarters (Sinkovics, Roath and Cavusgil, 2011). The results of this thesis begin to address some of the implications for the strategic management of innovation in MNEs with geographically dispersed innovation networks. It was proposed that headquarters plays a role in creating mutual interdependencies amongst subsidiaries in order to promote the emergence of communities of practice and in the creation of shared context through the initiation of practice transfer. The suggestion provided in this thesis is that the sooner mutual interdependencies are created, the easier innovation practices will transfer from sender to recipient. Communities tend to require substantial periods of time to form (Roberts, 2006), but creating mutual interdependencies prior to innovation practice transfer can hasten their emergence. Future research on the role of different MNE evolutionary paths is warranted, as the 
effectiveness of these and many other potential mechanisms will depend largely on the particular structure and strategy of the MNE. Some MNEs are structured as loosely coordinated federations, yet it is still likely that practice sharing can produce desirable outcomes in innovation capability development. Research in this area can examine when and how the various forms of practice transfer, including brokering, central administration and organic diffusion, are more appropriate.

\subsection{Limitations}

The contributions cited previously are enabled by the case based methodology used, as described in Chapter 5, which examined the phenomenon of innovation practice transfer and adaptation. The trade off with this methodology is that the findings do not necessarily generalize to a broader population, but instead generalize to theory (Yin, 2009). However, the case based approach employed is more suitable for examining the details of innovation practice transfer, in particular the various aspects which influence its components of adoption, adaptation and implementation. By analyzing the responses of interviewees in the context of the specific attributes of their subsidiary, HQ and MNE innovation network, it was able to more clearly discern the order in which various stages of the transfer process were undertaken, and thus provide more valid interpretations of causal ordering amongst the related constructs. Future researchers can use the results of this study to create measures of these constructs in order to carry out large sample research to validate and/or extend the findings presented here. 
It is possible that social desirability bias could have detracted from the validity of the results presented. As the data for the case was primarily recorded interviews, managers may have been less inclined to talk about difficult interpersonal issues, cultural issues between different countries, and also to present some aspects of the MNE in more positive language than others. Matters such as these were discussed on occasion, but it was noted that there was some hesitation on the part of respondents to share this information in greater detail. In order to partially mitigate against this bias, these statements were considered as evidence that such barriers to knowledge flow exist to varying extents in all organizations, and that some conditions, such as mutual interdependency could be used to mitigate against them. However the dynamics of conflict escalation and resolution were not analyzed in great detail.

Another potential source of bias is due to managers' ability to recall the details of past events and, further, the possibility that managerial sensemaking had shaped these recollections. As such, it is impossible to specify the strength of the relationships between transfer processes, national and organizational factors, practice adaptation and diffusion and capability. Instead, it was proposed that the nature of these relationships may be either positive or negative, but all references to magnitude were achieved through cross case examination, which provide relative rather than absolute differences.

Other unobserved factors operating at any of the observed levels may also have played a role in shaping innovation practice transfer, adaptation and adoption. Most notably, the subsidiary's ability to adopt the practice, its absorptive capacity (Cohen and 
Levinthal, 1990) likely must reach a certain threshold before adoption can commence. To some extent, the fit of the innovation practice to the subsidiary's business requirements, resources and path dependencies reflects its absorptive capacity with respect to a particular practice. Nonetheless, other factors such as organizational slack and attention may also play a role. These factors should be considered in future research, although the extent to which they have already received attention in the literature suggest that it may be appropriate to simply control for them when designing survey instruments.

Finally, this research focused mainly on dyadic exchange of innovation practices, and only in a more general sense to diffusion throughout the network. Hence, it was not possible to specify the potentially numerous influences on practice diffusion. Instead the focus here is on how the various modes of diffusion were shaped by organizational structure, evolution, strategy, and strategic initiatives. In fact, each type of diffusion listed is likely present in any given MNE network, and so future research is needed to examine the conditions under which each occurs, the process, and the extent to which each leads to intended and potentially unintended outcomes.

\subsection{Managerial Implications}

This research addresses an increasingly important area of decision making for MNE managers. The globalization of innovation has been spurred on by the increasing internationalization of technologically advanced industries. The market for industries such as telecommunications, aerospace, pharmaceuticals, healthcare equipment, electronics, and software, among many others, are growing quickly in the many rapidly 
developing economies of the world. Likewise, the talent to staff these industries is equally as dispersed, compelling substantial investment in globally dispersed research and development centers. Hence, managers are now faced with coordination of increasingly complex functions across multiple borders.

This research suggests that some MNEs innovation networks are evolving according to the international markets they pursue, while others internationalized through technology acquisition, and still others through seeking access to knowledge workers required to build the competencies of the MNE for the future. In order to coordinate and integrate the operations of these geographically dispersed subsidiaries and business units, this research suggests that a variety of mechanisms exist which allow managers to enhance shared context to promote subsidiary capability development and the diffusive capabilities of the MNE innovation network.

Managers should use common metrics to assess the performance and development of subsidiaries as an indirect way of monitoring and directing innovation practice sharing. Although directly controlling the flow of knowledge is difficult to achieve and generally inefficient through hierarchical means, it is suggested that managers instead focus their attention on creating the conditions through which knowledge sharing impediments are reduced. Using cross national product teams is one way to enhance knowledge sharing, as individuals will be more motivated to seek knowledge when needed, and more motivated to provide it when it is requested. However, it is also suggested that managers need to more fully understand the purpose of practices and the value they provide to the 
organization when initiating transfer within the MNE innovation network. It is through this deeper understanding that managers will be able to adequately resource and monitor subsidiaries as they develop their capabilities. This will also facilitate any adaptations that need to be made to the practice in order for it to fit the business requirements, resources and path dependencies of the subsidiary.

This research also suggests that national differences often induce the adaptation of practices. In some cases, these adaptations are unavoidable and thus should be expected. It is most important that subsidiary managers understand not only the purpose of a practice, but also its value to the overall MNE. If subsidiary managers do not realize the strategic importance of implementing a particular practice, they are unlikely to begin implementing it. Cultural differences between subsidiary employees can inhibit understanding of practices, which in turn can lead to different implementations. This may be especially true with respect to the social dimensions of practices if responsibilities for different aspects of the practice are divided inefficiently, such that more specialized workers take on more generalized tasks. For example, engineers being assigned additional responsibilities for documentation which could be more efficiently carried out by support staff. Managers need to be flexible in allowing some adaptations in order to ensure that the practice is used, but must understand the implications of those adaptations in order to maintain the effectiveness of the practice.

Finally, there are different modes with which to diffuse practices throughout the MNE, and each may be more valuable in some circumstances than others. To launch 
new initiatives or to adapt the MNE strategy to changing international conditions, headquarters should initiate the transfer of practices and provide adequate resources to enable implementation. Practice sharing amongst different subsidiaries should be promoted in order to help integrate them and diffuse valuable knowledge throughout the innovation network. Where there is little interaction amongst subsidiaries, and it is not warranted due to MNE strategy, individuals who do work with different subsidiaries can act as brokers of knowledge, creating network connections where none would exist otherwise.

\subsection{Conclusion}

This thesis was motivated by the increasing internationalization of innovation, resulting from the rapid emergence of market demand for technologically advanced products throughout the world, and the opening up of international markets. The MNE plays a central role in this internationalization, as it provides the knowledge and practices to aid in rapidly developing the capabilities of its overseas subsidiaries. Whereas prior research mainly focused on the efficiency gains in manufacturing process resulting from practice transfer, this thesis focused on this complex process in the context of innovation in order to investigate how it could help develop these capabilities. In addition, this research was motivated to analyze in greater detail the different influences on the adaptation of practices and their diffusion throughout the network. To investigate these issues, interviews were conducted with managers at four different MNEs. Each MNE 
provided a unique perspective on the role of innovation practice transfer which allowed the discernment of various influences on the process and its outcomes.

The data revealed that innovation practice transfer plays a major role in coordinating knowledge flows from source to recipient in that it provides some structure in which subsidiaries are able to develop the tacit knowledge required to, in turn, develop their capabilities. It was furthermore found that headquarters had a role to play in this through initiating practice transfer, creating mutual interdependency amongst the geographically dispersed subsidiaries, and promoting the emergence of communities within the MNE. These communities would then be more inclined to share information which develops not only the subsidiaries' capabilities, but the capabilities of the MNE as whole, as it develops the competence to address emerging market needs.

This research also suggests various types of adaptation influences to which practices are subject, when they are more likely to occur, and how they may influence the integration of subsidiaries and business units. Furthermore, it was proposed that headquarters can play a substantial role in diffusing practice throughout the MNE innovation network. In some cases, it is useful for headquarters to be directly involved in this process while in others it can take a more indirect role by structuring the flow of work and consequently knowledge. As innovation continues to evolve along international lines, decisions which influence the coordination and control of the MNE will require substantial attention from managers and researchers alike. 


\section{References}

Abrahamson E. (1991) 'Managerial fads and fashions: the diffusion and rejection of innovations', Academy of Management Review, 16(3): 586-612.

Adams R., Bessant J. and Phelps R. (2006) 'Innovation management measurement: A review', International Journal of Management Reviews, 8(1): 21-47.

Almeida P. (1996) 'Knowledge sourcing by foreign multinationals: Patent citation analysis in the US semiconductor industry', Strategic Management Journal, 17(Winter Special Issue): 155-165.

Almeida P. and Kogut B. (1997) 'The exploration of technological diversity and the geographic localization of innovation: Start-up forms in the semiconductor industry', Small Business Economics, 9(1): 21-31.

Almeida P. and Phene A. (2004) 'Subsidiaries and knowledge creation: The influence of the MNC and host country on innovation', Strategic Management Journal, 25(89): $847-864$.

Ambos T.C., Ambos B. and Schlegelmilch B.B. (2006) 'Learning from foreign subsidiaries: An empirical investigation of headquarters' benefits from reverse knowledge transfers', International Business Review, 15(3): 294-312.

Amit R. and Schoemaker P.J.H. (1993) 'Strategic assets and organizational rent', Strategic Management Journal, 14(1): 33-46.

Anand N., Gardner H. and Morris T. (2007) 'Knowledge-based innovation: Emerging and embedding of new practice areas in management consulting firms', Academy of Management Journal, 50(2): 406-428.

Andersson U., Björkman I. and Forsgren M. (2005) 'Managing subsidiary knowledge creation: The effect of control mechanisms on subsidiary local embeddedness', International Business Review, 14(5): 521-538.

Andersson U., Forsgren M. and Holm U. (2007) 'Balancing subsidiary influence in the federative MNC: A business network view', Journal of International Business Studies, 38(5): 802-818.

Andersson U., Forsgren M. and Pedersen T. (2001) 'Subsidiary performance in multinational corporations: The importance of technology embeddednes', International Business Review, 10(1): 3-23. 
Archibugi D. and Iammarino S. (2002) 'The globalization of technological innovation: Definition and evidence', Review of International Political Economy, 9(1): 98122.

Archibugi D. and Michie J. (1995) 'The globalisation of technology: A new taxonomy', Cambridge Journal of Economics 19(1): 121-40.

Asakawa K. (2001) 'Organizational tension in international R\&D management: The case of Japanese firms', Research Policy, 30(5): 735-757.

Asmussen C. G., Pedersen T. and Dhanaraj C. (2009) 'Host-country environment and subsidiary competence: Extending the diamond network model', Journal of International Business Studies, 40(1): 42-57.

Augier M., Shariq S.Z. and Vendelø M.T. (2001) 'Understanding context: Its emergence, transformation and role in tacit knowledge sharing', Journal of Knowledge Management, 5(2): 125-136.

Barney, J. (1991) 'Firm resources and sustained competitive advantage', Journal of Management, 17(1): 99-120.

Bartholomew S. (1997) 'National systems of biotechnology innovation: Complex interdependence in the global system', Journal of International Business Studies, 28(2): 241-266.

Bartlett C.A. and Beamish P.W. (2011) Transnational Management: Text, Readings, and Cases in Cross-Border Management, 6/E. Burr Ridge, Illinois: Irwin McGrawHill.

Bartlett C.A. and Ghoshal S. (1989) Managing Across Borders: The Transnational Solution, Harvard Business School Press: Boston, MA.

Bartlett C.A. and Ghoshal S. (1997) Managing Innovation in the Transnational Corporation, New York: Oxford University Press.

Bazeley P. (2007) Qualitative Data Analysis with NVivo, Thousand Oaks, CA: Sage Publications.

Becker M.C. (2004) 'Organizational routines: A review of the literature', Industrial and Corporate Change, 13(4): 643-677.

Becker-Ritterspach F. and Dörrenbächer C. (2009) 'Intrafirm competition in multinational corporations: Towards a political framework', Competition and Change, 13(3): 199-213. 
Berry H., Guillén M.F. and Zhou N. (2010) 'An institutional approach to cross-national distance', Journal of International Business Studies, 41(9): 1460-1480.

Bettis R.A. and Prahalad C.K. (1995) 'The dominant logic', Strategic Management Journal, 16(1): 5-14.

Bhagat R.S., Kedia B.L., Harveston P.D. and Triandis H.C. (2002) 'Cultural variations in the cross-border transfer of organizational knowledge: An integrative framework', Academy of Management Review, 27(2): 204-221.

Birkinshaw J. (1996) 'How multinational subsidiary mandates are gained and lost', Journal of International Business Studies, 27(3): 467-495.

Birkinshaw J. M. (1997) 'Entrepreneurship in multinational corporations: The characteristics of subsidiary initiatives', Strategic Management Journal, 18(3): 207-229.

Birkinshaw J., Hamel G. and Mol M.J. (2008) 'Management innovation', Academy of Management Review, 33(4): 825-845.

Birkinshaw J. and Hood N. (1998) 'Multinational subsidiary evolution: Capability and charter change in foreign-owned subsidiary companies', Academy of Management Review, 23(4): 773-795.

Birkinshaw J.M. and Sölvell Ö. (2000) 'Leading edge multinationals and leading edge clusters', International Studies of Management and Organization, 30(2): 3-9.

Bouquet C. and Birkinshaw J. (2008) 'Weight versus voice: How foreign subsidiaries gain attention from corporate headquarters', Academy of Management Journal, 51(3): 577-601.

Brown J.S. and Duguid P. (1991) 'Organizational learning and communities-of-practice: Towards a unified view of working, learning, and innovation', Organization Science, 2(1): 40-57.

Brown J.S. and Duguid P. (2001) 'Structure and spontaneity: Knowledge and organization', In: Nonaka I. and Teece D. (Eds.), Managing Industrial Knowledge, London: Sage.

Brown S.L. and Eisenhardt K.M. (1995) Product development: Past research, present findings, and future directions. Academy of Management Review, 20(2): 343-378.

Burgelman R. (1983) 'Corporate entrepreneurship and strategic management: Insights from a process study', Management Science, 29(12): 1349-1363. 
Camisón-Zornoza C., Lapiedra-Alcamí R., Segarra-Ciprés M. and Boronat-Navarro M. (2004) 'A Meta-analysis of Innovation and Organizational Size', Organization Studies, 25(3): 331-361.

Cantwell J. (1989) Technological Innovation and Multinational Corporations, New York: Blackwell.

Cantwell J.A. (1991) 'The international agglomeration of R\&D', In: Casson M.C. (Ed.), Global Research Strategy and International Competitiveness. Oxford: Basil Blackwell.

Cantwell J. (1995) 'The gobalisation of technology: What remains of the product cycle model', Cambridge Journal of Economics, 19(1): 155-74.

Cantwell J.A. and Fai F.M. (1999) 'Firms as the source of innovation and growth: The evolution of technological competence', Journal of Evolutionary Economics, 9(3): 331-366.

Cantwell J. and Janne O. (1999) 'Technological globalisation and innovative centres: The role of corporate technological leadership and locational hierarchy', Research Policy, 28(2-3): 199-144.

Cantwell J. and Mudambi R. (2005) 'MNE competence-creating subsidiary mandates', Strategic Management Journal, 26(11): 1109-1128.

Cantwell J. and Piscitello L. (2000) 'Accumulating technological competence: Its changing impact on corporate diversification and internationalization', Industrial and Corporate Change, 9(1): 21-51.

Carlsson B. (2006) 'Internationalization of innovation systems: A survey of the literature', Research Policy, 35(1): 56-67.

Carpenter M., Lazonick W. and O’Sullivan M. (2003) 'The stock market and innovative capability in the new economy: The optical networking industry', Industrial and Corporate Change, 12(5): 963-1034.

Cerrato D. (2006) 'The multinational enterprise as an internal market system', International Business Review, 15(3): 253-277.

Chan C.M. and Makino S. (2007) 'Legitimacy and multi-level institutional environments: Implications for foreign subsidiary ownership structure', Journal of International Business Studies, 38(4): 621-638. 
Chen C.J. and Huang J.-W. (2009) 'Strategic human resource practices and innovation performance: The mediating role of knowledge management capacity', Journal of Business Research, 62(1): 104-114.

Ciabuschi F., Dellestrand H. and Kappan P. (2011) 'Exploring the effects of vertical and lateral mechanisms in international knowledge transfer projects', Management International Review, 51(2): 129-155.

Cohen M. and Bacdayan P. (1994) 'Organisational routines are stored as procedural memory: Evidence from a laboratory study', Organization Science, 5(4): 554-568.

Cohen W.M. and Levinthal D.A. (1990) 'Absorptive capacity: A new perspective on learning and innovation. Administrative Science Quarterly, 35(1): 128-152.

Coopey J. (1998) 'Learning to trust and trusting to learn', Management Learning, 29(3): 365-382.

Corbin J.M. and Strauss A. (2008) Basics of Qualitative Research. (3rd. ed.) Thousand Oaks, CA: Sage.

Costello N. (1996) 'Learning and routines in high-tech SMEs: Analyzing rich case study material', Journal of Economic Issues, 30(2): 591-597.

Cui G. and Liu Q. (2001) 'Executive insights: emerging market segments in a transitional economy: A study of urban consumers in China', Journal of International Marketing, 9(1): 84-106.

Davenport T.H. and Prusak I. (1998) Working Knowledge, Cambridge, MA: Harvard University Press.

Delany E. (2000) 'Strategic development of the multinational subsidiary through subsidiary initiative-taking', Long Range Planning, 33(2): 220-244.

DiMaggio P.J. and Powell W.W. (1983) 'The iron cage revisited: Institutional isomorphism and collective rationality in organizational fields', American Sociological Review, 48(2): 147-160.

Dörrenbächer C. and Geppert M. (2009) 'A micro-political perspective on subsidiary initiative-taking: Evidence from German-owned subsidiaries in France', European Management Journal, 27(2): 100-112.

Dosi G. (1988) Sources, procedures, and microeconomic effects of innovation. Journal of Economic Literature, 26(3): 1120-1171. 
Dosi G. (1982) Technological paradigms and technological trajectories. Research Policy, 11(3): 147-162.

Dosi G., Gaffard J.-L. and Nesta, L. (2008). 'Schumpeterian themes on industrial evolution, structural change and their microfoundations: An introduction', Industrial and Corporate Change, 17(4): 601-609.

Dosi G., Nelson R.R. and Winter S.G. (2000) 'Introduction: The nature and dynamics of organizational capabilities', In G. Dosi, R. R. Nelson and S. G. Winter (Eds.), The Nature and Dynamics of Organizational Capabilities, pp. 1-22. Oxford: Oxford University Press.

Doz, Y. and Prahalad, C.K. (1981) 'Headquarters' influence and strategic control in MNCs', Sloan Management Review 23(1): 15-29.

Doz Y., Bartlett C.A. and Prahalad C.K. (1981) 'Global competitive pressures and host country demands', California Management Review, 23(3): 63-74.

Dunning J.H. (1977) 'Trade, location of economic activity and the MNE: A search for an eclectic approach', In B. Ohlin, P.-O. Hesselborn, and P. M. Wijkman (Eds), The International Allocation of Economic Activity, pp. 395-418, London: Macmillan.

Dunning J.H. (1988) 'The eclectic paradigm of FDI: A restatement and some possible extensions', Journal of International Business Studies, 19(1): 1-31.

Dunning J.H. (1993) Multinational Enterprises and the Global Economy. Workingham, England: Addison-Wesley.

Dunning, J.H. (1994) 'Multinational enterprises and the globalization of innovatory capacity', Research Policy, 23(1): 67-89.

Dunning J.H. (1996) 'The geographical sources of competitiveness of firms. Some results of a new survey', Transnational Corporations, 5(3): 1-21.

Dunning J.H. (1998) 'Location and the multinational enterprise: A neglected factor?', Journal of International Business Studies, 29(1): 45-66.

Dunning, J.H. (2000) 'The eclectic paradigm as an envelope for economic and business theories of MNE activity', International Business Review, 9(2): 163-190.

Dunning J.H. and Narula R. (1995) 'The R\&D activities of foreign firms in the United States', International Studies of Management and Organization, 25(1-2): 39-73. 
Dyer J.H. and Singh H. (1998) 'The relational view: Cooperative strategy and sources of interorganizational competitive advantage', Academy of Management Review, 23(4): 660-679.

Edmondson A.C., Bohmer R.M. and Pisano G.P. (2001) 'Disrupted routines: Team learning and new technology implementation in hospitals', Administrative Science Quarterly, 46(4): 685-716.

Eisenhardt K.M. (1989) 'Building theory from case study research', Academy of Management Review, 14(4): 532-550.

Eisenhardt K.M. and Graebner M.E. (2007) 'Theory building from cases: Opportunities and Challenges', Academy of Management Journal, 50(1): 25-32.

Eisenhardt K.M. and Martin J.A. (2000) 'Dynamic capabilities: What are they?', Strategic Management Journal, 21(10-11): 1105-1121.

Ethiraj S.K., Kale P., Krishnan M.S. and Singh J.V. (2005) 'Where do capabilities come form and how do they matter? A study in the IT Services industry', Strategic Management Journal, 26(1): 25-45.

Etzkowitz H. and Leydesdorff L. (2000) 'The dynamics of innovation: from National Systems and "Mode 2'" to a Triple Helix of university-industry-government relations', Research Policy, 29(2):109-123.

Fatas-Villafranca F., Sanchez-Choliz J. and Jarne G. (2008) 'Modelling the co-evolution of national industries and institutions', Industrial and Corporate Change, 17(1): 65-108.

Feinberg S. and Gupta A. (2004) 'Knowledge spillovers and the assignment of R\&D responsibilities to foreign subsidiaries', Strategic Management Journal, 25(8): 823-845.

Feldman M.S. (2003) 'A performative perspective on stability and change in organizational routines', Industrial and Corporate Change, 12(4): 727-752.

Feldman M.S. (2000) 'Organisational routines as a source of continuous change', Organization Science, 11(6): 611-629.

Feldman M.S. (1993) 'An examination of the geography of innovation', Industrial and Corporate Change, 2(3): 451-470. 
Feldman M.S. and Pentland B.T. (2003) 'Reconceptualizing organizational routines as a source of flexibility and change', Administrative Science Quarterly, 48(1): 94118.

Feinberg S.E. (2000) 'Do world product mandates really matter?', Journal of International Business Studies, 31(1): 155-167.

Felin T. and Hesterly W.S. (2007) 'The knowledge-based view, nested heterogeneity, and new value creation: philosophical considerations on the locus of knowledge', Academy of Management Review, 32(1): 195-218.

Florida, R. (1997) 'The globalisation of R\&D: Results of a survey of foreign-affiliated R\&D laboratories in the US', Research Policy, 26(1): 85-103.

Foray D. (1995) 'The economics of intellectual property rights and systems of innovation: The persistence of national practices versus the new global model of innovation', In: Hagedoorn, J. (Ed.), Technical Change and the World Economy: Convergence and Divergence in Technology Strategies, pp. 109-133, Aldershot, England: Edward Elgar.

Foss N.J., Laursen K. and Pedersen T. (2011) 'Linking customer interaction and innovation: The mediating role of new organizational practices', Organization Science, (forthcoming).

Foss N.J., Minbaeva D.B., Pedersen T. and Reinholt M. (2009) 'Encouraging knowledge sharing among employees: How job design matters', Human Resource Management, 48(6): 871-893.

Foss N.J. and Pedersen T. (2002) 'Transferring knowledge in MNCs: The role of sources of subsidiary knowledge and organizational context', Journal of International Management, 8(1): 49-67.

Fratochii L. and Holm U. (1998) 'Centres of excellence in the international firm', In: Birkinshaw J. and Hood N. (Eds.), Multinational Corporate Evolution and Subsidiary Development, (pp. 189-205), Basingstoke, Hampshire : Macmillan.

Frenkel A., Maital S. and Grupp H. (2000) 'Measuring dynamic technical change: A technometric approach', International Journal of Technology Management, 20(): 429-441.

Frost T. S., Birkinshaw J. and Ensign P. C. 2002. Centers of excellence in multinational corporations. Strategic Management Journal, 23(11): 997-1018. 
Frost T.S. and Zhou C. (2005) 'R\&D co-practice and reverse knowledge integration in multinational firm', Journal of International Business Studies, 66(6): 676-687.

Garcia R. and Calantone R. (2002) 'A critical look at technological innovation typology and innovativeness terminology: A literature review', Product Innovation Management, 19(2): 110-132.

Garcia-Pont C., Canales J. I. and Noboa, F. (2009) 'Subsidiary strategy: The embeddedness component', Journal of Management Studies, 46(2): 182-214.

Garud R. and Karnøe P. (2003) 'Bricolage versus breakthrough: distributed and embedded agency in technology entrepreneurship', Research Policy, 32(2): 277300.

Geppert M. and Williams K. (2006) 'Global, national and local practices in multinational coporations: Towards a socio-political framework', International Journal of Human Resource Management, 17(1): 49-69.

Gertler M.S. (2003) 'Tacit knowledge and the economic geography of context, or the undefinable tacitness of being (there)', Journal of Economic Geography, 3(1): 7599.

Ghoshal S. and Bartlett C. (1988) 'Creation, adoption, and diffusion of innovations by subsidiaries of multinational corporations', Journal of International Business Studies, 19(3): 365-388.

Ghoshal S. and Bartlett C.A. (1990) 'The multinational corporation as an interorganizational network', Academy of Management Review, 15(4): 603-625.

Glaser B.G. and Strauss A.L. (1967) The Discovery of Grounded Theory: Strategies for Qualitative Research. Hawethorne, NY: Aldine de Gruyter.

Gooderham P., Minbaeva D.B. and Pedersen T. (2011) 'Governance mechanism for the promotion of social capital for knowledge transfer in multinational corporations', Journal of Management Studies, 48(1): 123-150.

Gooderham P., Nordhaug O. and Ringdal K. (1999) 'Institutional and rational determinants of organizational practices: Human resource management in European firms', Administrative Science Quarterly, 44(3): 507-531.

Grandstrand O., Patel P. and Pavitt K. (1997) 'Multi-technology corporations: Why they have "distributed" rather than "distinctive core" competencies', California Management Review, 39(4): 8-25. 
Grant, R.M. (1996) 'Toward a knowledge-based theory of the firm', Strategic Management Journal, 17(10): 109-122.

Gregersen B. and Johnson B. (1997) 'Learning economies innovation systems and European integration', Regional Studies, 31(5): 479-490.

Guba E. and Lincoln Y. (1989) Fourth Generation Evaluation, Beverly Hills, CA: Sage.

Guler I.I. and Guillén M.F. (2010) 'Institutions and the internationalization of US venture capital firms', Journal of International Business Studies, 41(2): 185-205.

Gupta A.K. and Govindarajan V. (2000) 'Knowledge flows within multinational corporations', Strategic Management Journal, 21(4): 473-496.

Gupta A.K. and Govindarajan V. (1991) 'Knowledge flows and the structure of control within multinational corporations', Academy of Management Review, 16(4), 768792.

Hall P.A. and Soskice D. (2001) Varieties of Capitalism: The Institutional Foundations of Comparative Advantage, New York: Oxford University Press.

Hamel G. (2006) 'The why, what, and how of management innovation', Harvard Business Review, 84(2): 72-84.

Hedlund G. (1986) 'The hypermodern MNC: A heterarchy?' Human Resource Management, 25(1): 9-35.

Hedlund G. (1994) 'A model of knowledge management and the N-form corporation', Strategic Management Journal, 15(2): 73-90.

Helfat C.E. Finkelstein S., Mitchell W., Peteraf M., Singh H., Teece D. and Winter S.G. (2007) Dynamic Capabilities: Understanding Strategic Change in Organizations, Oxford: Blackwell.

Hillman A.J. and Wan W.P. (2005) 'The determinants of MNE subsidiaries' political strategies: Evidence of institutional duality', Journal of International Business Studies, 36(3): 322-340.

Hirschman A.O. (1970) Exit, Voice and Loyalty: Responses to Decline in Firms, Organizations, and States, Cambridge, MA: Harvard University Press.

Hislop D. (2003) 'The complex relations between communities of practice and the implementation of technological innovations', International Journal of Innovation Management, 7(2): 163-188. 
Hitt M.A., Beamish P.W., Jackson S.E. and Mathieu J.E. (2007) 'Building theoretical and empirical bridges across levels: Multilevel research in management', Academy of Management Journal, 50(6): 1385-1399.

Holm U. and Pedersen T. (2000) The Emergence and Impact of MNC Centres of Excellence, Basingstoke, Hampshire: Macmillan.

Hymer S.H. (1976) The International Operations of National Firms: A Study of Direct Investment, Cambridge, MA: MIT Press.

Jaffe A.B., Trajtenberg M. and Henderson R. (1993) 'Geographic localization of knowledge spillovers as evidenced by patent citations', Quarterly Journal of Economics, 108(3): 577-598.

Jaffe A.B. and Lerner J. (2004) Innovation and Its Discontents, Princeton, NJ: Princeton University Press.

Jarillo J.C. and Martinez J.I. (1990) 'Different roles for subsidiaries: The case of multinational corporations in Spain', Strategic Management Journal, 11(7), 501512.

Jensen R. and Szulanski G. (2004) 'Stickiness and the adaptation of organizational practices in cross-border knowledge transfers', Journal of International Business Studies, 35(6): 508-523.

Kedia B. and Bhagat R. (1988) 'Cultural constraints on transfer of technology across nations: Implications for research in international and comparative management', Academy of Management Review, 13(4): 559-571.

Kim C.W. and Mauborgne R.A. (1991) 'Implementing global strategies: The role of procedural justice', Strategic Management Journal, 12(S1): 125-143.

Kim C.W. and Mauborgne R.A. (1993) 'Making global strategies work', Sloan Management Review, 34(3): 11-27.

Kimble C., Li F. and Barlow A. (2000) 'Effective virtual teams through communities of practice', Strathclyde Business School, Research Paper No. 2000/9.

Kindleberger C.P. (1969) American Business Abroad. Six Lectures on Direct Investment, New Haven: Yale University Press.

Kogut B. (1991) 'Country capabilities and the permeability of borders', Strategic Management Journal, 12(Special issue: Global strategy, Summer, 1991): 33-47. 
Kogut B. (2000) 'The network as knowledge: generative rules and the emergence of structure', Strategic Management Journal, 21(3): 405-425.

Kogut B. and Chang, S.-J. (1991) 'Technological capabilities and Japanese foreign direct investment in the United States', Review of Economics and Statistics, 73(3): 401413.

Kogut B. and Singh H. (1988) 'The effect of national culture on the choice of entry mode', Journal of International Business Studies, 19(3): 411-432.

Kogut B. and Zander U. (1995) 'Knowledge and the speed of the transfer and imitation of organizational capabilities: An empirical test', Organization Science, 6(1): 76-92.

Kogut B. and Zander U. (1993) 'Knowledge of the firm and the evolutionary theory of the multinational corporation', Journal of International Business Studies, 24(4): 625-645.

Kogut B. and Zander U. (1992) 'Knowledge of the firm, combinative capabilities, and the replication of technology', Organization Science, 3(3): 383-397.

Kostova T. (1999) 'Transnational transfer of strategic organizational practices: A contextual perspective', Academy of Management Review, 24(2): 308-324.

Kostova T. and Roth, K. (2002) 'Adoption of an organizational practice by foreign subsidiaries of multinational corporations: Institutional and relational effects', Academy of Management Journal, 45(1): 215-233.

Kostova T. and Zaheer S. (1999) 'Organizational legitimacy under conditions of complexity: The case of the multinational enterprise', Academy of Management Journal, 24(1): 64-81.

Kozlowski S.W.J. and Klein K.J. (2000) 'A multilevel approach to theory and research in organizations: Contextual, temporal and emergent processes', In: Klein, K.J. and Kovlowski S.W.J. (Eds.) Multilevel Theory, Research and Methods in Organizations (pp. 3-90), San Francisco: Jossey-Bass.

Kuemmerle W. (1999a) 'Foreign direct investment in industrial research in the pharmaceutical and electronics industries - Results from a survey of multinational firms', Research Policy, 28(2-3): 179-193.

Kuemmerle W. (1999b) 'The drivers of foreign direct investment into research and development', Journal of International Business Studies, 30(1): 1-24. 
Kurokawa S., Iwata S. and Roberts E. B. (2007) 'Global R\&D activities of Japanese MNCs in the US: A triangulation approach', Research Policy, 36(1): 3-36.

Lave J. and Wenger E. (1991) Situated Learning: Legitimate Peripheral Participation, Cambridge, U.K.: Cambridge University Press.

Langley A. (1999) 'Strategies for theorizing from process data', Academy of Management Review, 24(4): 691-710.

Laursen K. and Foss N.J. (2003) 'New human resource management practices, complementarities, and the impact on innovation performance', Cambridge Journal of Economics, 27(2): 243-63.

Lawrence P.R. and Lorsch J.W. (1967) Organization and Environment: Managing Differentiation and Integration, Boston: Harvard University.

Lazonick W. (2003) 'The theory of the market economy and the social foundations of innovative enterprise', Economic and Industrial Democracy, 24(1): 9-44.

Lee S.H. and Williams C. (2007) 'Dispersed entrepreneurship within multinational corporations: A community perspective', Journal of World Business, 42(4): 505519.

Lemak D.J. and Arunthanes W. (1997) 'Global business strategy: A contingency approach', Multinational Business Review, 5(1): 26-37.

Lucas, L.M. (2006) 'The role of culture on knowledge transfer: The case of the multinational corporation', The Learning Organization, 13(30): 257-275.

Lundvall B.-Å., Johnson B., Anderson E.S. and Dalum B. (2002) 'National Systems of production, innovation and competence-building', Research Policy, 31(2): 213231.

Luo Y. (2001) 'Determinants of local responsiveness: Perspectives from foreign subsidiaries in an emerging market', Journal of Management, 24(4): 451-477.

Lyle S.W. and Zawacki R.A. (1997) 'Centers of excellence: Empowering people to manage change', Information Systems Management, Winter: 26-29.

Mahnke V., Pedersen T. and Venzin M. (2005) 'The impact of knowledge management on MNC subsidiary performance: The role of absorptive capacity', Management International Review, 45(2): 101-119. 
Manolopoulos D. (2008) 'A systematic review of the literature and theoretical analysis of subsidiary roles', Journal of Transnational Management, 13(1): 23-57.

March J.G. (1991) 'Exploration and exploitation in organizational learning', Organization Science, 2(1): 71-87.

March J.G. (1962) 'The business as a political coalition', The Journal of Politics, 24(4): 662-678.

Maskell P., Pedersen, T., Petersen B. and Dick-Nielsen J. (2007) 'Learning paths to offshore outsourcing: From cot reduction to knowledge seeking', Industry and Innovation, 14(3): 239-257.

McGrath R.G. and Nerkar A. (2004) 'Real options reasoning and a new look at the R\&D investment strategies of pharmaceutical firms', Strategic Management Journal, 25(1): $1-21$

Merton R.K. (1968) 'The Matthew effect in science', Science, 159(3810): 56-63.

Merton R.K. (1988) ‘The Matthew effect in science II', ISIS, 79(3): 606-623.

Meyer A. and Rowan B. (1977) 'Institutionalized organizations: Formal structure as myth and ceremony', American Journal of Sociology, 83(2): 340-363.

Miles M.B. and Huberman A. M. (1994) Qualitative Data Analysis, Thousand Oaks, CA: Sage Publications.

Miller D.J., Fern M.J. and Cardinal L.B. (2007) 'The use of knowledge for technological innovation within diversified firms', Academy of Management Journal, 50(2): 308-326.

Minbaeva D., Pedersen T., Björkman I., Fey C.F. and Park H.J. (2003) 'MNC knowledge transfer, subsidiary absorptive capacity and HRM', Journal of International Business Studies, 34(6): 586-599.

Moore K. and Birkinshaw J.M. (1998) 'Managing knowledge in global service firms: Centers of excellence', Academy of Management Executive, 12(4): 81-92.

Morgan G. and Kristensen P.H. (2006) 'The contested space of multinationals: Varieties of institutionalism, varieties of capitalism', Human Relations, 59(11): 1467-1490.

Morosini P., Shane S. and Singh H. (1998) 'National cultural distance and cross-border acquisition performance', Journal of International Business Studies, 21(1): 137158. 
Muchinsky P. (1977) 'An intraorganizational analysis of the Roberts and O'Reilly organizational communication questionnaire', Journal of Applied Psychology, 62(2): 184-188.

Mudambi R. and Navarra P. (2004) 'Is knowledge power? Knowledge flows, subsidiary power and rent-seeking within MNCs', Journal of International Business Studies, 35(5): 385-406.

Mudambi R. and Swift T. (2009) 'Professional guilds, tension and knowledge management', Research Policy, 38(5): 736-745.

Nelson R.R. (1991) 'Why do firms differ, and how does it matter?', Strategic Management Journal, 12 (Winter special issue): 61-74.

Nelson R.R. (1992) 'National innovation systems: A retrospective on a study', Industrial and Corporate Change, 1(2): 347-374.

Nelson R.R. (1993) National Innovation Systems: A Comparative Analysis, Oxford, UK: Oxford University Press.

Nelson R.R. and Winter S.G. (2002) 'Evolutionary theorizing in economics', Journal of Economic Perspectives, 16(2): 23-46.

Nelson R.R. and Winter S.G. (1982) 'The Schumpeterian tradeoff revisited', American Economic Review, 72 (1): 114-132.

Nelson R.R. and Winter S.G. (1977) 'In search of a useful theory of innovation', Research Policy, 6(1): 36-76.

Newey L.R. and Zahra S.A. (2009) 'The evolving firm: How dynamic and operating capabilities interact to enable entrepreneurship', British Journal of Management, 20(issue supplement s1): 81-100.

Niosi J. and Bellon B. (1994) 'The global interdependence of national innovation systems: Evidence, limits, and implications'. Technology in Society, 16(2): 173197.

Niosi J. and Bellon B. (1996) 'The globalization of national innovation systems', In: De la Mothe, J., Paquet, G. (Eds.), Evolutionary Economics and the New International Political Economy, pp. 138-159, New York: Pinter.

Nohria N. and Ghoshal S. (1997) The Differentiated Network: Organizing Multinational Corporations for Value Creation, San Francisco: Jossey-Bass. 
Nonaka I. (1994) 'A dynamic theory of organizational knowledge creation', Organization Science, 5(1): 14-37.

Nonaka I. and von Krogh G. (2009) 'Tacit knowledge and knowledge conversion: Controversy and advancement in organizational knowledge creation theory', Organization Theory, 20(3): 635-652.

Nonaka I. and Takeuchi H. (1995) The Knowledge-Creating Company: How Japanese Companies Create the Dynamics of Innovation, New York: Oxford University Press.

Nonaka I., Toyama R. and Nagata A. (2000) 'A firm as a knowledge creating entity: A new perspective on the theory of the firm', Industrial and Corporate Change, 9(1): 1-20.

Orr J.E. (1990) 'Sharing knowledge, celebrating identity: Community memory in a service culture', In D. S. Middleton and D. Edwards (Eds.), Collective remembering, Newbury Park, CA: Sage Publications.

Orr J.E. (1996) Talking about machines: An ethnography of a modern job. New York: ILR Press.

O'Sullivan M. (2000) 'The innovative enterprise and corporate governance', Cambridge Journal of Economics, 24(4): 393-416.

Papanastassiou M. and Pearce R.D. (1997) 'Technology sourcing and the strategic roles of manufacturing subsidiaries in the U.K.: Local competences and global competitiveness', Management International Review, 37(1): 5-25.

Papanastassiou M. and Pearce R. (1999) Multinationals, Technology and National Competitiveness. Cheltenham, U.K.: Edward Elgar.

Parkhe A. (1993) 'Messy research, methodological predispositions, and theory development in international joint ventures', Academy of Management Review, 18(2): 227-268.

Pauly L.W. and Reich S. (1997) 'National structures and multinational corporate behaviour: Enduring differences in the age of globalization', International Organization, 51(1): 1-30.

Pavitt K. (1998) 'The social shaping of the national science base', Research Policy, 27(8): 793-805. 
Pavitt K. (2001) 'Managing global innovation: Uncovering the secrets of future competitiveness', Research Policy, 30(1): 176-177.

Pavitt K. (2002) 'The globalizing learning economy', Academy of Management Review, 27(1): 125-127.

Pavitt K. and Patel P. (1999) 'Global corporations and national systems of innovation: Who dominates whom?', In: Archibugi D., Howells J. and Michie J. (Eds.), Innovation Policy in a Global Economy, pp. 94-119, Cambridge: Cambridge University Press.

Pearce R.D. (1999) 'Decentralised R\&D and strategic competitiveness: Globalised approaches to generation and use of technology in MNEs', Research Policy, 28(23): $157-178$.

Pedersen T., Petersen N. and Sharma D. (2003) 'Knowledge transfer performance of multinational companies', Management International Review, Special Issue(3): 69-90.

Penrose E.T. (1959) The Theory of the Growth of the Firm, New York: Wiley.

Perlmutter H.V. (1969) 'The tortuous evolution of the multinational corporation', Columbia Journal of World Business, 4(1): 9-18.

Petersen B. and Pedersen T. (2002) 'Coping with liability of foreignness: Different learning engagements of entrant firms', Journal of International Management, 8(3): 339-351.

Petersen B., Pedersen T. and Lyles M.A. (2008) 'Closing knowledge gaps in foreign markets', Journal of International Business Studies, 39(7): 1097-1114.

Peteraf M.A. (1993) 'The cornerstones of competitive advantage: A resource-based view', Strategic Management Journal, 14(3): 179-191.

Pettigrew A.M., Woodman R.W. and Cameron K.S. (2001) 'Studying organizational change and development: Challenges for future research', Academy of Management Journal, 44(4): 697-713.

Phene A. and Almeida, P. (2008) 'Innovation in multinational subsidiaries: The role of knowledge assimilation and subsidiary capabilities', Journal of International Business Studies, 39(5): 901-919.

Polanyi M. (1975) 'Personal knowledge', In Polanyi M. and Prosch H. (Eds.), Meaning, pp. 22-45, Chicago: Chicago University Press. 
Porter M.E. (1980) Competitive Strategy: Techniques for Analyzing Industries and Competitors, New York: Free Press.

Prahalad, C.K. and Doz Y.L. (1987) The Multinational Mission: Balancing Local Demands and Global Vision, Free Press: New York.

Reger R.K., Gustafson L.T., Demarie S.M. and Mullane J.V. (1994) 'Reframing the organization: Why implementing total quality is easier said than done', Academy of Management Review, 19(3): 565-584.

Richards, L. R. (2005) Handling Qualitative Data: A Practical Guide, Thousand Oaks, CA: Sage Publications.

Roberts J. (2006) 'Limits to communities of practice', Journal of Management Studies, 43(3): 623-639.

Roberts K.H. and O'Reilly C.A. (1974) 'Measuring organizational communication', Journal of Applied Psychology, 59(3): 321-326.

Rogers, E.M. (1983) Diffusion of Innovations, New York: Free Press.

Rosenzweig P. and Singh H. (1991) 'Organizational environments and the multinational enterprise', Academy of Management Review, 16(2): 340-361.

Roth K. and Morrison A.J. (1990) 'An empirical analysis of the integrationresponsiveness framework in global industries', Journal of International Business Studies, 21(4): 541-564.

Rugman AM. and Douglas S. (1986) 'The strategic management of multinationals and world product mandating', Canadian Public Policy, 12(2): 320-328.

Scott R. (1995) Institutions and Organizations, Thousand Oaks, CA: Sage.

Scott W.R. (1987) 'The adolescence of institutional theory', Administrative Science Quarterly, 32(4): 493-511.

Schelling T.C. (1960) Strategy of Conflict, London: Oxford University Press.

Schmidt M. (1982) 'Does corporatism matter? Economic crisis, politics and rates of unemployment in capitalist democracies in the 1970s', In: Lembruch G. and Schmitter P. (Eds.), Patterns of Corporatist Policy-Making (pp. 221-237), London: Sage. 
Schumpeter J.A. (1942) Capitalism, Socialism, and Democracy, London: Harper and Brothers.

Selznick P. (1957) Leadership in Administration: A Sociological Interpretation, New York: Harper and Row.

Siggelkow N. (2007) 'Persuasion with case studies', Academy of Management Journal, 50(1): 20-24.

Simon H.A. (1991) 'Bounded rationality and organizational learning', Organization Science, 2(1): 125-134.

Sinkovics R.R., Roath A.S. and Cavusgil S.T. (2011) 'International integration and coordination in MNEs: Implications for international management', Management International Review, 51(2): 121-127.

Spradley J.P. (1979) The Ethnographic Interview, New York: Holt, Rinehart and Winston.

Starbuck W. (1992) 'Learning by knowledge-intensive firms', Journal of Management Studies, 29(6): 713-740.

Stopford J.M. and Wells Jr. L.T. (1972) Managing the Multinational Enterprise: Organisation of the Firm and Ownership of Subsidiaries, New York: Basic Books.

Suddaby R. (2010) 'Construct clarity in theories of management and organizations', Academy of Management Review, 35(3): 346-357.

Szulanski G. (1996) 'Exploring internal stickiness: Impediments to the transfer of best practice within the firm', Strategic Management Journal, 17(1): 27-43.

Szulanski G. and Jensen R.J. (2006) 'Presumptive adaptation and the effectiveness of knowledge transfer', Strategic Management Journal, 27(10): 937-957

Taggart J.H. (1997) 'Autonomy and procedural justice: A framework for evaluating subsidiary strategy', Journal of International Business Studies, 28(1): 51-76.

Taggart J.H. (1998) 'Strategy shifts in MNC subsidiaries', Strategic Management Journal, 19(7), 663-681.

Teece D.J. (2007) 'Explicating dynamic capabilities: The nature and microfoundations of (sustainable) enterprise performance', Strategic Management Journal, 28(13): 1319-1350. 
Teece D.J. and Pisano G. (1994) 'The dynamic capabilities of firms: An introduction', Industrial and Corporate Change, 3(3): 537-556.

Tellis G.J., Prabhu J.C. and Chandy R.K. (2009) 'Radical innovation across nations: The preeminence of corporate culture', Journal of Marketing, 73(1): 3-23.

Thomke S. and Nimgade A. (2001) 'Siemens AG: Global development strategy(A)', Harvard Business School Case No 9-602-061, Harvard Business School Publishing: Boston.

Tolbert P. and Zucker L. (1996) The Institutionalization of Institutional Theory. In S. Clegg, C. Hardy, and W. Nord (Eds.), Handbook of Organization Studies: 175190. Thousand Oaks, CA: Sage.

Tönnies F. (1887) Community and Society (Gemeinschaft und Gesellschaft), Translated and Edited by: Loomis C.P. (1957), New York: Harper and Row.

Tsai W. (2001). 'Knowledge transfer in intraorganizational networks: Effects of network position and absorptive capacity on business unit innovation and performance', Academy of Management Journal, 44(5): 996-1004.

Tsoukas H. and Vladimirou E. (2001) 'What is organizational knowledge?', Journal of Management Studies, 38(7): 973-992.

Tushman M., (1977) 'Special boundary roles in the innovation process', Administrative Science Quarterly, 22(4): 587-606.

Unger, B. (2000) 'Innovation systems and innovation performance: Voice systems', Organization Studies, 21(5): 941-969.

Van de Ven A.H. and Poole M.S. (1995) 'Explaining development and change in organizations', Academy of Management Review, 20(3): 510-540.

Van Wijk R., Jansen J.J.P. and Lyles M.A. (2008) 'Inter- and intra-organizational knowledge transfer: A meta-analytic review and assessment of its antecedents and consequences', Journal of Management Studies, 45(4): 830-853.

Vernon R. (1966) 'International investment and international trade in the product cycle', Quarterly Journal of Economics, 80(2): 190-207

Vernon R. (1979) 'The product cycle hypothesis in a new international environment', Oxford Bulletin of Economics and Statistics, 41(4): 255-267. 
Von Zedtwitz M. and Gassman O. (2002) 'Market versus technology drive in R\&D internationalization: Four different patterns of managing research and development', Research Policy, 31(4): 569-588.

Walsh M. and Le Roux M. (2004). 'Contingency in innovation and the role of national systems: Taxol and taxotère in the US and France', Research Policy, 33(9): 13071327.

Weick K.E. (1995) Sensemaking in Organizations, London: Sage Publications.

Wenger E. (2000) 'Communities of practice and social learning systems', Organization, 7(2): 225-246.

Wenger E. (1998) Communities of Practice: Learning, Meaning and Identity, Cambridge, UK: Cambridge University Press.

Wenger E., McDermott R. and Snyder W.M. (2002) Cultivating Communities of Practice: A Guide to Managing Knowledge, Boston: Harvard Business School Press.

Wernerfelt B. (1984) 'The resource-based view of the firm', Strategic Management Journal, 5(2): 171-180.

Westney E. (1993) 'Institutionalization theory and the multinational corporation', In S. Ghoshal and E. Westney (Eds.), Organization Theory and the Multinational Corporation: 53-75. New York: St. Martin's Press.

White R.E. and Poynter T.A. (1984) 'Strategies for foreign-owned subsidiaries in Canada', Business Quarterly, 49(2): 59-69.

Williams C. (2010) 'Client-vendor knowledge transfer in IS offshore outsourcing: Insights from a survey of Indian software engineers', Information Systems Journal, 21(4): 335-356.

Williams C. (2009) 'Subsidiary-level determinants of global initiatives in multinational corporations', Journal of International Management, 15(1): 92-104.

Williams C. and Ecker B. (2011) 'R\&D subsidiary embedment: A resource dependence perspective', Critical Perspectives on International Business, (forthcoming).

Williams C. and Nones B. (2009) 'R\&D subsidiary isolation in knowledge-intensive industries: Evidence from Austria', R\&D Management, 39(2): 111-123. 
Winter S.G. (2003) 'Understanding dynamic capabilities', Strategic Management Journal, 24(10): 991-995.

Winter S.G. and Szulanski G. (2001) 'Replication as strategy', Organization Science, 12(6): 730-743.

Wittgenstein L. (1958) Philosophical Investigations, Oxford, UK: Blackwell.

Wolfe R.A. (1994) 'Organizational innovation: Review, critique and suggested research directions', Journal of Management Studies, 31(3): 405-430.

Yamin M., Tsai H. and Holm, U. (2011) 'The performance effects of headquarters' involvement in lateral innovation transfers in multinational corporations', Management International Review, 51(2): 157-177.

Yanow D. (2004) 'Translating local knowledge at organizational peripheries', British Journal of Management, 15(S1): S9-S25.

Yin R.K. (2009) Case Study Research (Fourth Edition), Thousand Oaks, CA: Sage.

Yu J. and Zaheer S. (2010) 'Building a process model of local adaptation of practices: A study of six sigma implementation in Korean and US firms', Journal of International Business Studies, 41(3): 475-499.

Zaheer S. (1995) 'Overcoming the liability of foreignness', Academy of Management Journal, 38(2): 341-363.

Zahra S.A., Sapienza H.J. and Davidsson P. (2006) 'Entrepreneurship and dynamic capabilities: A review, model and research agenda', Journal of Management Studies, 43(4): 917-955.

Zander I. (1997) 'Technological diversification in the multinational corporation: Historical evolution and future prospects', Research Policy, 26(2): 209-227.

Zander I. (1999) 'How do you mean 'global'? An empirical investigation of innovation networks in the multinational corporation', Research Policy, 28(2-3): 195-213.

Zander U. and Kogut B. (1995) 'Knowledge and the speed of the transfer and imitation of organizational capabilities: An empirical test', Organization Science, 6(1): 76-92.

Zanfei A. (2000) 'Transnational firms and the changing organization of innovative activities', Cambridge Journal of Economics, 24(5): 515-542. 
Zellmer-Bruhn M.E. (2003) 'Interruptive events and team knowledge acquisition', Management Science, 49(4): 514-528.

Zollo M. and S.G. Winter (2002) 'Deliberate learning and the evolution of dynamic capabilities’, Organization Science, 13(3): 339-351.

Zucker L. (1991) 'Postscript: Microfoundations of institutional thought', In Powell A. and DiMaggio P. (Eds.), The New Institutionalism in Organizational Analysis, pp. 103-106, Chicago: University of Chicago Press. 


\section{Appendices}

\section{Appendix 1}

\section{Ethics Certificate (Exploratory Phase)}
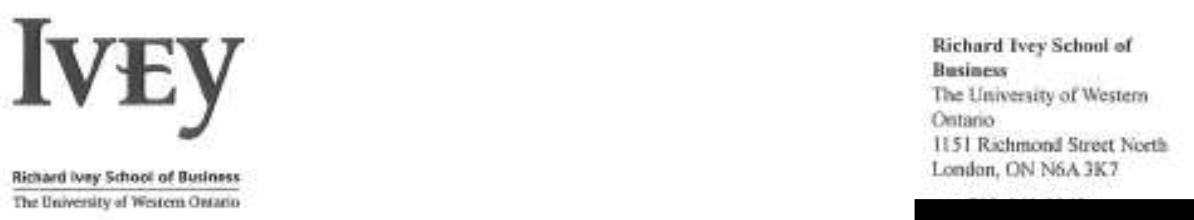

Use of Human Subjects - Ethics Approval Notice

Principal Investigator: Paul Beamish

Re Pho Candidate: Nathaniel Lupton

Review Number: 007/10 BREB

Protocol Title: Towards a Contemporary Theory of Strategic Innovation

Ethics Approval Date: April 15, 2010

Expiry Date: April 15, 2011

Documents Reviewed and Approved: Ethics Protocol, Discussion Guide, Information Letter, Consent Form

This is to notify you that The Ivey School of Business Research Ethics Board for Non-Medical Research Involving Human Subjects (NMREB) which is organized and operates according to the Tri-Council Policy Statement: Ethical Conduct of Research Involving Humans and the applicable laws and regulations of Ontario has granted approval to the above named research study on the approval date noted above.

This approval shall remain valid until the expiry date noted above assuming timely and acceptable responses to the NMREB's periodic requests for survellance and monitoring information. If you require an updated approval notice prior to that time you must request it using the Uwo Updated Approval Request Form.

During the course of the research, no deviations from, or changes to, the study or consent form may be initiated without prior written approval from the NMREB except when necessary to eliminate immediate hazards to the subject or when the change(s) involve only logistical or administrative aspects of the study (e.g. change of monitor, telephone number). Expedited review of minor change(s) in ongoing studies will be considered. Subjects must receive a copy of the signed information/consent documentation.

Investigators must promptly also report to the NMREB:

a) changes increasing the risk to the participant(s) and/or affecting significantly the conduct of the study:

b) all adverse and unexpected experiences or events that are both serious and unexpected;

c) new information that may adversely affect the safety of the subjects or the conduct of the study.

If these changes/adverse events require a change to the information/consent documentation, and/or recruitment advertisement, the newly revised information/consent documentation, and/or advertisement, must be submitted to this office for approval.

Members of the NMREB who are named as investigators in research studies, or declare a conflict of interest, do not participate in discussion related to, nor wote on. such studies when they are presented to the NMREB.

Signature:

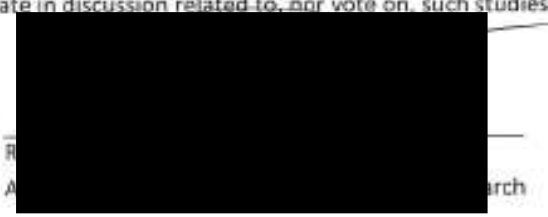

This is an official document. Please retain the oniginal ia your files. 


\section{Ethics Certificate (Explanatory Stage)}

\section{IVEy \\ Richaed ivey Schosi of Buainan \\ The Uniwestity of Westem Oniarie}

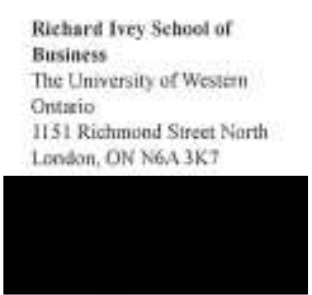

Use of Human Subjects - Ethics Approval Notice

Principal Investigator: Paul Beamish

Re PhD Candidate: Nathan Lupton

Review Number: 025/10 BREB

Protocol Titie: International Innovation Practice Transfer and Capability Development

within the Multinational Enterprise

Ethics Approval Date: October 25, $2010 \quad$ Expiry Date: October 25, 2011

Documents Reviewed and Approved: Ethics Protocol, Discussion Guide, Information Letter, Consent Form

This is to notify you that The Ivey $5 \mathrm{chool}$ of Business Research Ethics Board for Non-Medical Research involving Human Subjects (NMREB) which is organized and operates according to the Tri-Council Policy Statement: Ethical Conduct of Research Involving Humans and the applicable laws and regulations of Ontario has granted approval to the above named research study on the approval date noted above.

This approval shall remain valid until the expiry date noted above assuming timely and acceptable responses to the NMREB's periodic requests for surveillance and monitoring information. If you require an updated approval notice prior to that time you must request it using the UWO Updated Approval Request Form.

During the course of the research, no deviations from, or changes to, the study or consent form may be initiated without prior written approval from the NMREB except when necessary to eliminate immediate hazards to the subject or when the change(s) involve only logistical or administrative aspects of the study (e.g. change of monitor, telephone number). Expedited review of minor change(s) in angoing studies will be considered. Subjects must receive a copy of the signed information/consent documentation.

Investigators must promptly aiso report to the NMREB

a) changes increasing the risk to the participant(s) and/or affecting significantly the conduct of the study;

b) all adverse and unexpected experiences or events that are both serious and unexpected;

c) new information that may adversely affect the safety of the subjects or the conduct of the study.

If these changes/adverse events require a change to the information/consent documentation, and/or recruitment advertisement, the newly revised information/consent documentation, and/or advertisement, must be submitted to this office for approval.

Members of the NMREB who are named as investigators in research studies, or declare a conflict of interest, do not participats in dicassionr ralated to nor vate on. such studies when they are presented to the NMREB.

Signature:

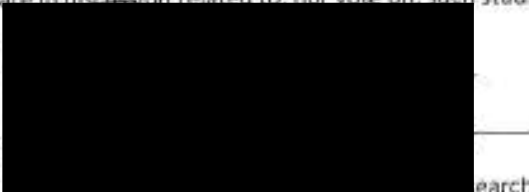

This is an officiai document. Please retain the original in your files. 
Appendix 2

\section{Letter of Information and Consent}

\section{IVEy \\ Richard Ivey School of Business The University of Western Ontario}

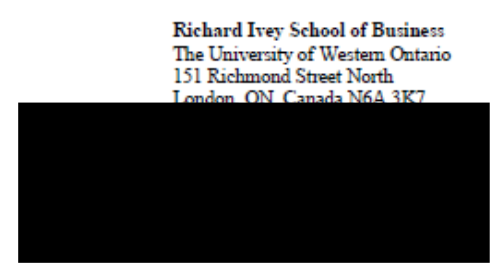

International Innovation Practice Transfer and Capability Development within the Multinational Enterprise

(Date)

Dear (name),

My name is Nathaniel Lupton and I am a doctoral candidate at the Ivey Business School at the University of Western Ontario and the information I am collecting will be used in my thesis.

You are being invited to take part in a research study on the internationalization of innovation in multinational firms. The purpose of this letter is to provide you with the information you require to make an informed decision on participating in this research.

If you agree, I will ask you to participate in an interview. During this interview I will ask a series of questions about your experiences with issues related to building innovation capabilities in your organization and its subsidiaries. It should take approximately 60 minutes to complete the interview and with your agreement, it will be audio taped and later transcribed. Pseudonyms will be used in place of your name and the name of all organizations mentioned during the interview in order to guarantee your anonymity in any publication or presentation of the results of this research. There are no known risks to your involvement in this study. Please note that your responses are strictly confidential, that your participation is completely voluntary. You may refuse to participate, refuse to answer any questions or withdraw from the study at any time. Should the results of the study be published, your name will not be used.

Should you have any questions or concerns about this study, please contact Paul Beamish at 1-519-

If you have any questions about the conduct of this study or your rights as a research participant, you may contact the Office of Research Ethics, the University of Western Ontario 1-519-

or email at: Signing the consent form indicates your consent to participate in the study.

To indicate that you are willingly participating in this project, please give us your informed consent by signing the attached consent form and return it to the interviewer. We look forward to hearing from you, and wish to thank you again for your time and participation.

Yours sincerely,

Nathaniel Lupton and Dr. Paul Beamish

Richard Ivey School of Business

1151 Richmond Street N, London, Ontario, N6A 3K7, Canada 
IVEy

Richard Ivey School of Business

The University of Western Ontario
Richard Irey School of Business

The University of Westem Ontanio

151 Richmond Street North

London, ON Canada N6A 3K7

Consent Form

Research Project Title: International Innovation Practice Transfer and Capability Development within the Multinational Enterprise

I have read the letter of information, have had the nature if the study explained to me and I agree to participate. All questions have been answered to my satisfaction.

Name (please print)

Signature

Date

Person Obtaining Consent:

Signature

Date:

If you have any questions about this research, please contact the researchers.

Please sign and hand or send this form back to the researchers:

Nathaniel Lupton and Dr. Paul W. Beamish

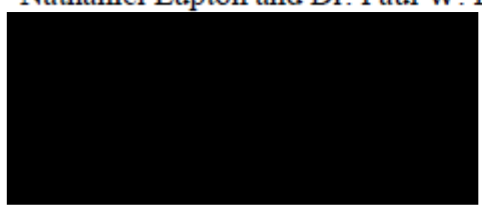




\section{Appendix 3}

\section{Interview Protocol}

$\underline{\text { Introduction, outline broad purpose of research }}$

1. Remind the participant that I wish to record the call and obtain their verbal consent before proceeding to start recording.

2. Ask the participant to provide general information on their role and history within the organization.

3. Explain different modes of sharing practices within the organization, and ask the respondent to explain how this is achieved in their own organization:

A. Hub and spoke, headquarters is hub, creates best practices, and disseminates to the subunits.

B. Best practices are adapted at each subunit.

C. Different subunits come up with best practices and diffuse them throughout the organization.

D. Different units do things differently and there is limited, ad-hoc transfer of practices.

Next, ask questions which are specific to the respondent's experiences

1. Which organizational units do you interact with?

a. Where are they located?

b. What is the objective of your interaction with them?

2. Can you describe innovation in your organization?

What organizational units are involved in innovation?

3. Based on the descriptions of different modes of practice sharing, how would you describe knowledge sharing amongst the different units?

a. How are project teams structured geographically?

b. What are some of the barriers to knowledge transfer?

c. Can you describe a specific instance of an attempt to transfer practices?

i. Who was involved?

ii. What challenges were faced? 
iii. How were they overcome?

iv. Can you describe the transfer process?

d. Can you describe an instance of practice transfer in which the practices were altered or adapted in some way?

i. $\quad$ Why were they adapted?

ii. Who was involved?

iii. Were the adaptations made locally or distributed throughout the organization?

4. What are the roles of the (organizational units)?
a. How are they interrelated?
b. What does each contribute to innovation?
c. How are they governed?

5. How is the location for a (organizational unit) decided upon?
a. Who is involved in setting each up?
b. Are there standard processes involved?
c. How is their performance evaluated?
d. What is the ramp up time like?
e. What are the major issues such as transferring knowledge which must be overcome in setting up and operating day to day?
f. What metrics are used to evaluate the performance of the (organizational unit)?
g. How is the unit performing according to those metrics?

Finally, thank the respondent for their time and ask for referral to other contacts

1. Based on our discussion today, are there any colleagues within your organization who you think could offer additional insights into my study?

2. Suggest specific geographic locations I wish to pursue further with my research (dependent on the organization of the MNE). 


\section{Appendix 4}

\section{Case Summaries}

\section{Telecom Company}

Telecom Company designs and markets telecommunications hardware and software including digital switching equipment and routers, as well as a host of interactive communications technologies (ICT) and office productivity software. The company's origins and current headquarters are located in United States. Like many companies, Telecom's revenues are recovering from the effects of the recent recession, yet with sales of USD 40 billion, fiscal 2010 was a record year.

\section{Interviewees}

Access to interviewees at Telecom is highly restricted by company policy. Most employees must gain supervisor approval before talking to any member of the public on behalf of the company. Indeed, one request for interview was denied on this ground, and snowball sampling was not possible. One interview was conducted during the exploratory phase of this research under the terms of a non-disclosure agreement.

Despite these restrictions, recorded phone interviews were conducted with two senior managers at Telecom. The first, on March 12, 2011 took place with a Senior Program Management Office (PMO) manager. His job responsibility was to manage a portfolio of projects carried out by other managers at Telecom. This job entailed monitoring projects as they progressed through a series of predefined stages or 'gates', as they are referred to in traditional innovation jargon, and making decisions regarding 
whether they should proceed to the next. The second interviewee was a Senior Program Manager, with a similar set of responsibilities as the first interviewee, working in the ICT segment of the business. He had joined the company through an acquisition.

\section{Innovation}

Innovation was considered by the respondents, and evidenced further in corporate publications, as extremely important for the overall strategy at Telecom. According to the most recent financial data, about $14 \%$ of revenue was reinvested in research and development (R\&D). However, the company was structured and motivated to use available funding as efficiently as possible. The company is a user of its own technology which provides it with a steady stream of information which is used to improve customers' experience with the products, as well as the products themselves. Employees are extensively encouraged to generate and evaluate new ideas from within the organization, as well as beyond, however there is apparently little time and available funding now to pursue new ideas:

“...we have to cut $10 \%$ of our budget so there isn't really room for too many new ideas. ... We have so many neat ideas that we're working on right now, that creating more than we can execute on, it may not be the best use of our time."

\section{Internationalization}

Telecom sells and services its products globally. It therefore has significant investments distributed extensively throughout the world. In addition, it has many global 
development centers. However, unlike other organizations, Telecom does not select geographic regions in which to establish operations, other than sales. Instead, geographic presence is often a by-product of the company's strategy to access technology, most often through acquisition. The company has varying level of success at integrating new acquisitions within the organization, but this is always the intent. As a result, development teams are constituted by members chosen for their capabilities and expertise, leading to highly internationalized virtual teams.

\section{Practices}

Overall, most innovation at Telecom is incremental with respect to the product, but more radical with respect to management practices. The aforementioned crowdsourcing tactic is one practice contributing to innovation. In addition, substantial 'openinnovation' practices are used which include licensing, sourcing new ideas from customers, technology partnerships, and acquisitions. While there are certainly mechanisms in place to encourage employees to share new ideas and ways of doing things, there is apparently a 'Telecom' way of doing things, which employees are expected to internalize, and which subsequently results in post-acquisition attrition. 


\section{Aero Company}

Aero is the aerospace division of a large engineering firm. Aero accounts for roughly a third of the parent company's 130,000 employees and USD 33 billion in sales. Aero's business is split roughly 50/50 between commercial and defence contracts. Aero was established and is currently headquartered in the US, where about $75 \%$ of its engineering workforce is located. The recent recession took a substantial toll on the aerospace industry, but Aero's revenues are recovering substantially according to the most recent data.

\section{Interviewees}

A total of six recorded telephone interviews were conducted with members of Aero between March 2 and May 2, 2011. The first interview took place with the Director of Engineering Business Management at Aero, who subsequently provided contact to five senior managers in five different countries. Senior managers were subsequently interviewed in each of Latin America, China, Eastern Europe, the United States, and India. All sites were highly involved with development work within Aero, usually for US-based customers, but also increasingly for local markets. Unlike Aero's presence in the US, the sites included in this research have been in existence for a decade or less. Each of the managers interviewed from these sites has relatively lengthy tenure in their organization.

All interviewees worked directly and extensively on Aero projects, but the nonUS sites are not specifically part of the Aero organization, but instead provide 
engineering services to the all segments of the parent company. The site in India, in particular, is actually part of corporate headquarters.

\section{Innovation}

The aerospace industry is quite mature, and respondents predicted very few major innovations in the near future. $\mathrm{R} \& \mathrm{D}$ spending accounts for about $4.5 \%$ of revenues for the parent company, and is likely very similar for Aero. Most innovation, therefore, involves the adaptation of existing technology for new applications. Knowledge flows primarily from the US, where Aero's capabilities were established over the course of decades, outwards to the international sites where it is exploited in the design and development of new products. Respondents cite difficulties in establishing new capabilities as attrition in the US and international sites has increased substantially in recent years.

\section{Internationalization}

Given the nature of the aerospace industry, it should be noted that the customer base for Aero's products is quite concentrated, although with applications used throughout the world. International presence is a result of Aero managements' predictions about global trends in the aerospace industry, in particular defence. Hence, while the main reason for the more recent geographic entries is to access the local markets, most work performed by these units services the traditional business lines and customers of Aero. The type of work performed by each of the units depends on the availability of local expertise. Hence, flight controls are designed in Eastern Europe and 
are tested in India, for example. At present, three quarters of Aero's engineers, and associated core capabilities, are located in the US.

\section{Practices}

Aero is quite distinct from other cases within this research in that its practices are very rigid, as a result of the highly regulated nature of the aerospace industry. Due to safety and accountability concerns, deviations from established processes are not tolerated. Variations on processes directly related to design must be approved by organizational councils. Changes approved are typically relatively minor, as they are related to the modification of existing components and systems for new applications. Interaction between sites is quite high, with the US acting as the primary knowledge hub.

Local national regulations concerning the importation of technology often necessitate adaptation of Aero processes and practices. Interaction and collaboration on projects amongst the international sites, for example, is often coordinated through the US as a result of technology export license restrictions. In some rare instances, Aero practices are adapted to local business practices, but typically these changes must be reflected globally and hence necessitates the involvement of headquarters for approval and dissemination. 


\section{Software Company}

Software is a long tenured company providing integrated applications to business clients used to increase operational efficiency, as well as information sharing and availability. The company is headquartered in Western Europe with other regional headquarters, sales and development organizations established throughout the world. Software has extensively penetrated global markets through sales and service of its core products.

\section{Interviewees}

Interviews were conducted on Feb. 18 and March 1, 2011, respectively, with Marketing VPs in Canada and the US. Subsequent interviews were conducted with lab heads and a Senior Engineering Manager at various sites within Canada. Both VPs provided substantial input into how practices are established within the organization. The lab heads and engineering manager provided a perspective on how knowledge and practices are established, both initiated by headquarters and, to a lesser extent, by the labs themselves.

\section{Innovation}

Incremental innovation is carried out by labs and development centers at Software, enabled by close interaction with customers. In fact, most innovation is a direct result of requests made by customers. Given the rapid pace of technological change in this industry, one VP mentioned that the practices and processes by which innovation is achieved are constantly subject to revision. More radical innovation is 
typically carried out in conjunction with other business partners, two of which are included in this research.

Project teams consist primarily of global teams, with members from a variety of sites. However, due to concerns for the communication impediments posed by differing time zones, work on specific components of a project is typically carried out by subteams which are more geographically proximate.

\section{Internationalization}

Software co. is a highly internationalized company as its products are extensively deployed in global markets. As stated by one VP of marketing: "We operate in global markets now so we have to have a true global presence." The sales force tends to work very closely, and is often co-located, with the development centers. Hence, international presence is established in order to access global markets. In addition, internationalization has been driven by the need to access local talent pools, for proximity to partners, and as a by-product of acquisitions.

The function of international development centers is typically a result of the type of expertise which reside there, as well as its developmental history. Each center, or lab, has a unique value proposition which they use to compete for enhanced mandates and the accompanying resources.

\section{Practices}

Many practices are quite standardized within Software. The establishment of new practices such as these is driven by headquarters, as success is deemed dependent upon 
the commitment of resources and formal training. Adherence to a common set of software and project management practices facilitates collaboration across multiple sites. Inter-unit sharing of practices occurs primarily on occasions when lab heads meet in person. Hence, it is likely that many unique, unshared practices develop within individual business units. 


\section{IT Services Company}

Information Technology (IT) Services, provides customers with a host of hardware and software products and services, as well as outsourcing of various business processes. This company services more than ten distinct industry groupings representing a broad range of business needs. The company was founded in India and, like many Indian firms, is one of many self-contained, independent business within a much larger conglomerate. Although serving global markets, development work is mainly carried out in India, in part due to the inherent capability and cost advantages.

\section{Interviewees}

An initial interview took place via recorded phone call on January 6, 2011, with the head of one of the major development labs within India. Subsequently, an interview was conducted, also via recorded telephone call, with the company's Chief Technology Officer and another VP. The first interview provided details on how innovation and business practices are created and established within the development units, in India and abroad. The subsequent interviews reaffirmed these findings, and provided further insights on the general strategy of IT Services with respect to internationalization and leveraging capabilities and resources.

\section{Innovation}

Innovation at IT Services is classified, by one VP interviewed, as incremental, platform, or breakthrough. The incremental and platform types of innovation are largely developed in response to customer needs and requests. The breakthrough forms of 
innovation are developed in research labs which conduct basic research with a view to taking new offerings to global markets. Each of these labs focuses on a particular set of product/market offerings, based mainly on local resources and capabilities, which gives the lab its unique "character" according to interviewees. The intention is to leverage local resources, both internal and external to the company, in global markets.

\section{Internationalization}

Sales and service units are distributed globally, with presence in nearly every major market. Development is concentrated mainly within India, with smaller, early stage establishments in Europe and North America, and intentions to move into other Asian and Latin American markets. Within India, development labs are built around particular individuals who possess capabilities which IT Services considers valuable. The location of international labs, conversely, is chosen based on proximity to institutions, such as local universities, research institutes, and firms, with competencies in areas that IT Services deems it can leverage globally. One of the primary internationalization difficulties faced by IT Services, as noted by one VP, is that "the biggest problem is still the ability to establish a meaningful connect to the local ecosystem" which consists of "academic institutions, the start up or venture capital ecosystem, the other industrial partners, strategic partners, customers that (we) may have in the region." 


\section{Practices}

Practices discussed by all respondents at IT Services were of a fairly formalized sort, pertaining to everything from basic research processes, to general operational procedures such as the management of materials and equipment. Practices originate from the involvement of top management in systematizing and regulating processes evolving from the different labs. The labs will sometimes "push back" on attempts to establish processes, insisting that they be "light weight" which apparently involves less documentation.

It should be noted that in many of the innovation labs, as stated by one VP, "we have to establish a certain level of, maybe call it academic freedom, which is a prereq for trying to innovate..." However, this less formal mode of operation, involving "academic freedom" is not the desired end-state for the labs. Rather, it is seen as a necessary precursor to innovation which will eventually be replaced by more formal practices with input from the labs. As stated by the CTO, "if we do find local variations, we will probably find ways to roll them up to be global processes and actually improve the global process based on experience, or suggestions, or improvement coming from the local labs". 


\section{Curriculum Vitae}

\section{Nathaniel C. Lupton}

$\mathrm{PhD}$ Candidate (International Business and Strategy)

Richard Ivey School of Business

The University of Western Ontario

\section{Education}

PhD (Expected: August 2011).

General Management (International Business and Strategy).

Richard Ivey School of Business, University of Western Ontario.

London, Ontario, Canada.

\section{Master of Business Administration}

Eric Sprott School of Business, Carleton University.

Ottawa, Ontario, Canada.

\section{Bachelor of Commerce}

Eric Sprott School of Business, Carleton University.

Ottawa, Ontario, Canada.

\section{Research}

\section{Journal Articles}

Chrysostome, E.V. and Lupton, N.C. (2011). Characteristics and performance of Japanese foreign direct investment in Africa. International Journal of Economic Policy in Emerging Economies, 4(1): 54-77.

Beamish, P.W. \& Lupton, N.C. (2009). Managing Joint Ventures. Academy of Management Perspectives, 23(2): 75-94. 
Murphy, S.A., Hine, M.J., Lupton, N.C. \& Zelenski, J.M. (2009). Emotion and Judgement in Virtual Environments: A Research Framework. Journal of Electronic Commerce in Organizations, 7(3): 21-43.

Lupton, N, Hine, M.J. \& Murphy, S. (2008). Emotional Intelligence in Computer Mediated Group Communications, Journal of eWorking, 2(2): 177-206.

\section{Book Chapters}

Thompson, R., Compeau, D., Higgins, C., \& Lupton, N. (2007). Intentions to use information technologies: An integrative model. In S. Clarke (Ed.), End user computing challenges technologies: Emerging tools \& applications (pp. 79-101). Hershey, PA: Information Science Reference.

Lupton, N.C., Hine, M.J. \& Murphy, S.A. (2006). Social Construction and Emotion and its Role in Virtual Work Arrangements. In M.G. Hunter \& S. Burgess (Eds.) Grand Challenges in Business and Information Management Processes (pp. 76-97), Las Vegas, NV: The Information Institute.

\section{Conferences Presentations and Proceedings}

Lupton, N.C., Spiegel, H., Wang, Y., Meister, D.B., Gray, P.H. \& Kang, J. (2010). Knowledge Sourcing Effectiveness in The People's Republic of China and the United States: A Comparative Study. Academy of International Business, Rio de Janeiro, Brazil.

Ruppenthal, T. \& Lupton, N.C. (2010). Export and Firm Performance: A Market- and Resource-Based View. Academy of International Business, Rio de Janeiro, Brazil.

Roberts, M.J. \& Lupton, N.C. (2009). Diminishing MNE Control of Foreign Subsidiaries: The Distinction Between Service and Manufacturing Firms. Academy of International Business, San Diego, CA.

Lupton, N.C. (2008). Structure and Evolution of Global Innovation Systems. 36th Administrative Sciences of Canada (ASAC) Conference, Halifax, NS.

Murphy, S.A., Lupton, N.C., Hine, M.J. \& Zelenski, J.M. (2007). Emotion and Judgment in Virtual Environments: A Research Framework. Proceedings of the 35th Administrative Sciences of Canada (ASAC) Conference, Ottawa, Ontario.

Lupton, N.C., M.J. Hine, \& S.A. Murphy. (2006). Social Construction and Emotion and its Role in Virtual Work Arrangements. Proceedings of the 5th Annual ISOneWorld Conference, Las Vegas, Nevada. 
Murphy, S.A., Lupton, N.C. \& Hine, M.J. (2006). The Role of Personality, Emotions and Judgement in Virtual Environments: A Research Framework. Proceedings of the Fifth International Conference on Emotions and Worklife (EMONET V), Atlanta, Georgia.

\section{Teaching Materials}

The Prince Edward Island Preserve Company: Turnaround [with Paul Beamish] [9B08M049] in Cases in Strategic Management, 9/E by P. W. Beamish, McGraw Hill, Feb. 2009, (pp. 110-127).

The Prince Edward Island Preserve Company: Turnaround [with Paul Beamish] [9B08M049] in Cases in Strategic Management, 10/E by P. W. Beamish, McGraw Hill, 2011 (forthcoming).

\section{Work Experience}

Adjunct Professor, (2009-2010) International Business (MBA, EMBA), Lansbridge University.

Instructor, (2009), Strategic Management, Management and Organization Studies, University of Western Ontario.

Research Assistant (2006 - 2009), Richard Ivey School of Business, University of Western Ontario, London, Ontario.

Research Assistant (2005 - 2006), Eric Sprott School of Business, Carleton University, Ottawa, Ontario.

Instructor, (2005) Programming for Business Students, Eric Sprott School of Business, Carleton University, Ottawa, Ontario.

Systems Analyst (2004), Lee Valley Tools, Ottawa, Ontario.

Team Leader (2000-2002), Nortel Networks, Ottawa, Ontario.

\section{Selected Awards and Honours}

Finalist, Best Paper Award of the Academy of Management Perspectives for 2009 for "Managing Joint Ventures" (with Paul Beamish).

Plan for Excellence Scholarship (2006-2010). Faculty of Graduate Studies, University of Western Ontario. 
C.B. Johnston Ontario Graduate Scholarship, (2008-2009). Faculty of Graduate Studies, University of Western Ontario.

Ontario Graduate Scholarship (2010-2011). Government of Ontario, Canada.

Canada Graduate Scholarship (2006-2009). SSHRC - Government of Canada.

Ontario Graduate Scholarship (2006 -2010). Government of Ontario (declined)

R.A. Barford Graduate Scholarship (2007-2008). Faculty of Graduate Studies, University of Western Ontario.

Senate Medal (2006). Carleton University.

University Medal in Commerce (2004). Carleton University.

H. Bruce Gordon Scholarship (2004). Carleton University.

\section{Academic Service}

Ad hoc Reviewer

Journal of International Business Studies

Academy of International Business Conference (2008-2011)

Academy of Management Business Conference (2009-2010)

Administrative Sciences Association of Canada Conference (2007-2008) 